\title{
"Being" in pain : the role of self-discrepancies in explaining emotional well-being and activity patterns in chronic pain
}

Citation for published version (APA):

Kindermans, H. P. J. (2012). "Being" in pain : the role of self-discrepancies in explaining emotional wellbeing and activity patterns in chronic pain. [Doctoral Thesis, Maastricht University]. Datawyse / Universitaire Pers Maastricht. https://doi.org/10.26481/dis.20120301hk

Document status and date:

Published: 01/01/2012

DOI:

10.26481/dis.20120301hk

Document Version:

Publisher's PDF, also known as Version of record

\section{Please check the document version of this publication:}

- A submitted manuscript is the version of the article upon submission and before peer-review. There can be important differences between the submitted version and the official published version of record.

People interested in the research are advised to contact the author for the final version of the publication, or visit the DOI to the publisher's website.

- The final author version and the galley proof are versions of the publication after peer review.

- The final published version features the final layout of the paper including the volume, issue and page numbers.

Link to publication

\footnotetext{
General rights rights.

- You may freely distribute the URL identifying the publication in the public portal. please follow below link for the End User Agreement:

www.umlib.nl/taverne-license

Take down policy

If you believe that this document breaches copyright please contact us at:

repository@maastrichtuniversity.nl

providing details and we will investigate your claim.
}

Copyright and moral rights for the publications made accessible in the public portal are retained by the authors and/or other copyright owners and it is a condition of accessing publications that users recognise and abide by the legal requirements associated with these

- Users may download and print one copy of any publication from the public portal for the purpose of private study or research.

- You may not further distribute the material or use it for any profit-making activity or commercial gain

If the publication is distributed under the terms of Article 25fa of the Dutch Copyright Act, indicated by the "Taverne" license above, 


\section{"Being" in Pain}

The Role of Self-discrepancies in Explaining Emotional Well-being and Activity Patterns in Chronic Pain 
"Being" in pain: the role of self-discrepancies in explaining emotional well-being and activity patterns in chronic pain H.P.J. Kindermans

ISBN 978946159 I2I O

Printed by: Datawyse | Universitaire Pers Maastricht

Copyright (C) H.P.J. Kindermans, Maastricht 2012

All rights reserved. No part of this publication may be reproduced or transmitted in any form or by any means, electronical or mechanical, including photocopy, recording or any other information storage or retrieval system, without the prior written permission of the copyright owner. 


\title{
"Being" in Pain
}

\section{The Role of Self-discrepancies in Explaining Emotional Well-being and Activity Patterns in Chronic Pain}

\author{
PROEFSCHRIFT \\ Ter verkrijging van de graad van doctor \\ aan de Universiteit Maastricht, \\ op gezag van de Rector Magnificus, \\ prof. mr. G.P.M.F. Mols, \\ volgens het besluit van het College van Decanen, \\ in het openbaar te verdedigen op \\ donderdag I maart 2012 om I6:00 uur \\ door \\ Hanne Paula Joke Kindermans
}

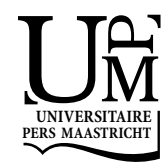


PROMOTOR

Prof. dr. J.W.S. Vlaeyen

\section{COPROMOTORES}

Dr. M.E.J.B. Goossens

Dr. J. Roelofs

\section{BEOORDELINGSCOMMISSIE}

Prof. dr. R. Smeets (voorzitter)

Prof. dr. G. Crombez, Ghent University, Gent, Belgium

Dr. J.R. De Jong

Prof. dr. F.J. Keefe, Duke university, Durham, US

Prof. dr. M.L. Peters 


\section{ConTents}

$\begin{array}{lll}\text { Chapter I Introduction } & 7\end{array}$

Chapter 2 A content analysis of ideal, ought, and feared selves in patients with chronic low back pain.

Chapter 3 Self-discrepancies in Work-related Upper Extremity Pain: Relation to emotions and flexible-goal adjustment

Chapter 4 The role of self-discrepancies in the emotional experience and activity patterns of patients with chronic low back pain

Chapter 5 Activity patterns in chronic pain: underlying dimensions and associations with disability and depressed mood

Chapter 6 The effects of ideal, ought, and feared selfguides on task performance

Chapter 7 General discussion

Summary

References

Dankwoord 

|| Chapter I ||

Introduction 
According to The World Health Organization pain can be defined as 'an unpleasant sensory and emotional experience associated with actual or potential tissue damage, or described in terms of such damage' (Merskey \& Bogduk, 1994). Following the International Association for the Study of Pain, chronic pain occurs when it has persisted beyond the normal tissue healing time (usually taken to be 3 months). In most cases of chronic pain, there is no apparent biological value. Based on a systematic review of epidemiological studies in the general population and primary care setting, the prevalence of chronic pain was estimated to be II $\%$ in adults (Ospina \& Harstall, 2003). In Europe, prevalence rates range from I2\% to $30 \%$. Pain is mostly musculoskeletal of nature and located at the back (unspecified: $24 \%$, lower back: I $8 \%$ ), followed by knee (I6\%), head ( $5 \%)$ and leg (14\%) (Breivik, Collett, Ventafridda, Cohen, \& Gallacher, 2006). Musculoskeletal pain disorders appear to be one of the most expensive disease categories (Heijink, Koopmanschap, \& Polder, 2006; Meerding, Bonneux, Polder, Koopmanschap, \& van der Maas, I998; Slobbe, et al., 2006). Noteworthy, whereas an increase was observed in health related costs for spine problems (back and neck), there were no improvements in health outcomes (Martin, et al., 2008). Furthermore, next to health care costs, about $70 \%$ of the total costs are due to change in employment status, lowered productivity, and sick leave (Goossens, 2002; Jensen, Sjogren, Ekholm, Rasmussen, \& Eriksen, 2004; Kemler \& Furnee, 2002). These enormeous disability related costs illustrate the tremendeous impact of chronic pain for society as well as for the individual. Besides disability, chronic pain is associated with depression, anxiety, sleep disturbances, and even suicidal ideation (Breivik, et al., 2006; Smith, Perlis, \& Haythornthwaite, 2004), resulting in low quality of life (Lame, Peters, Vlaeyen, Kleef, \& Patijn, 2005). For all these reasons, increased understanding of the mechanisms behind the transition from acute to chronic pain, the perpetuation of pain, and associated disability is of great importance.

\section{UNDERSTANDING THE DEVELOPMENT OF CHRONIC PAIN AND ITS CONSEQUENCES}

Historically, one of the most important developments for the study of chronic pain was the shift from a purely biomedical to a biopsychosocial approach (Turk \& Monarch, 2002; Waddell, 2004). From a biomedical perspective, pain was considered a direct consequence of physical pathology (e.g. tissue damage). Yet, the shortcomings of the biomedical perspective are easily illustrated by findings such as the clear presence of physical abnormalities or tissue damage in pain-free individuals, relief from pain by placebo, and phantom limb pain (e.g. Jensen, et al., I994; Nikolajsen \& Jensen, 200I; Turner, Deyo, Loeser, Von Korff, \& Fordyce, 1994). Importantly, besides the fact that physical pathology does not 
provide a sufficient explanation for reported pain, neither does it for experienced disability (Flor \& Turk, I988; Waddell, I987; Waddell, Main, Morris, Di Paola, \& Gray, I984).

In the mid $2 \mathrm{O}^{\text {th }}$ century, attention was drawn to the role of psychosocial factors in pain (Engel, 1977). Also, novel theories evolved, such as the gate-control theory (Melzack \& Wall, 1965), of which the key feature is that pain experience is modulated by a gating mechanism in the spinal cord that is influenced by both peripheral nociceptive stimulation as well as central processes in the brain. The integration of these higher order processes in the explanation of pain paved the way for contemporary biopsychosocial approaches to (chronic) pain. Within this approach, psychosocial factors are identified to be important determinants of pain experience in itself, through for example attention and mood (Villemure \& Schweinhardt, 20I0; Wiech \& Tracey, 2009), as well as of responses to pain and its detrimental consequences, such as experienced disability (Jensen, 2010; Keefe, Rumble, Scipio, Giordano, \& Perri, 2004).

The impact of chronic pain can be organized according to three effects: interruptive and interference effects, and the effect it has on identity (Harris, Morley, \& Barton, 2003; Morley, 2008; Morley \& Eccleston, 2004). Interruption refers to the process that pain immediately draws attention and affects behaviour. This is illustrated by the observation that one is most likely to stop immediately with performing other activities when feeling pain. The degree of interruption varies as a function of pain characteristics (e.g. threath value, novelty, intensity) and environmental characteristics (e.g. positive affect, task difficulty) (Eccleston \& Crombez, 1999). Treatment at this level may for example involve pain medication or distraction techniques. Interference is a result of repeated interruption and refers to the unability to complete tasks (in a satisfactory way) due to the ongoing presence of pain. For example, chronic pain may interfere with work-related or leisure activities. Patients may differ in the way they perform their daily activities while being in pain. These activity patterns are considered important predictors of disability and emotional wellbeing, and seem to play a crucial role in the transition from acute to chronic, as well as in the perpetuation of chronic pain (Hasenbring, Plaas, Fischbein, \& Willburger, 2006; Vlaeyen \& Linton, 2000). Treatment at this level is aimed at restoring daily functioning, for example by comprehensive cognitive-behavioural rehabilitation programs. Yet, beyond interruptive and interference effects, chronic pain affects the person's identity or self. When chronic pain prevents the achievement of valued goals, it may alter the feeling of 'self', and the patient may no longer feel to be the same person (Harris, Morley, \& Barton, 2003; Morley, 2008; Morley \& Eccleston, 2004). 
Thus far, the majority of research studies in chronic pain has focused on the interruptive and interference effects of chronic pain. In addition, current explanatory models for dysfunctional activity patterns operate at these levels. The focus of the present thesis, however, will be on changed activity patterns due to pain interference and the role of the self and selfregulatory processes in chronic pain. Increased understanding of the processes at this level are significant in the light of patients' emotional well-being and, moreover, may help to clarify dysfunctional activity patterns through self-regulatory pathways. In part one of this introduction, detailed information on the role of (dysfunctional) activity patterns and an overview of current explanatory models for these activity patterns will be provided. In part two, a broader self-regulatory framework is presented, demonstrating that insights into the dynamics at the identity level of chronic pain patients are of utmost importance. In this self-regulatory framework, the effect of chronic pain on the self (part three) as well as the effects of the self on behaviour (part four) are considered. Finally, an outline of the present thesis is provided in part five.

\section{ACtivity PATterns}

In the present thesis, three activity patterns will be considered namely avoidance, persistence and pacing behaviour.

\section{AVOIDANCE BEHAVIOUR}

Whereas avoidance behaviour might be an adaptive response in an acute stage of pain, in a chronic state it may no longer serve a protective but instead, a disabling function (Bortz, I984; Wall, I979). Already in I983, Lethem and colleagues introduced a fear-avoidance model of pain perception. Central to their model was the role of fear of pain and two possible responses to cope with this fear: (adaptive) confrontation or (maladaptive) avoidance. A few years later, Philips (1987) provided a more thorough understanding of the role of avoidance as a maintaining factor in chronic pain. Building on these early propositions and incorporating the extent of studies originating from them, Vlaeyen et al. (1995) and Vlaeyen and Linton (2000) described the fear-avoidance model of chronic pain as illustrated in Figure I. 


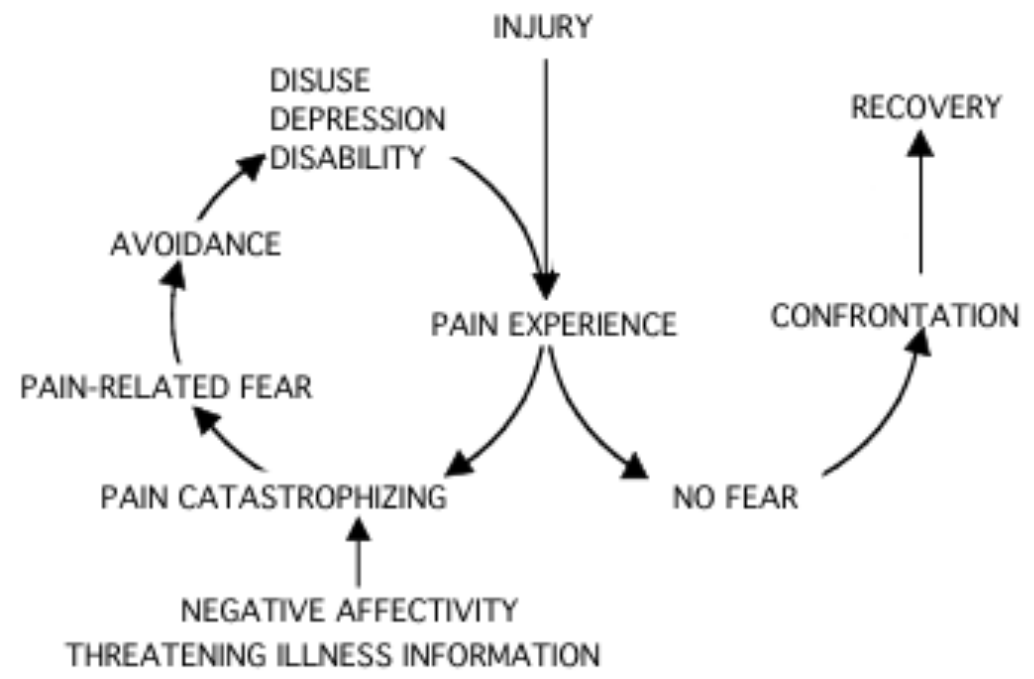

Figure I. The fear-avoidance model. From Fear-avoidance and its consequences in chronic musculoskeletal pain: a state of the art, by J.W.S Vlaeyen and S. Linton, 2000, Pain, 85, p. 329. Reprinted with permission.

In the fear-avoidance model, two pathways can be distinguished following pain experience. The adaptive pathway, characterized by low pain-related fear, includes confrontation with pain experience and is expected to lead to fast recovery. A key variable starting the maladaptive pathway is the level of pain catastrophizing, which is defined as an exaggerated negative orientation towards painful stimuli and experiences (Sullivan, Bishop, \& Pivik, 1995). Negative affectivity and the level to which the patient received threatening information about his/her illness might fuel these catastrophizing beliefs about pain. Consequently, pain might be interpreted as threatening leading to a vicious circle in which pain-related fear causes avoidance behaviour and hypervigilance of bodily sensations, followed by disuse, depression and disability (Vlaeyen, et al., I995; Vlaeyen \& Linton, 2000).

Numereous studies, building on the fear-avoidance model, have been conducted and provided support for the hypothesized relationships between pain catastrophizing and pain-related fear, their effect on attentional processes and avoidance-related responses, as well as the relationships with disability and depression (Goubert, Crombez, \& Van Damme, 2004; Leeuw, et al., 2007; Vlaeyen, et al., 1995; Vlaeyen \& Linton, 2000). The evidence on disuse is however unclear so far and whereas there have been some recent prospective studies there remains 
some discussion on the prognostic value of fear-avoidance beliefs and catastrophizing (Gheldof, et al., 20 Io; Lakke, Soer, Takken, \& Reneman, 2009; Pincus, Smeets, Simmonds, \& Sullivan, 2010; Sieben, et al., 2005; Verbunt, Smeets, \& Wittink, 20I0; Wideman, Adams, \& Sullivan, 2009). Nevertheless, the fear-avoidance model has demonstrated applicability to a number of chronic pain complaints, such as chronic low back pain, whiplash, osteoarthritis, and complex regional pain syndrome (de Jong, et al., 2005; Heuts, et al., 2004; Leeuw, et al., 2007; Somers, et al., 2009; Vangronsveld, Peters, Goossens, Linton, \& Vlaeyen, 2007).

\section{PERSISTENCE BEHAVIOUR}

Whereas the fear-avoidance model has contributed to a better understanding of the role of pain-catastrophizing and fearful appraisal of pain as initiating or maintaining factors in chronic pain, the model may not apply to all patients. There appears to be a group of patients with chronic pain who do not avoid activities but, instead, persist in activities despite pain (Arntz \& Peters, I995; Pascarelli \& Hsu, 200I). This is supported by studies showing that the mean activity level of chronic pain patients does not differ from that of healthy controls and that there is only a subgroup of patients who show a decrease in physical activity over one year after pain-onset (Bousema, Verbunt, Seelen, Vlaeyen, \& Knottnerus, 2007; van Weering, Vollenbroek-Hutten, Tonis, \& Hermens, 2009). Yet, persistence behaviour can hardly be understood by the fear-avoidance model only, nor would patients with activity patterns characterized by persistence behaviour benefit from the common treatments aimed at activity increments. Consequently, the study of explanatory mechanisms behind behavioural persistence, rather than avoidance, gained increased attention in the past decade. Three explanatory models have been proposed, the ergomania model (Van Houdenhove \& Neerinckx, 1999), the avoidance-endurance model (Hasenbring, Hallner, \& Rusu, 2009b) and the mood-as-input model (Vlaeyen \& Morley, 2004). The ergomania model stresses the role of an overactive (hyperactive) lifestyle. This high action-proneness is considered as a possible etiological, predisposing, initiating and perpetuating factor for chronic pain (Van Houdenhove, 2005; Van Houdenhove, Neerinckx, Onghena, Lysens, \& Vertommen, 200I). Yet, while several hypotheses have been raised on the reasons behind this overactive lifestyle, such as being active as a mean to protect self-esteem, robust empirical evidence is lacking.

In the avoidance-endurance model, emphasis is placed on how patients cope with their pain. Avoidance behaviour is conceived in a similar way as in the fear-avoidance model. In addition, endurance (i.e. behavioural persistence) is considered as a consequence of cognitive suppression of 
pain-related thoughts or ignorance or minimalization of pain experience (Hasenbring, Hallner, \& Rusu, 2009b; Hasenbring \& Verbunt, 2010). Yet, as well as the ergomania model, the avoidance-endurance model remains largely descriptive of nature. That is, these models describe processes involved in persistence behaviour rather than formulate predictions about mechanisms causing persistence behaviour. The moodas-input model takes a more dynamic approach. The original model (Martin, Ward, Achee, \& Wyer, 1993) proposes that behaviour is a resultant of interactions between stop rules and affect-regulation processes. One of the basic assumptions is that not mood per se, but the informational value of mood within a motivational context influences task performance. Two motivational stop rules have been described, namely, an as-many-as-can stop rule in which the progress made on the task is the primary interest and a feel-like-discontinuing stop rule, which involves preoccupation with how much the individual, enjoys the task. The model predicts that for individuals adopting an as-many-as-can stop rule, positive mood indicates sufficient task progress leading to early task disengagement. Yet, negative mood signals discontentment with task progress and motivates task persistence. In contrast, a feel-likediscontinuing stop rule in combination with positive mood indicates task enjoyment, and thus motivates task persistence whereas in combination with negative mood task disengagement is facilitated. Vlaeyen and Morley (2004) suggested that the mood as input model might help to explain (avoidance and persistence) behavioural patterns in chronic pain patients based on the habitual use of stop rules in changing moods or, when in a certain mood, fluctuating task performance because of changing stop rules. Preliminary research however, demonstrated independent effects of mood and stop rules on task persistence, but failed to provide evidence for the hypothesized interaction between mood and stop rules (Karsdorp, Nijst, Goossens, \& Vlaeyen, 20IO).

While the aforementioned models have advanced the study of persistence behaviour in patients with chronic pain, empirical evidence is scarce and inconclusive. As a consequence, persistence behaviour remains poorly understood.

\section{PACING}

A third activity pattern that has been documented in the chronic pain literature is pacing. In contrast to the aforementioned activity patterns, pacing was introduced as a pain management strategy aimed at increased activity tolerance by balancing pain dependent periods of activity and rest. A multitude of pacing strategies have been described such as breaking activities into smaller (manageable) pieces, taking frequent short rests, speeding up or slowing down (contrasting a patient's habitual 
activity), maintaining a steady pace and using a timer to counteract paincontingent activity (Birkholtz, Aylwin, \& Harman, 2004). While pacing techniques are widely used in clinical practice, Nielson and colleagues (200I) were the first to develop a (self-report) pacing scale for empirical use. Pacing was operationalized by the methods used and did not include the aim, namely increased activity tolerance, since the authors considered it to be a consequence rather than an element of pacing (Nielson, et al., 200I). In line with the expectations, pacing was related to lower levels of depression and physical impairment and was associated with better outcomes (e.g. less distress) in a multidisciplinary pain program in patients with Fibromyalgia Syndrome (Nielson \& Jensen, 2004; Nielson, et al., 200I). Some more recent studies, however, were unable to demonstrate the functional character of pacing (Ersek, Turner, \& Kemp, 2006; Karsdorp \& Vlaeyen, 2009; McCracken \& Samuel, 2007). In these studies, pacing was unrelated or positively associated with disability related measures. For example, McCracken and Samuel (2007) studied pacing in a heterogeneous group of chronic pain patients, using a newly developed scale to assess pacing. Based on their results, pacing largely resembled avoidance behaviour as reflected by positive associations with avoidance and physical disability and negative associations with daily uptime. In line with Williams and Wheatley (2006), who described how pacing strategies could wrongfully be used by patients as ways to avoid certain activities, Mccracken and Samuel (2007) argued that pacing should include its purpose, being the reduction of the influence of pain on functioning. They differentiated between two approaches to pacing: a formal approach, involving a focus on steady activity rates (counteracting extreme cycling between activity and rest) and a, preferable, functional approach, incorporating the purpose of pacing. Karsdorp and Vlaeyen (2009), who found that pacing (as measured by Nielson and colleagues) was not related to physical functioning or disability, also emphasized consideration of the function of pacing for patients, that is using it as an avoidance strategy versus using it with graded activity to improve functioning. A recent attempt of Gill and Brown (2009) to provide a review of the evidence for pacing as a chronic pain intervention did not reveal any significant benefits, and the authors concluded that the construct 'pacing' is in need of a clear definition and thorough investigation of its effectiveness. Thus, so far, empirical evidence on pacing is limited and has shown contrasting results regarding relationships with disability-related measures.

In sum, a lot of effort has been put into identifying and explaining dysfunctional activity patterns, as they are subscribed a pivotal role in the onset and maintenance of chronic pain. Thus far, the fear-avoidance model has received the most empirical attention and support. However, it cannot be applied to the explanation of activity patterns characterized by persistence behaviour. Yet, in spite of some recent propositions, the 
study of persistence behaviour in patients with chronic pain is still in its infancy and merits further investigation. Furthermore, studies on the role of supposedly functional activity patterns, such as pacing, are inconclusive.

In the present thesis, a self-regulatory perspective on the origin of dysfunctional behavioural patterns is introduced, which is elucidated in the next part of this introduction.

\section{THE IMPORTANCE OF THE (MOTIVATED) SELF}

Recently, pain researchers have argued in favour of a reconsideration of pain behaviours in a motivational context (Karoly, Okun, Ruehlman, \& Pugliese, 2008; Van Damme, Crombez, \& Eccleston, 2008; Vlaeyen, Crombez, \& Linton, 2009). Whereas in fear-avoidance models on chronic pain, patient's goals are implicitly reduced to preserving physical integrity, a motivational perspective calls for an expanded consideration of patients' goals. Goals are defined as internal representations of desired states (Austin \& Vancouver, 1996). Besides specific pain-related goals (e.g. getting rid of pain), patients', possibly conflicting, higher order goals (e.g. being a good parent) should also be considered. This motivational perspective is in accordance with early self-regulation theories in the domain of personality and social psychology. In these self-regulation theories, behaviour is considered to be a consequence of regulation based on goals. In such an approach, the person is considered an active agent in regulating his/her behaviour by volitional goal striving (Carver \& Scheier, 1998; de Ridder \& de Wit, 2006). In the process of goal striving, goals act as reference values to which the individual compares himself or the progress he has made in achieving the goal. Goals differ in their level of abstraction and can be placed within a hierarchy on a dimension of concreteness with feedback loops (Carver \& Scheier, 2000; Powers, 1973).

As illustrated in Figure 2, goals on top of the hierarchy refer to systems concepts and are the most abstract, such as the ideal self. These system concepts provide input for so-called "be-goals" at the lower level of the "principle control". These be-goals are abstract formulations such as "be thoughtful", which define do-goals at the "programs" level in order to accomplish the be-goal ("Prepare dinner"). In contrast to principles, programs are more concrete. In order to fulfill these do-goals, sequences of movements are necessary ("Slice broccoli"), which are also referred to as "motor control" goals. This goal hierarchy fits within the cybernetic control theory as described by Carver and Scheier (1998). Central to this self-regulation theory is the idea of cybernetics, which refers to the dynamic feedback processes involved in self-regulation. Crudely applied to the example in the goal hierarchy in Figure 2, the perception that one 
may not be thoughtful enough instigates behaviour such as preparing dinner, which, in turn, increases the sense of perceived thoughtfulness.

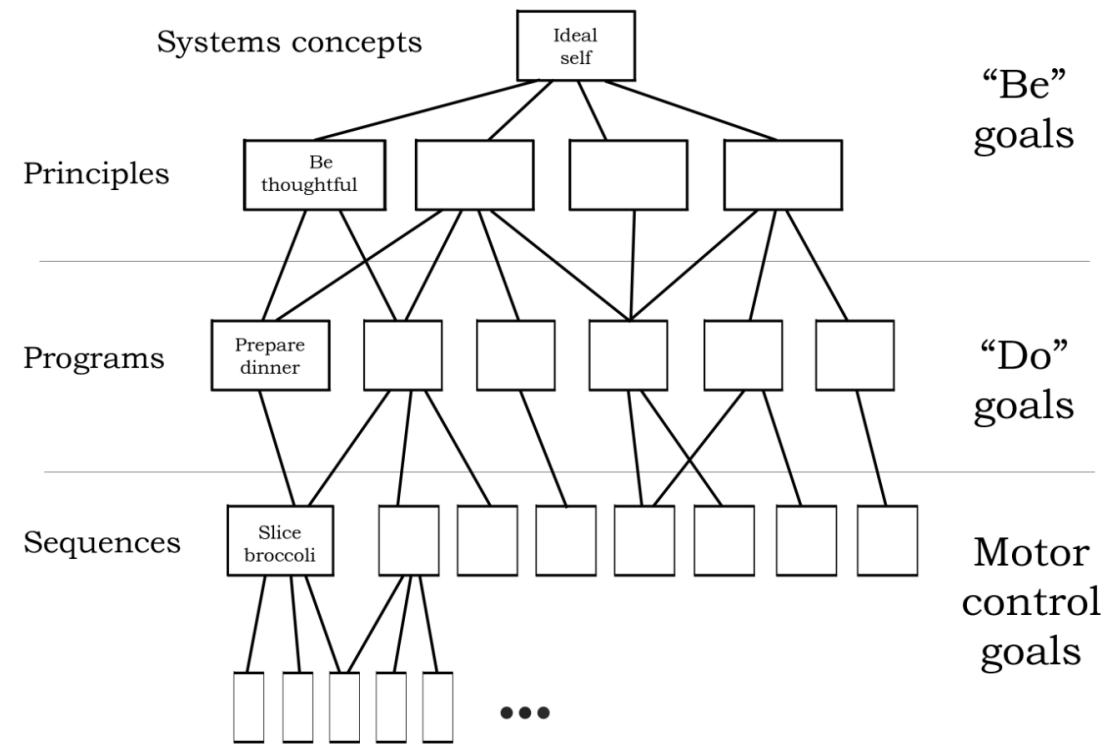

Figure 2. A hierarchy of goals (or of feedback loops). From On the self-regulation of behavior, by C.S. Carver and M. F. Scheier, 1998, New York: Cambridge University Press; Copyright 1998 by Cambridge University Press. Reprinted with permission.

\section{PAIN AS A BARRIER TO THE PURSUIT OF GOALS}

Studies comparing goal behaviour between persons with and without pain, illustrated that those with persistent or recurrent pain experience degraded goal-construal and striving (Karoly \& Lecci, 1997; Karoly \& Ruehlman, 1996). Furthermore, pain and fatigue are barriers to goal progress, leading to decreased goal progress and positive affect. On the other hand, goal progress can lead to increments in positive mood independent of pain levels (Affleck, et al., I998; Affleck, et al., 200I). In a recent study it was also shown that pain-induced fear mediates the relationship between the degree of experienced conflict between important goals and perceived goal self-efficacy on the one hand and depression and disability on the other hand (Karoly, et al., 2008).

When considering pain as a barrier to the pursuit of goals and aspirations (Affleck, et al., 200I; Eccleston \& Crombez, 1999), inspection of how patients cope with these barriers is of importance. Within the research domain of healthy ageing, Brandstadter and colleagues (Brandtstädter \& Renner, I990; Brandtstädter \& Rothermund, 2002) differentiated between two forms of coping with discrepancies between actual and 
desired courses of development involved with ageing. In assimilative coping, personal efforts are adapted (increased) to approach the desired outcomes, whereas in accomodation, the desired oucomes are adapted (reframed to standards that are more obtainable). Assimilation and accomodation have been operationalized as, respectively, tenacious goal pursuit and flexibile goal adjustment. As long as tenacious goal pursuit is successful, assimilative coping can be maintained, yet, in case repeated unsuccessful assimilative efforts have been made, it is preferable to flexibly adjust the goals (i.e. to accommodate by changing the standards) (Rothermund \& Brandtstadter, 2003). It has been suggested that assimilation and accomodation might also be important in patients who are trying to cope with chronic pain (Schmitz, Saile, \& Nilges, 1996; Van Damme, et al., 2008). In fact, it was shown that flexible goal adjustment is associated with lower levels of disability and depression in patients with chronic pain. Thus, flexibility might act as a buffer against the effects of pain on well-being (Schmitz, et al., 1996).

The aforementioned studies focused on goals in general, which can be placed on multiple levels of the goal hierarchy. Yet, in line with Morley's (2008) description of the effects of chronic pain, which emphasized the role of identity, it is worthwhile to specifically zoom in on those goals at the highest level, namely self-related goals. Within this approach, two main pathways in the aforementioned goal hierarchy are important. A bottom-up pathway, in which pain and associated disabilities influence the self (and associated well-being) and, secondly, a top-down pathway in which self-perceptions or self-related goals guide behaviour. Accordingly, the impact of chronic pain on the self is considered in the next part of the introduction (part 3) and the influence of the self on behaviour is considered in part 4 .

\section{THE IMPACT OF CHRONIC PAIN ON THE SELF}

Many consequences of experiencing chronic pain on the "sense of self" are known from qualitative studies investigating the experiences of patients living with chronic illness. Persistent pain altering the self or challenging self-perceptions is one of the consistently emerging themes in these studies (Johansson, Hamberg, Westman, \& Lindgren, 1999; Miles, Curran, Pearce, \& Allan, 2005; Osborn \& Smith, 1998; Paulson, Danielson, \& Soderberg, 2002; Smith \& Osborne, 2007). Aldrich and Eccleston (2000) demonstrated that narratives on everyday pain show close relationships between pain and the self as well. Uncertainty regarding the cause of the pain, which is inherent to chronic non-specific pain, often challenges a valued sense of self (Eccleston, Williams, \& Rogers, 1997). Based on interviews of chronic pain patients, Miles and 
colleagues (2005) identified three types of constraints that are associated with pain. Besides bodily and activity constraints, patients also mentioned identity constraints that refrained them from 'living a normal life'. An example of a patients' quote in this context is: "I am a person who was always busy, I was never still, I was always on the road and I loved it. When I could not do it any longer I felt like a second-class citizen" (Informant 4, page 5; Lundberg, Styf, \& Bullington, 2007). Patients with chronic pain often experience a disheartening division between the old me without pain and the present me with pain and pain and associated disabilities makes them feel as not me (Crowe, et al., 20I0; Johansson, et al., I999; Lundberg, et al., 2007; Miles, et al., 2005; Williams, 2000). Johansson and colleagues (1999) found that women with chronic non-specific musculoskeletal pain often used expressions such as 'one should and would' indicating the importance of social expectations and, following the authors, demonstrating "the gaps between the women's actual circumstances and societal ideals, between their personal capacities and what they felt was expected of them" (p. 1799; Johansson, et al., 1999). It has also been shown that others have an altered perception of chronic pain patients' identity. In this context, Bernardes and Lima (2010) studied the preceived gender identities of patients with chronic low back pain by laypeople and nurses. Their study indicated that men and women with chronic low back pain were perceived as less masculin, respectively feminine, compared to the stereotypical man or woman. The authors suggested that these perceptions of others might aggravate identity conflicts in chronic pain patients and complicate integration of the chronic illness into their identities. It is noteworthy that besides detrimental consequences of the influence of pain on living, there are also reports of positive consequences in which patients feel their pain or illness has taught them ways to value life (Sim \& Madden, 2008). Unfortunately, this does not apply to all patients.

Recently, researchers interested in the changing self due to chronic pain started to systematically investigate the detrimental effects of pain on the self and its consequences for well-being. One of the first studies was a study of Harris and colleagues (2003) on the social roles of patients with chronic musculoskeletal pain. It was demonstrated that the experienced loss of social roles (mostly work-related) and attributes due to chronic pain was associated with depression, also after controlling for pain-related variables (e.g. pain duration). Harris and colleagues (2003) operationalized the self by administering social roles of patients and the attributes (i.e. personality characteristics) that described them in that role. Yet, referring to the work of Higgins (1987) on self-discrepancies, Harris and colleagues (2003) suggested to employ a single measure of attributes, which enables determination of the relative contribution of attribute loss to well-being, apart from role loss. After that, studies of the self in chronic pain started to focus on multiple facets of the self, such as 
described in the self-discrepancy theory (Higgins, 1987) and the possible selves theory (Markus \& Nurius, 1986). These theories provide insights into the structure and agency of the self, based on differentiations between multiple representations of the self. Preparatory to a description of the findings on self-discrepancies and possible selves in chronic pain, an overview of these theoretical models is provided below.

\section{TWO THEORETICAL MODELS OF THE SELF}

\section{Self-discrepancy theory}

The Self-discrepancy theory was introduced by Higgins (1987) as a theory 'relating self and affect'. The theory explains how discrepancies between the actual self and self-guides, which guide the actual self, lead to negative emotions. Within the aforementioned goal hierarchy, self-guides constitute higher order be-goals. Higgins (i987) differentiated between two self-guides, the ideal and the ought self. The ideal self is the person you 'ideally would like to be' whereas the ought self is the person you feel you 'should be'. Higgins (1987) also noted that two standpoints on these selves should be considered, the personal standpoint (own perspective) and the standpoint of a significant other such as the spouse (other perspective). The other perspective comprises the values the individual believes the important other (e.g. spouse, parent, boss) holds for him/her. Thus, four self-guides can be distinguished: ideal/own, ideal/other, ought/own, and ought/other. A basic premise of the self-discrepancy theory is that individuals are motivated to reach a state in which the actual self matches the self-guides. Yet, in case an individual experiences self-discrepancies, this leads to specific negative emotions. It is hypothesized that individuals with actual-ideal (own or other) discrepancies are vulnerable to dejection-related emotions (e.g. disappointment, sadness) and depression, whereas individuals with actualought (own or other) discrepancies would be vulnerable to agitationrelated emotions (e.g. fear, edginess) and anxiety. Following Higgins (1987), the intensity of the discomfort depends on the magnitude of the self-discrepancies. A number of correlational and experimental studies have found evidence for the hypothesised relations between the type of self-discrepancy and distinct types of emotions (e.g., Boldero \& Francis, 2000; Higgins, I989a; Higgins, Bond, Klein, \& Strauman, I986a; Scott \& O'Hara, I993; Strauman, I989; Strauman \& Higgins, 1988). However, there are also studies which have failed to confirm the unique relations between self-discrepancies and agitation/dejection-related emotions (Bruch, Rivet, \& Laurenti, 2000; Carver, Lawrence, \& Scheier, I999; Gramzow, Sedikides, Panter, \& Insko, 200o; Tangney, Niedenthal, Covert, \& Barlow, 1998). 
Already in 1987 , Ogilvie drew attention to the undesired self as "a neglected variable in personality research". His studies compared discrepancies regarding the ideal self with discrepancies regarding the undesired self. Results showed the latter to be a better predictor of life satisfaction (Ogilvie \& Clark, I992). In addition, Carver and colleagues (I999) studied a third self -the feared self- in relation with ideal and ought self-guides in explaining negative emotions. The feared self is the self one fears to become and, in contrast to ideals and oughts, is to be avoided. Carver and colleagues found that feeling close to the feared self might take priority over actual-ought discrepancies. Therefore, being close to the feared self might draw all attention to the avoidance of this 'danger'. Once there is greater distance between the actual and the feared self, people can focus again on their approach goals (Carver \& Scheier, 1999). In other words, the additional value of the feared self was demonstrated by its moderating effects on the relation between actual-ought discrepancies and negative emotions. These findings where successfully replicated, using a different measure of self-discrepancies, by Heppen and Ogilvie (2003).

\section{Possible selves theory}

Almost simultaneously with Higgins' proposition of the Self-discrepancy theory, Markus and Nurius' (I986) paper on possible selves was published. Possible selves encompass representations of the self in the future. This temporal focus is the foremost difference between possible selves and self-discrepancies. Whereas in Markus and Nurius' original paper, possible selves included a variety of selves, mostly difference is made between two important possible selves, namely, hoped-for and feared-for (e.g., Cross \& Markus, I99I). Hoped-for selves include representations of the self one hopes to become in the future. Opposite to that, feared-for selves include representations of the self one fears to become. It is appararent that these possible selves are closely related to the aforementioned selves, as suggested by Higgins (1987) and Carver, Lawrence, and Scheier (1999). Possible selves theory was, in contrast to the self-discrepancy theory, less focused on explaining affect, and has demonstrated utility in an array of other research domains such as delinquency (e.g., Oyserman \& Markus, I990). Noteworthy in the light of the present thesis is a recent study by Sutherland and Morley (2008), who demonstrated that the hoped-for self of pain patients is saturated with ideal characteristics and the feared-for self with negative ideal characteristics (i.e. attributes patients ideally did not want to possess).

\section{SELF-DISCREPANCIES AND POSSIBLE SELVES IN CHRONIC PAIN}

With respect to the study of self-discrepancies in chronic pain paients, Waters and colleagues (2004) were the first to study ideal and ought self- 
discrepancies (from both perspectives) in patients with chronic low back pain. In line with the hypotheses, their results indicated that patients who felt distant from their ideal-own reported higher levels of depression and psychological distress. Also, feeling distant from the ought-other was associated with psychological distress. The authors explained these findings, drawing on the theory of symbolic interactionism, by suggesting that patients may have adopted self-concepts including overly negative views of themselves as a consequence of behaviour of significant others. More specifically, it might be that others reacted to patients in ways that made them feel more dependent or less capable of fulfilling their responsibilities. Consequently, patients might have internalized these views. Waters and colleagues (2004) also found that ought-other discrepancies were related to pain intensity. Two possible explanations for this finding were reported. On the one hand, it might be that patients who experience higher levels of pain intensity, feel less able to fulfill important social roles and consequentially experience larger discrepancies between their actual and ought-other self. On the other hand, higher levels of pain may also provide justification to patients for experienced discrepancies. Whereas no meaningful relationships were found for idealother and ought-own discrepancies, this was in line with studies from Higgins and colleagues (1985) in which the ideal-own and the ought-other are often most prominent (Waters, et al., 2004).

\section{SCHEMA-ENMESHMENT THEORY}

In the schema-enmeshment theory, a differentiation is made between three schemas important to patients with chronic pain, namely a painschema, an illness-schema, and a self-schema. The case in which these schema's are fully enmeshed represents the most detrimental state in which pain and illness are incorporated into the self (Pincus \& Morley, 200I). Morley and colleagues (2005) added a measure of enmeshment into the measurement of possible selves by asking patients if they felt it was possible to be that hoped-for or feared-for self with pain. Enmeshment is high in case the future selves are conditional on the presence or absence

of pain. Morley, Davies, and Barton (2005) and Sutherland and Morley (2008) predicted that possible selves, besides their role in emotional wellbeing, would also be important in the process of pain acceptance. Pain acceptance involves a willingness to experience pain without attempting to control or eliminate it and was shown to play an important role in successful adaption in living with chronic pain (McCracken \& Vowles, 2006). Indeed, Morley, Davies, and Barton (2005) and Sutherland and Morley (2008) demonstrated that the conditional hoped-for self was associated with depression and pain acceptance beyond interruptive (e.g. pain intensity) and interferential (e.g. experienced disability) effects and after controlling for the simple discrepancy measure. More specifically, 
the more patients felt their hoped-for selves depended on the absence of pain, the more depressed they felt and the less accepting they were towards pain. Neither conditional feared-for selves nor feared-for selfdiscrepancies were meaningfully related to feelings of anxiety, depression or acceptance. The authors also discussed that emotional adjustment is hampered in patients who primarily stay focused on pain relief and this might lead to increased self-pain enmeshment (Morley, et al., 2005). With respect to this, Sutherland and Morley (2008) explored the role of state motivational preferences. More specifically, differences were made between needs for autonomy versus sociotrophy characteristics (i.e. needs for caring for others, associated with high dependency). In patients who experienced low hoped-for own enmeshment, high levels of autonomy were related to higher levels of anxiety and in patients with low hoped-for other enmeshment, sociotrophy was related to anxiety. Though preliminary, it is worthwile to mention that self-discrepancies and selfpain enmeshment might also play a role in subacte pain as well. It appeared that self-discrepancies remained relatively stable whereas selfpain enmeshement decreased during a three-week interval in patients with subacte neck pain (Vangronsveld, Morley, Peters, Vlaeyen, \& Goossens, 20IO)

\section{THE INFLUENCE OF THE SELF ON BEHAVIOUR}

Miles and colleagues (2005) have identified three types of constraints in patients with chronic pain. These are bodily, activity, and identity constraints. In addition, they also identified four types of coping with these constraints which largely resemble the coping strategies as proposed by Brandstädter and Renner (1990) namely, a) Assimilation, characterized by minor body or identity constraints and making minor life changes to counteract activity restraints, b) Accomodation, used by those who perceived 'the normal life' to be unobtainale and characterized by trying to adjust to the new situation, c) Subversion, charaterized by trying to appear to be the same person as before, yet, with high activity constraints, and d) Confrontation, involving doing as much as possible regardless of pain. Links can also be drawn between subversion and confrontation on the one hand and aforementioned dysfunctional activity patterns, respectively avoidance and persistence behaviour. Though informative, the study of Miles and colleagues (2005) does not clarify how the self is actually regulated. In the present thesis, however, one focus is on how patients with chronic pain regulate their self despite pain and how this might be associated with dysfunctional activity patterns. To our knowledge, no studies on this matter have been conducted so far. In order to develop a well-founded explanatory mechanism, we focus on selfregulatory processes to manage self-discrepancies and turn to theories 
expanding on the mechanisms that reduce or enlarge (in case of the feared self) self-discrepancies.

\section{SELF-DISCREPANCY REDUCING OR ENLARGING LOOPS}

Carver and Scheier (1998) differentiated between an approach system in which the aim is to approach a desired reference value and an avoidance system in which the aim is to avoid an undesired reference value. SelfDiscrepancy Theory (Higgins, 1987) holds that there are two important reference values (i.e. the ideal and the ought self), which are both positive reference values but differ at how these positive end states are approached. More specifically, ideal (maximal) goals are concerned with positive outcomes and thus involved with approaching a match whereas ought (minimal) goals are concerned with negative outcomes ("not living up to expectations") and thus involved with avoiding a mismatch (Higgins, Roney, Crowe, \& Hymes, 1994). These ideas were integrated into the regulatory focus theory, an expansion of the self-discrepancy theory (Higgins, I997b). Following the self-discrepancy theory, negative emotions that arise from self-discrepancies serve as warning signals, alerting the individual to undertake self-regulatory actions. Regulatory focus theory elaborates on the fact that the type of discrepancy determines which discrepancy-decreasing strategy is used. It was hypothesized that ideal discrepancies are associated with a promotion focus and ought discrepancies with a prevention focus. In a promotion focus, the person is focused on the presence or absence of positive outcomes and is concerned with the approach of matches. In a prevention focus, the person is focused on the presence or absence of negative outcomes and aims at avoiding mismatches. Furthermore, a promotion focus involves eagerness to attain advancement and gains whereas a prevention focus entails vigilance to assure safety and nonlosses (Higgins, 1997b; Higgins, et al., 1994).

Importantly, Higgins' self-discrepancy theory and Carver and Scheier's cybernetics control theory differ with regard to the interpretation of the reference value. In the control theory, a reference value is considered as a goal, it represents what is desired for the future. In the self-discrepancy theory, the reference value is a standard. It contains the desires for the self in the present. Consequently, both theories hold different beliefs about what motivates individuals to reduce self-discrepancies. Within the theoretical framework of the self-discrepancy theory, feeling far away from the ideal and ought self or feeling close to the feared self in the present would cause negative emotions. According to Higgins, these negative emotions motivate the individual to decrease the discrepancies. According to Carver and colleagues, self-discrepancies do not neccesarily cause negative emotions. Yet, the valence of the emotion is a function of 
the rate of discrepancy reduction relative to some expected rate. Consequently, from Carver's point of view, negative emotions do not motivate discrepancy-reduction per se. Rather, the discrepancy itself instigates approach (or avoidance) behaviour (Boldero \& Francis, 2000). Thus, it is possible that observed self-discrepancies are not associated with negative emotions but still are important in the light of selfregulatory behaviours.

If the conceptualizations from Higgins and colleagues (1987; 1997b) and Carver and colleagues (1998, 1999; 1999) are integrated, it could be concluded that at the level of the self-guides, ideal and ought selves are approach goals whereas the feared self is an avoidance goal. With regard to the regulatory focus, though, the ideal involves a promotion focus whereas the ought and feared self involve a prevention focus. Or, in other words, the ideal self is an approach goal with approach orientation, the ought self an approach goal with avoidance orientation, and the feared self an avoidance goal involving avoidance orientation.

There is a handful of studies examining the hypothesized relationships between selves and actual self-regulatory behaviour. Suggestions have been made that anti-goals (such as the feared self) are not adaptive because they draw the individual away from certain experiences and toward safety, rather than toward positive goals (Mansell, 2005). Also, it has been shown that holding more avoidance versus approach motivations (goals) is associated with lower levels of subjective well-being, more physical symptoms (e.g. headaches), and lower perceived competence and autonomy (Elliot \& Church, 2002; Elliot \& Sheldon, 1998; Elliot, Sheldon, \& Church, 1997). In a similar vein, holding a strong promotion focus in contrast to a prevention focus has also been found to be more adaptive, as reflected in well-being related measures (Miller \& Markman, 2007; Schokker, Links, Luttik, \& Hagedoorn, 2010). Yet, these studies remain silent about the behavioural consequences of approach versus avoidance motivations. Experimental studies on regulatory focus demonstrated that a promotion focus is associated with task persistence and a prevention focus with early disengagement of difficult tasks (Crowe \& Higgins, 1997). On the other hand, participants in a prevention focus might persist in tasks despite low certainty on achieving results because the goal might feel as a necessity (Shah \& Higgins, 1997). There are however no studies on behavioural consequences that have incorporated both Higgins' selves (Higgins, 1987) and the feared self as proposed by Carver and colleagues (Carver \& Scheier, I998; Carver, et al., I999). 


\section{AIM AND OUTLINE OF THE PRESENT THESIS}

The overall aim of the present thesis is to investigate the role of selfdiscrepancies in chronic musculoskeletal pain. Based on the finding that self-discrepancies not predict negative emotions or emotional disorders, but also instigate self-regulatory behaviours, the self-discrepancy model is applied to the prediction of activity patterns in chronic pain patients (Figure 3). The main research question of the present thesis is: What is the role of self-discrepancies in the emotional well-being and activity patterns of patients with chronic pain?

It is hypothesized that ideal and ought discrepancies are associated with persistence behaviour, whereas feared discrepancies are expected to be related to avoidance behaviour. The ideal self could be related to an active approach because of the strong inner motivation. With regard to the ought self, a preventive approach might seem contradictory, however one can prevent self-disapproval or disapproval of significant others by approaching the self one ought to be. It is hypothesized that chronic pain patients with a chronically accessible ought discrepancy will try to avoid self-disapproval or disapproval of significant others by approaching ought-goals. In addition, it is expected that in patients with chronic pain, a focus on the feared self elicits processes similar to those predicted by the fear-avoidance model, and consequently might lead to avoidance behaviour. Furthermore, as illustrated, both avoidance and persistence behaviour are expected to be detrimental in terms of high levels of disability and diminished quality of life.

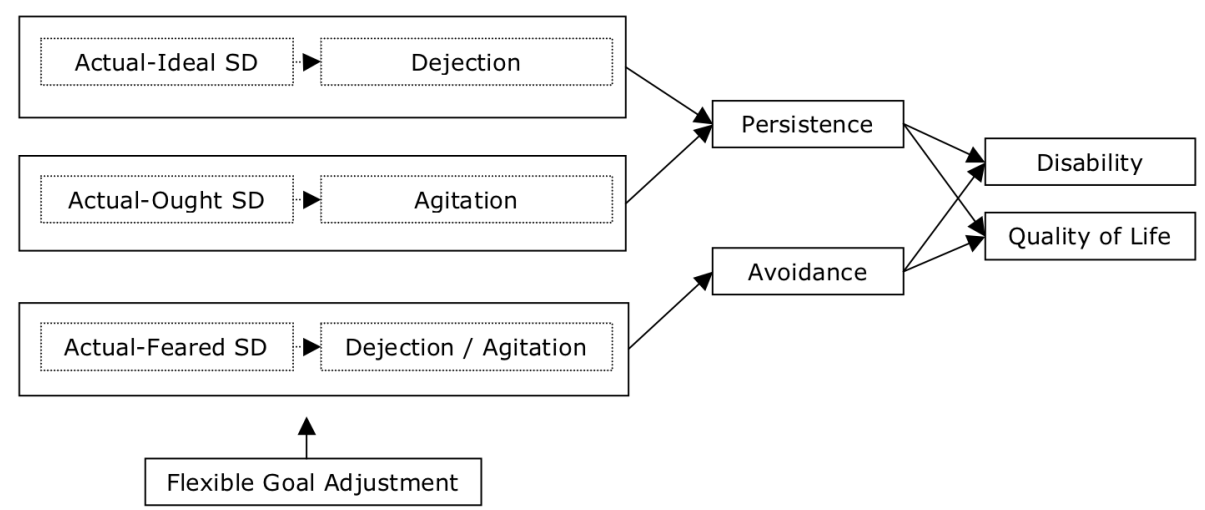

Figure 3. A self-discrepancy model for chronic pain

Chapter 2 and 3 mainly focus on the first part of the model, that is the relationships between self-discrepancies and emotional well-being. A first step in this was to investigate the content of the different selves. Although the ideal, ought, and feared self of patients with chronic pain 
has already been studied, so far, it is unclear what their ideals, oughts, and fears are. Therefore, in chapter 2, we report on a content analysis of the selves in the context of pain. In chapter 3 , the emotional consequences of experienced discrepancies between the actual and ought and feared selves are studied in patients with work-related upper extremity pain. In this chapter, the possibly protecting effects of flexible-goal adjustment are also considered. In chapter 4 , the validity of the full model, as depicted in Figure 3, is examined using hierarchical multiple regression analyses. Pathways from self-discrepancies to activity patterns and disability and quality of life are studied in patients with chronic low back pain. Chapter 5 specifically focuses on the latter part of the model, and considers the relative contribution of activity patterns (avoidance and persistence behaviour and also pacing) to experienced disability and depression levels. Self-regulatory consequences of self-discrepancies were also studied at a more fundamental level. Accordingly, an experimental study with healthy subjects is conducted to examine the effects of self-discrepancies on the persistence on an anagram task (chapter 6). In chapter 7 , the results of the aforementioned studies are integrated and discussed in the light of present hypotheses and related studies. Furthermore, suggestions for future research are made and clinical implications discussed. 



\section{|| Chapter 2 ||}

\section{A content analysis of ideal, ought, and feared selves in patients with chronic low back pain.}

This chapter is published as: Kindermans, H., Goossens, M., Roelofs, J., Huijnen, I., Verbunt, J., Morley, S., Vlaeyen, J. (2009). A content analysis of ideal, ought, and feared selves in patients with chronic low back pain. European Journal of Pain, I4, 648-653. 


\section{Abstract}

Patients with chronic pain are not only faced with disabilities but are also challenged to maintain a valued sense of self. This sense of self is in part determined by the extent to which patients can accomplish their identity-related goals. The present study explores the content of three domains of the self, namely the ideal, ought and feared self and examines how the content relates to disability and depression.

The ideal, ought and feared attributes of 80 chronic low back pain patients were analyzed and categorized in eight general goal-domains: interpersonal attributes, personal abilities, physical, emotional and psychological well-being, close interpersonal relationships, self-expression abilities, achievement-related attributes, physical appearance, and religion. Results showed that most of the attributes that patients generated involved interpersonal attributes. Comparisons between the self-guides revealed that ideal attributes were more intrapersonally focused while ought and feared attributes were interpersonally focused. The content appeared to be related to disability but not to depression. More specifically, the more disabled patients were, the more they listed well-being related attributes as part of their ought self. None of the other goal-domains was related to disability or depression.

The present study provides additional insight into the goals of patients with chronic pain at the level of identity and has shown that these are, at least in part, related to the level of functional disability. These results might be useful for future studies incorporating the role of identity in chronic pain, such as psychological interventions.

\section{INTRODUCTION}

The self and identity can be seen as an individuals' knowledge and understanding of his or her self, and has received increased attention in the field of chronic pain. Several authors put forward that chronic pain is associated with loss of desired social roles or attributes, and hence, has detrimental effects on the sense of self (e.g., Harris, et al., 2003; Morley \& Eccleston, 2004; Smith \& Osborne, 2007). Based on Higgins' SelfDiscrepancy Theory (SDT; Higgins, 1987), the study of the self in chronic pain has focused on three self-guides (i.e. self-directive standards), that refer to regulating the actual self based on the experienced discrepancies between the actual self and the ideal self-guide (reflecting aspirations), the ought self-guide (reflecting duties), and the feared self-guide (reflecting fears). In chronic pain populations, this line of research not only has confirmed SDT's predicted relationships between discrepancy and psychological distress, it also extended these findings with important 
relationships between discrepancies, pain experience, and disability (Morley, et al., 2005; Sutherland \& Morley, 2008; Waters, et al., 2004) ${ }^{\mathrm{I}}$.

However, none of these studies has shed light on the content of selfguides, while it is known from research in other domains that this might be related to health status. For example, a content analyses of the feared identity of patients with obsessive compulsive behaviour illustrated that this behaviour might be a strategy to prevent their feared self, characterized by a 'dangerous me' theme (Ferrier \& Brewin, 2005). Moreover, the content of the self-guides might serve as a lead for treatment and with the growing interest in identity-related motivational treatments for chronic pain patients (Van Damme, et al., 2008), there is a need for more insight into patients' identity-related goals. A first attempt to explore the content of self-guides in chronic pain patients revealed that the feared self embodies pain and physical health-related attributes. Yet, these findings rely on merely providing examples of attributes patients feared (Morley \& Eccleston, 2004). Therefore, a systematic investigation is needed to draw firm conclusions on the content of selfguides in chronic pain patients.

The first aim of the present study was to provide a content analysis of selves in patients with chronic low back pain. The ideal, ought, and feared self-guides were examined by means of a categorization structure for 30 goal-domains provided by Chulef, Read and Walsh (200I). In the current study, this categorization was used to identify which of the 30 categories were most frequent and how this differs between self-guides. Based on the findings of Morley and Eccleston (2004), the self-guides were hypothesized to contain pain or health-related selves. Second, we explored whether the content of the selves was related to the level of disability. We hypothesized that higher levels of disability would be related to a higher number of pain and health-related selves. Furthermore, the role of depression was explored, as in previous studies the magnitude of self-discrepancies in pain patients has shown to be associated with depression (e.g., Waters, et al., 2004).

\section{METHOD}

\section{I PARTICIPANTS}

The present study was part of an ongoing longitudinal cohort study from which baseline data were used. Participants were 80 patients 39 women

\footnotetext{
${ }^{1}$ Morley et al. (2005) and Morley and Sutherland (2008) used the hoped-for self but this has been shown to be saturated with attributes of the ideal self.
} 
and 4I men) with non-specific chronic low back pain who were recruited from departments of rehabilitation medicine in hospitals and a rehabilitation center in the South of The Netherlands and through advertisements placed in local newspapers. There were no significant differences on socio-demographics or disability or depression scores between participants from different locations, except for age differences, which were controlled for in the analyses. Ages ranged from 22 to 65 years with a mean of 47.8 years. Mean average pain duration was Ir.2 years (range 5 months to 44 years). Approximately half of all participants were still employed for more then $30 \mathrm{~h}$ per week $(33.8 \%)$ or less then $30 \mathrm{~h}$ per week (17.6\%). 21.6\% were recipients of disablement insurance benefits. All others were unemployed. With regard to education level, most of the participants completed lower secondary professional education $(58.9 \%)$, $30.1 \%$ higher general secondary education (30.I\%), and a minority achieved vocational training or higher education (II\%).

\subsection{MEASURES}

\subsection{Self-guides}

Hardin's Selves Questionnaire (HSQ; Hardin \& Leong, 2005) was used to identify significant attributes in three domains of the self: the ideal self, the ought self, and the undesired self. Consistent with Carver and colleagues (1999), the undesired self was reformulated in terms of the feared self. Based on earlier experiences, the HSQ was administered in the form of a semi-structured interview to facilitate better understanding of the questions. Patients were asked to generate Io attributes for the ideal self-guide ("Which attributes would you ideally like to possess?"), the ought self-guide ("Which attributes do you think you should possess?") and the feared self-guide ("Which attributes do you fear to possess?"). Of these Io attributes, five attributes were generated from their own perspective and five from the perspective of a significant other (e.g. spouse). This resulted in a total of thirty attributes per patient. Patients were first encouraged to come up with attributes themselves but if they experienced difficulties they were provided with a list of attributes (e.g. helpful, lazy) to complete the questionnaire. This combination of idiographic and nomothetic questionnaire methods ensures salience of attributes and feasibility of completing the questionnaire. The HSQ has found to be a reliable and valid instrument of assessing self-discrepancies (Hardin \& Leong, 2005).

\subsubsection{Disability}

Disability was measured with the Roland Disability Questionnaire (RDQ; Roland \& Morris, 1983). The RDQ is a self-report questionnaire consisting of 24 items reflecting the level of impairment in the 
performance of daily activities, that are given a score of I (my low back pain interferes with this activity) or $O$ (no interference). Total scores range from $O$ (not disabled) to 24 (seriously disabled). The reliability and validity of the Dutch version of the RDQ have been supported (Brouwer, et al., 2004).

\subsubsection{Depression}

Depression was measured by the Beck Depression Inventory II (BDI-II; Beck, Steer, \& Brown, 1996). The BDI-II is a self-report questionnaire which measures depressive symptoms in $2 \mathrm{I}$ items. For each item, several possible responses are listed with scores ranging from o to 3 . Total scores are obtained by adding the responses on the 2I items, leaving a range from $\mathrm{O}$ to 63 , in which higher scores reflect more depressive symptomatology. The BDI-II has good validity and reliability scores (Beck, et al., 1996).

\subsubsection{Pain intensity}

Pain intensity was measured with three Ioo mm Visual Analogue Scales (VAS; Price, McGrath, Rafii, \& Buckingham, 1983). Patients were asked to rate their actual pain (at that moment) and their worst and best pain level of the past week on three separate VAS-scales. A general pain intensity composite score was calculated by calculating the mean of the aforementioned three VAS-scales. This composite score was used in further analyses.

\subsection{Procedure}

Patients were either referred to the study by their consultant in rehabilitation medicine or contacted the researchers themselves as a result of the advertisement about the study in local newspapers. Patients who responded to the advertisement were screened by a consultant in rehabilitation medicine before participating in the study. After the informed consent procedure, patients were given the choice to have the HSQ-interview at the university or by telephone. Subsequently, patients could either complete the questionnaires on paper or on-line through the internet. All patients $(N=80)$ completed the interview but seven did not fill in the questionnaires. The study protocol was approved by the Medical Ethical Committee of the Maastricht University Medical Center (The Netherlands). 


\subsection{DATA ANALYSIS}

\subsection{Content analysis of the HSQ}

Responses to the HSQ were categorized as follows using the 30 categories reported by Chulef, Read and Walsh (2OOI) in their study of general human goals (see Table I; Chulef, et al., 200I). Two independent raters with a clinical psychology background, blind to the objectives of the study, were provided with a list of all unique attributes elicited by the participants when filling in the HSQ. The attributes were put in alphabetical order. The raters were also given a list of the 30 categories of general goals from Chulef et al. (200I). Each category was accompanied by a definition and by the sub-categories going together with that specific category (see Table $\mathrm{I}$ ). The two raters were requested to provide each single attribute with a code ranging from $\mathrm{I}$ to 30 , reflecting one of the 30 categories from Chulef et al. (20OI). For the feared attributes, having a negative valence, the raters evaluated the attribute based on its reverse. For example, the feared self 'unhealthy' is the reverse of 'healthy', and belongs to the category 'Physical Health'.

\subsubsection{Statistical analysis}

Data were analyzed using the Statistical Package for Social Sciences (SPSS I3.O). After completion of the categorization of the content of the self-guides, the number of times a patient generated an attribute of that specific category within a specific self-guide was calculated. This was done for each self-guide from both perspectives separately (ought own ought other, ideal own - ideal other, feared own - feared other).

Prior to analysis, we checked whether the measurement scores were normally distributed. For some variables, skewness and kurtosis deviated from the acceptable range of $-\mathrm{I}$ to $+\mathrm{I}$. For these variables non-parametric analyses were performed. To investigate differences in the frequency of content categories across self-guides, Friedman tests and post hoc Wilcoxon signed rank tests were conducted. Furthermore, the relationships between the content categories and disability and depression were determined by partial Pearson correlations or nonparametric partial Kendall's tau correlations, dependent on the distribution of the variables tested. Gender, age, pain duration, and pain intensity were partialled out in these analyses. To prevent type I errors due to multiple testing, a Bonferroni correction was applied to Friedman tests and Wilxocon signed rank tests, resulting in an alpha of .oo8 for Friedman tests and.004 for Wilcoxon signed rank tests. For the partial correlations coefficients, alpha was set to .OI. 


\section{Results}

\section{I GENERAL DESCRIPTIVE INFORMATION}

Before addressing the main results, descriptive information from the questionnaires is presented. Mean pain intensity as assessed on a $100 \mathrm{~mm}$ visual analogue scale was 50.5 $(\mathrm{SD}=17.3)$. The mean disability score $(\mathrm{RDQ})$ was II.7 $(\mathrm{SD}=4.7)$ and the mean depression score (BDI-II) was I3.7 $(\mathrm{SD}=\mathrm{II} .2)$.

\subsection{CATEGORIZATION OF THE CONTENT OF THE SELF-GUIDES}

In total, patients listed 905 unique attributes in the HSQ for the ideal, ought, and feared selves from both perspectives. Two independent raters categorized these attributes into 30 categories of general human goals. The initial inter-rater reliability was low (Cohen's Kappa $=.38, p<$. .ooI), which was not surprising given the large number of attributes and categories. In deciding how to deal with this finding, an expert meeting involving all authors of this paper was organized, during which it was decided to merge categories based on the number of attributes the raters systematically disagreed on. Categories with similar content but rated differently and categories that were seldomly selected by both raters were lumped together. Additionally, the cluster solution as presented by Chulef and colleagues (200I) was taken as a general lead. A third independent rater resolved disagreements by assigning the attribute to one of the two categories the initial raters disagreed on. This process resulted in a reduction of the 30 categories to 8 categories with a satisfactory Cohen's Kappa of $.62(p<.00 \mathrm{I})$ and an overall simple agreement coefficient of $72.4 \%\left(905^{-25} / 905\right)$. Table I presents the 8 categories as well as some examples for the ideal, ought and feared self within each of these categories. 
Table r. The original categories organized according the new categories with examples of attributes of the ideal, ought, and feared self

\begin{tabular}{|c|c|c|c|c|}
\hline & & & Self Aspects & \\
\hline New Category & Original categories & Ideal self & Ought self & Feared self \\
\hline $\begin{array}{l}\text { Interpersonal } \\
\text { attributes }\end{array}$ & $\begin{array}{l}\text { 'Belonging, social } \\
\text { recognition and } \\
\text { approval' 'Friendship' } \\
\text { 'Receiving from } \\
\text { others' 'Defence } \\
\text { versus rejection' } \\
\text { 'Positive social } \\
\text { qualities' 'Teaching } \\
\text { and helping, others' } \\
\text { 'Leadership' 'Social } \\
\text { awareness' 'Ethics } \\
\text { and idealism' } \\
\text { 'Flexibility, openness } \\
\text { and excitement' }\end{array}$ & $\begin{array}{l}\text { 'Honest' } \\
\text { 'Patient' }\end{array}$ & $\begin{array}{l}\text { 'Friendly' } \\
\text { 'Helpful' }\end{array}$ & $\begin{array}{l}\text { 'Greedy' } \\
\text { 'Selfish' }\end{array}$ \\
\hline $\begin{array}{l}\text { Personal } \\
\text { abilities }\end{array}$ & $\begin{array}{l}\text { 'Order' 'Achievement' } \\
\text { 'Self-sufficiency and } \\
\text { determination' }\end{array}$ & $\begin{array}{l}\text { 'Ambitious' } \\
\text { 'Go-getter' }\end{array}$ & $\begin{array}{l}\text { 'Hard } \\
\text { working' } \\
\text { 'Independent' }\end{array}$ & $\begin{array}{l}\text { 'Lazy' } \\
\text { 'Slovenly' }\end{array}$ \\
\hline $\begin{array}{l}\text { Physical, } \\
\text { emotional and } \\
\text { psychological } \\
\text { well-being }\end{array}$ & $\begin{array}{l}\text { 'Physical health' } \\
\text { 'Amusement' } \\
\text { 'Psychological well- } \\
\text { being' 'Stability and } \\
\text { safety' 'Higher } \\
\text { meaning' 'Personal } \\
\text { growth' }\end{array}$ & $\begin{array}{l}\text { 'Healthy' } \\
\text { 'Without } \\
\text { pain' }\end{array}$ & $\begin{array}{l}\text { 'Accepting of } \\
\text { complaints' } \\
\text { 'Energetic' }\end{array}$ & $\begin{array}{l}\text { 'Less active' } \\
\text { 'Unhealthy' }\end{array}$ \\
\hline $\begin{array}{l}\text { Close } \\
\text { interpersonal } \\
\text { relationships }\end{array}$ & $\begin{array}{l}\text { 'Sex and romance', } \\
\text { 'Marriage' 'Family' }\end{array}$ & $\begin{array}{l}\text { 'Loyal } \\
\text { husband' } \\
\text { 'Good } \\
\text { housewive' }\end{array}$ & $\begin{array}{l}\text { 'Good father' } \\
\text { 'Being there } \\
\text { for the family' }\end{array}$ & $\begin{array}{l}\text { 'Unfaithful' } \\
\text { 'Strict with } \\
\text { children' }\end{array}$ \\
\hline $\begin{array}{l}\text { Self-expression } \\
\text { abilities }\end{array}$ & $\begin{array}{l}\text { 'Freedom' } \\
\text { 'Aesthetics' } \\
\text { 'Creativity' }\end{array}$ & $\begin{array}{l}\text { 'Artistic' } \\
\text { 'Free' }\end{array}$ & $\begin{array}{l}\text { 'Inventive' } \\
\text { 'Creative' }\end{array}$ & $\begin{array}{l}\text { 'No longer } \\
\text { able to take } \\
\text { care of self' }\end{array}$ \\
\hline $\begin{array}{l}\text { Achievement- } \\
\text { related } \\
\text { attributes }\end{array}$ & $\begin{array}{l}\text { 'Career' 'Intellect and } \\
\text { education' 'Finances' }\end{array}$ & $\begin{array}{l}\text { 'Intelligent' } \\
\text { 'Inquisitive' }\end{array}$ & $\begin{array}{l}\text { 'Analytical', } \\
\text { 'Employed' }\end{array}$ & $\begin{array}{l}\text { 'Materialistic' } \\
\text { 'Too } \\
\text { generous' }\end{array}$ \\
\hline $\begin{array}{l}\text { Physical } \\
\text { appearance }\end{array}$ & 'Physical appearance' & $\begin{array}{l}\text { 'Attractive' } \\
\text { 'Slim’ }\end{array}$ & $\begin{array}{l}\text { 'Decent' } \\
\text { 'Well-cared- } \\
\text { for' }\end{array}$ & $\begin{array}{l}\text { 'Uncared-for } \\
\text { look' }\end{array}$ \\
\hline Religion & 'Religion' & 'Religious' & 'Religious' & 'Unchristian' \\
\hline
\end{tabular}

\subsection{THE CONTENT OF THE IDEAL, OUGHT AND FEARED SELVES}

Figure I displays frequency data of the categories for each self-guide. In the absence of any significant differences in content between own and other perspectives, the frequencies of the own and the other perspective were summed for each self-guide. Consequently, the bars in the figure represent the frequencies of the self-guides regardless of the perspective.

The majority of the attributes that patients generated appear to relate to their interpersonal life, physical, emotional and psychological well-being 
and to personal abilities. The pattern of results was largely comparable across the three self-guides. Compared to attributes relating to the broad interpersonal domain, patients mentioned fewer attributes related to the close interpersonal domain (within the family or romantic relationships). The number of times that self-expression abilities (e.g. creative) or religion-related attributes, were mentioned is negligible. For this reason, these categories were not subjected to further analyses.

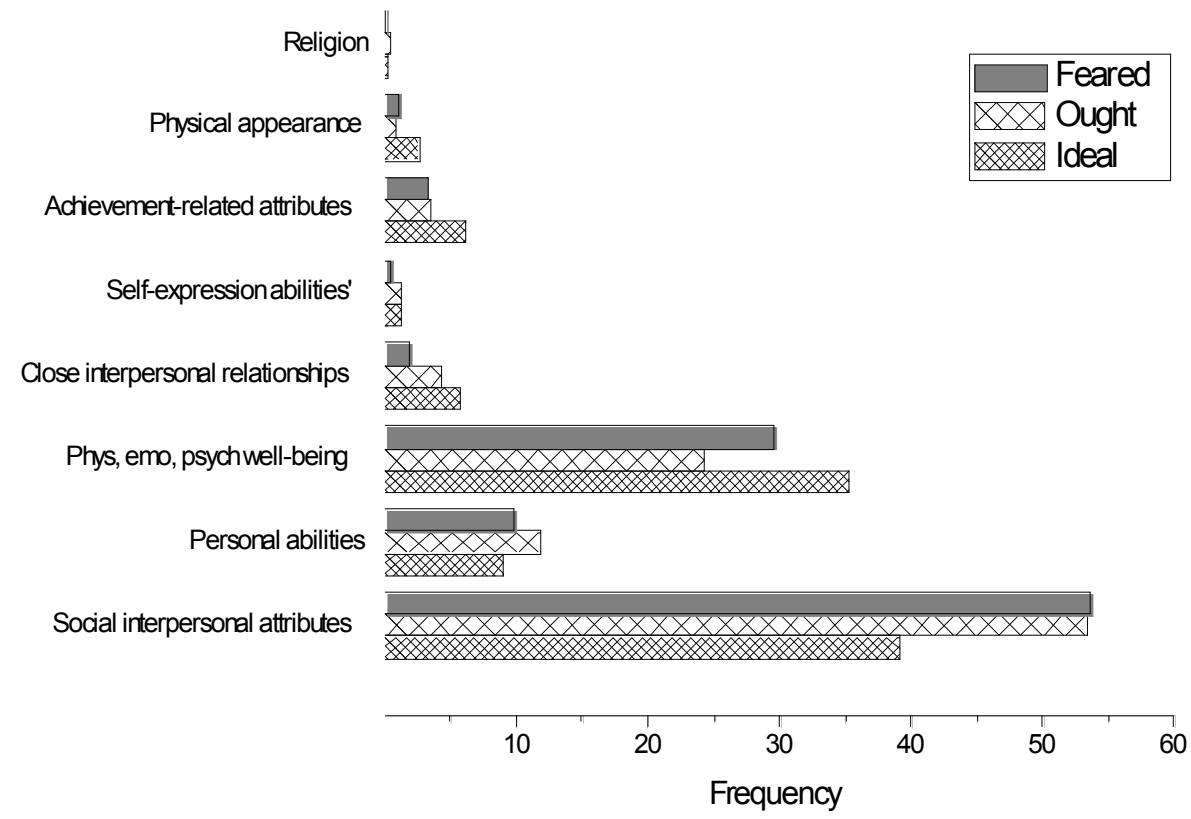

Figure r. Frequencies of categories in the ideal, ought and feared self-guides.

While a same trend in the prevalence of content categories can be observed for the ideal, ought, and feared self, there are differences in content between the self-guides. Friedman tests showed differences between the ideal, ought, and feared self for the following categories 'Interpersonal attributes' $\left(\chi^{2}(2)=23.39, p<.00 \mathrm{I}\right)$, 'Physical, emotional and mental well-being' $\left(\chi^{2}(2)=\right.$ I0.16, $\left.p<.008\right)$, 'Close interpersonal relationships' $\left(\chi^{2}(2)=\mathrm{I} 2.67, p=.00 \mathrm{I}\right)$ and 'Physical appearance' $\left(\chi^{2}(2)=\mathrm{II} .5 \mathrm{I}\right.$, $p<.008$ ). Post hoc Wilcoxon signed rank tests were used to identify these differences. Analyses showed that the ought self was characterized by more 'Interpersonal attributes' (as compared to the ideal self; $\mathrm{z}=4.64$, $p<.00 \mathrm{I}$ and the feared self; $\mathrm{z}=4 . \mathrm{I} 4, p<. \mathrm{OOI})$. Accordingly, an interpersonal attribute such as 'being helpful' is something patients often impose on themselves or feel imposed upon them by others (also see Table I). On the other hand, patient's ideal self was characterized by more attributes related to 'Physical, emotional and mental well-being' as 
compared to the ought self, ( $z=4.0 \mathrm{I}, p<$. .ooI $)$. For example, 'being healthy' is something patients would ideally like to be but do not necessarily (or to a lesser degree) feel compelled to be. Attributes related to 'Close interpersonal relationships' were mentioned more times in the feared self in contrast to the ideal self, $(z=3.23, p=.00 \mathrm{I})$. As an illustration; being a bad parent is something patients fear more as compared to ideally wanting to be a good parent.

\subsection{THE RELATION BETWEEN DISABILITY AND DEPRESSION, AND THE CONTENT OF THE SELF-GUIDES}

We hypothesized that disability and depressive symptoms would be associated with the content of the self-guides in the sense that patients with higher levels of disability and/or depression would yield more physical-related attributes. As a consequence of the merging of the categories this hypothesis could not be tested solely for physical-related attributes but was tested in the larger context of 'Physical, emotional and psychological well-being'. Table 2 presents the results of the partial correlational analyses between the content categories and, disability and depression, controlling for gender, age, pain duration, and pain intensity. First, we aggregated the number of times a particular category was mentioned per self-guide. In other words, the scores reflect the number of times a patient mentioned a particular category regardless of the selfguide. Both categories 'physical, emotional and psychological well-being' and 'physical appearance' seemed to be related to disability but only at $p<$ 0.05 . As we expected that the more disabled patients are, the more they generate attributes related to physical, emotional or psychological wellbeing as part of their ideal, ought or feared self, we further explored this relationship per self-guide. Partial correlations were performed between disability and the number of times this category was mentioned for each self-guide, controlling for gender, age, pain duration, and pain intensity. Disability was related exclusively to the number of times patients felt they ought to possess attributes concerning their well-being $(\tau=.23 ; p=$ $.002)$ but not to the number of times they ideally would like to $(r=. \mathrm{I} 6 ; p=$ $.23)$ or fear to possess $(r=.14 ; p=.28)$ these attributes.

With regard to the relationship between the content of the self-guides and depression, no significant relations were found. The number of attributes patients listed within certain domains was not related to their level of depression. 
Table 2. Partial correlations between the content categories and disability and depression controlling for gender, age, pain duration, and pain intensity

\begin{tabular}{|c|c|c|}
\hline & Disability & Depression \\
\hline Interpersonal Attributes $^{\alpha}$ & -.06 &. $\mathrm{OI}$ \\
\hline Personal Abilities $^{\mathrm{a}}$ & $-.0 \mathrm{I}$ & -.17 \\
\hline Physical, Emotional, and & $.28^{\mathrm{c}}$ & .22 \\
\hline Close Interpersonal &.$- \mathrm{OI}$ & -.05 \\
\hline Achievement-Related &.$- I I$ & .03 \\
\hline Physical appearance $^{\mathrm{v}}$ & $-.17^{\mathrm{c}}$ & -.12 \\
\hline
\end{tabular}

\section{Discussion}

The present study sought to shed light on the content of the ideal, ought, and feared self-guides of patients with chronic low back pain and the relationships between the content and disability and depression. The results can be summarized as follows. First, the attributes pain patients generate could be categorized using eight high level categories. Second, the hypothesized pain and health-related attributes were indeed present, and were incorporated in the broader category 'Psychological, emotional and physical well-being'. These attributes were most often mentioned within the ideal self-guide. Social and interpersonal attributes were also incorporated within the ought self-guide. Finally, patients who reported higher levels of disability also mentioned more well-being related attributes as part of their ought self-guide. Unexpectedly, depression was not related to the content of the self-guides.

The ideal, ought, and feared attributes that patients listed from both perspectives, could all be categorized into eight categories. Initially, the thirty categories structure from Chulef, Read and Walsh (200I) was used but this resulted in a low agreement between raters due to the large number of categories in combination with the large number of attributes. A process of merging the thirty categories resulted in the final eight categories. Despite the need for a replication in another sample of patients, the eight categories did provide informational value and was used to answer the research questions.

For patients with chronic pain, not only the loss of physical well-being is a burden but also the (threat of) loss of their social roles (Harris, et al., 2003; Morley \& Eccleston, 2004; Ranjan, 2004). The results from the present study indicate that most attributes can be categorized as 'Interpersonal attributes', which illustrates the importance of the societal role to patients with chronic pain. That is, the person they want to, feel compelled to, or fear to be in their social environment, in relation to 
others. In addition, attributes related to 'Psychological, emotional, and physical well-being' represented the second largest category of all attributes. A tentative conclusion that might be drawn from these findings, is that for patients with chronic low back pain, the challenges they face involving their social role functioning are at least as important for their sense of self as their health condition. In addition, results from the comparisons between the content of self-guides provide insight into the role of different connotations with respect to self-goals. The fact that there were indeed differences in content between the self-guides already suggest that it is worthwhile studying all three types of self-guides. With respect to the results, we might conclude that the focus of the ideal self is in the intrapersonal domain, while the ought and feared self seem more focused at the interpersonal domain. These findings may be of interest in light of the emotional and self-regulatory consequences of discrepancies between the actual self and specific self-guides. As mentioned before, the content of the self-guides might be related to the demonstrated behaviour (Ferrier \& Brewin, 2005).

Based on research on Self-Discrepancy Theory (Higgins, I999a), discrepancies between the actual and the ideal self are causally related to different negative emotions (i.e. dejection/depression) and self-regulatory behaviour, in contrast to discrepancies between the actual and the ought self (i.e. agitation/anxiety). Research on the consequences of actual-feared congruencies, being close to your feared self, is limited but seems to interact with the ought self in causing agitation (Carver et al., 1999). Previous studies confirmed that (the magnitude of) self-discrepancies in chronic pain patients relate to mood disorders such as depression (Morley, et al., 2005). In addition, the present study showed that the content of the self-discrepancies does not relate to depression. This finding underpins the Self-discrepancy Theory, stating that the mood disorders are a consequence of the perceived distance between the actual self and the self-guides. From this point of view, it is not surprising that the content in itself was not related to depression. Yet, to regulate their negative moods, patients have to find a way to bring their actual self closer to their self-guides (or further away in case of the feared self) or should adapt their self-guides to more realistic standards.

Furthermore, the content was not related to patients' emotional status but, in line with the hypothesis, it was related to their functional status. Apparently, patients with higher levels of disability generated more wellbeing related attributes in their ought self. In other words, they felt they ought to be for example healthy. It would be interesting to unravel the nature of this relationship. It might be that highly disabled patients mention a higher number of well-being attributes because of the greater discrepancy but it might also be that patients, who compare themselves to more well-being self-guides, feel more disabled. 
How do self-guides relate to pain problems? So far, it is not clear how these self-discrepancies might operate in patients with chronic pain and how they possibly influence pain-related behaviours. Sutherland and Morley (2008) also pointed out the importance of future studies to not only focus on self-guides and attributes but to also focus on the selfregulatory behaviours. From a clinical perspective, self system therapy is an example of an intervention which is focused on identifying patients' goals and discrepancies and creating a plan for what patients can do to attain these goals (Strauman, Vieth, Merrill, Kolden, et al., 2006; Vieth, et al., 2003). In this context, however, knowledge of the content of the self-guides might be useful.

The findings of the present study might also be related to the context of the research setting. That is, as patients underwent the self-discrepancies interview in the context of being engaged in a chronic pain research, the setting could have played a role in that patients might have felt they needed to mention attributes related to their pain. Also, the research setting might also have directed their attention to their pain, making pain-related constructs more accessible. With regard to the methods used in the present study, some limitations have to be taken into account. Although a reduction of categories yielded eight categories that seem to cover meaningful categories in which attributes can be categorized, the original "Physical health" category was merged in a more general cluster of well-being related attributes. Therefore, the selves could no longer be compared on the single "Physical health" category. Possibly, stronger relationships with the level of disability would have been found if this category involved only the physical health status because of the focus on physical well-being instead of general well-being. Related to this, it remains to be determined whether the reduction of categories can be replicated in another population. This research is warranted to further guarantee the reliability and validity of the HSQ categories. Furthermore, the nature of the relation between disability and the content of the selves cannot be termed in causal directions because of a cross-sectional design. Because of these limitations and the fact that the correlation coefficients in the present study were relatively low, cross-validation of the findings is warranted.

In spite of these limitations, this is the first study to look at the content of self-guides in chronic low back pain patients and has shown that the content is related to disability and more specifically to the number of well-being related attributes patients generate. Furthermore, the results draw attention to the fact that next to patient's health status, their interpersonal roles are of great importance and should not be neglected in research or treatment. 


\section{ACKNOWLEdgements}

The contribution of Hanne Kindermans, Marielle Goossens, Ivan Huijnen and Jeanine Verbunt was supported by ZonMW, Program Rehabilitation Research, Grant No. 60-60500-98015. Participation of Dr. J. Roelofs was supported by the EFIC Grünenthal Grant (EGG). The contribution of Johan W.S. Vlaeyen was supported by the NWO Social Sciences Research Council of The Netherlands, Innovational Grant No. $453^{-} \mathrm{O} 4^{-003}$. 



\section{|| Chapter 3 ||}

\section{Self-discrepancies in Work-Related Upper Extremity Pain: Relation to emotions and flexible-goal adjustment}

This chapter is published as: Goossens, M.E., Kindermans, H.P., Morley, S.J., Roelofs, J., Verbunt, J., Vlaeyen, J.W. (20IO). Self-discrepancies in work-related upper extremity pain: Relation to emotions and flexible-goal adjustment. European Journal of Pain, 14, 764-770. 


\section{Abstract}

Recurrent pain not only has an impact on disability, but on the long term it may become a threat to one's sense of self. This paper presents a crosssectional study of patients with work-related upper extremity pain and focuses on I) the role of self-discrepancies in this group, 2) the associations between self-discrepancies, pain, emotions and 3 ) the interaction between self-discrepancies and flexible goal adjustment. Eighty-nine participants completed standardized self-report measures of pain intensity, pain duration, anxiety, depression and flexible-goal adjustment. A Selves questionnaire was used to generate selfdiscrepancies. A series of hierarchical regression analyses showed relationships between actual-ought other, actual-ought self, actual-feared self discrepancies and depression as well as a significant association between actual-ought other self discrepancy and anxiety. Furthermore, significant interactions were found between actual-ought other selfdiscrepancies and flexibility, indicating that less flexible participants with large self-discrepancies score higher on depression.

This study showed that self-discrepancies are related to negative emotions and that flexible-goal adjustment served as a moderator in this relationship. The view of self in pain and flexible-goal adjustment should be considered as important variables in the process of chronic pain.

\section{INTRODUCTION}

Chronic pain often is associated with diminished functional abilities (Ostelo, et al., 2005; Vlaeyen \& Morley, 2005) and a disparity between a persons' views of self (Chapman \& Gavrin, I999; Harris, et al., 2003; Morley \& Eccleston, 2004). The chronic pain patient is faced with a need to re-examine his/her sense of self and matching goals and beliefs (Brandtstädter \& Renner, I990). Although several studies mention the loss of self in pain (Johansson, et al., 1999; Lundberg, et al., 2007; Morley \& Eccleston, 2004; Smith \& Osborne, 2007), there are few studies that examine the self in relation to chronic pain. Self-Discrepancy Theory (SDT) provides a useful theoretical framework for considering the emotional influences of pain experience on the self (Higgins, I987; Higgins, 1999b). Discrepancies between who one believes oneself to be and who one would like to be (ideal self) or ought to be (ought self), are assumed to elicit emotions of agitation (anxiety) and dejection (depression) respectively. Another important self, the feared self (who one fears one might become) has been proposed by Carver and Scheier (1990). A key aspect of SDT is that people are motivated to reduce the discrepancies between the self states, using strategies which best go together with their dominant self-discrepancy (actual-ought, actual-ideal, 
actual-feared). In chronic pain, this could imply that patients with different dominant self-discrepancies may experience different emotions and hence behave differently. To date, the role of self-discrepancies has only begun to be explored. For example, Waters and colleagues were the first to find evidence for the predicted relationships between depression and actual-ideal self discrepancies and between psychological distress and actual-ideal as well as actual-ought self discrepancies in chronic pain patients (Waters, et al., 2004).

This aim of the present study was to examine the role of selfdiscrepancies in patients with work-related upper extremity pain disorder (WRUED). WRUED-patients are often described as perfectionists and overcommitted workers (Heuvel van den, Beek van der, Blatter, \& Bongers, 2007), we hypothesised that mainly ought self-discrepancies are present and related to negative emotions. In addition to testing the basic predictions of SDT we were also interested in the possible impact of variation in flexible-goal adjustment on emotional adjustment. In a study of assimilative (e.g. self-corrective actions to maintain goals) and accommodative coping (e.g. re-evaluation of personal goals), Schmitz et al. (1996) found that the ability to flexibly adjust personal goals attenuated the negative impact of the pain experience on psychological well-being. We tested the hypothesis that the relationship between pain experience, emotional adjustment and self-discrepancies is moderated by individual differences in how individuals adjust to the pursuit of goals in the face of obstacles. Individuals with flexible-goal adjustment are expected to experience comparatively less discrepancy between their actual and ought selves, and have less depressive emotions; to experience greater discrepancy between actual and feared selves, and to be less depressed and anxious.

More knowledge about the way chronic pain may influence the self as a result of the above mentioned discrepancies, might improve both the assessment and treatment of the large number of individuals seeking help for their chronic pain complaints.

\section{METHODS}

\section{I PARTICIPANTS}

Participants were recruited from one rehabilitation ward in an academic hospital and one health and safety executive in the Southern Part of the Netherlands. Participants were referred to these authorities because their work was interfered because of their pain. Inclusion criteria were: aged between I8-65 years, labeled as having pain in the upper extremities (arm, 
neck, shoulder), able to read and write in Dutch. Participants were excluded when another specific medical disorder was diagnosed which required medical treatment. Participants with other a-specific pain problems at other locations were included.

\subsection{DESIGN}

This study was a cross-sectional study with a single group. The sample size was based on (Morley, et al., 2005), and determined using an algoritm suggested by Tabacknick and Fidell (Tabachnick \& Fidell, 20OI) for a power of $80 \%$ with $\alpha=0.05$ and a medium effect size. In this study, 89 subjects are needed to find an $\mathrm{R}^{2}$ of o.I2.

\subsection{MEASURES}

In addition to the basic demographic (age, gender, education) and medical descriptive data (pain duration, use of medication and therapies) the following variables were assessed.

\subsection{Pain intensity}

Visual analogue scales (VAS; Ioomm) were used to measure pain at its highest intensity, pain at its lowest intensity and pain at its usual intensity. Since correlations between these three VAS scores were all significant at a 0.01 level, in further analysis the mean pain VAS scores were entered as a composite score.

\subsubsection{Mood states}

Seven visual analogue scales (VAS; Ioomm) were used to measure the following emotions that had accompanied the pain over the past week; anxiety, sadness, happiness, alertness, frustration, pride, and shame (Morley, et al., 2005).

\subsubsection{Depression}

The Beck Depression Inventory - II (BDI; Beck, Steer, \& Brown, 1996) was used to measure depression. The BDI is a $2 \mathrm{I}$ item self-report measure of depressive symptomatology. Each item has four possible responses, ranging from $\mathrm{o}$ to 3 , with $\mathrm{o}$ indicating absence of the symptom 3 the most intense statement. The conventional cut points for mild, moderate and severe depression are: < IO, minimal depression; IO-I9, mild depression; 20-29, moderate depression; > 30, severe depression. The internal consistency and the construct validity of the BDI are good. 


\subsubsection{Anxiety}

The trait version of the State-Trait Anxiety Inventory (STAI-T; Spielberger, Gorsuch, \& Lushene, 1970) is a self-report measure of trait anxiety and contains 20 items rated on a 4 -point scale, with I indicating no anxiety and 4 very anxious. STAI-T scores range between 20 and 80 . A score of 50 labels a respondent as "anxious". The scale is highly valid and reliable (Spielberger, et al., 1970; Van der Ploeg, Defares, \& Spielberger, 1980).

\subsubsection{Upper extremity Functioning}

The Upper Extremity Function Scale (UEFS) measures how participants perceive symptoms affect their overall function on daily activities. It is an eight item self-report measure in which each item has ten possible responses ( $\mathrm{I}=$ no problem to $\mathrm{IO}=$ cannot do the activity); total scores range from 8 to 80 . The UEFS has high internal consistency $(\alpha=0.83-0.93)$ and is correlated with measures of pain (Pransky, Feurerstein, Himmelstein, Katz, \& Vickers-Lathi, 1997). Although this was not a hypothesis, we expected that less functioning would be associated with larger discrepancies between the actual and ought self and with smaller discrepancies between the actual and feared self (Morley, et al., 2005).

\subsubsection{Self-discrepancies}

Self-discrepancies were assessed with a modified semi-structured interview version of the Hardin's Selves Questionnaire (Hardin \& Leong, 2005). This questionnaire was developed to address the criticism of the original Selves questionnaire of Higgins (Higgins, Klein, \& Straumann, I985), which was thought to be too difficult for patients to complete and may limit the ability to obtain unique self-representations. The questionnaire (Hardin \& Leong, 2005) combines idiographic and nomothetic methods, which allows participants the opportunity to not only generate attributes most salient to themselves, but also provides help to those participants for whom the task of idiographically generating attributes is too difficult.

Discrepancies from two domains of the self were measured; ought (attributes a person feels obligated to possess) and feared (attributes a person does not want to possess). According to SDT actual-ought selfdiscrepancies lead to agitation-related emotions (e.g. guilt, anxiety and fear), whereas actual-feared self-discrepancies give rise to dejectionrelated emotions (e.g. disappointment, frustration, dissatisfaction) as well to agitation-related emotions (Carver, et al., 1999). Consistent with Higgins's original approach (Higgins, Klein, \& Straumann, 1985), participants were first asked to generate a list of five attributes for each domain of the self, from their own perspective and from the perspective of a self-generated significant other, resulting in four self-states (ought- 
own, ought-other, feared-own, feared-other). For example, for the actualought self respondents were instructed to enter five attributes/qualities that they ought to be or that they ought to possess, seen from their own perspectives. Thus for each self-state the participant entered up to five attributes. If fewer than five attributes were generated, participants were shown a list of Ioo attributes from which they could choose additional words. Examples of attributes on the list were aggressive, ambitious, independent, pessimistic, and unhappy. Second, participants were asked to rate the extent to which each of the 20 attributes describing their ought and feared selves applied to them at the current time on a fivepoint rating scale, where $\mathrm{I}=$ does not apply to me at all, to $5=$ completely applies to me. If for example the participant mentioned "independent" as one of the actual-ought(own) self attributes, then the participant was instructed to rate the extent to which being independent describes your actual-ought self at the moment. For the actual-feared self the instructions were: "Please rate the extent to which being (f.e.) unhappy describes your actual-feared self seen from your own perspective at this moment".

By doing so, the participants directly rated the extent to which they perceived a discrepancy between their actual self and the two target selves. So for the actual-ought self-discrepancy a higher score indicates a smaller discrepancy between the actual self and the ought self and a small score means a more detrimental state. For the actual-feared selfdiscrepancy a higher score indicates a more detrimental state, which means that the distance between who you are at the moment and who you fear to become is small. The internal consistency of the ideal, ought and feared self-discrepancy were satisfactory ( $\alpha=0.73^{-}$o.88). Psychometric evidence to support the validity of the SDT was presented by Hardin and Leong (2005); significant correlations were found between de actual-ideal discrepancies and depression, between actual-ought discrepancies and anxiety and between actual-feared discrepancies and both type of emotions.

\subsubsection{Flexible-goal Adjustment (FGA)}

Flexible-goal adjustment was measured with the Brandstädter and Renner Questionnaire (Brandtstädter \& Renner, 1990). The flexible-goal adjustment scale describes the tendency to adjust personal goals and standard to situational limitations. The questionnaire consists of 15 items. Each item has five possible answers (totally agree to not agree at all); total scores range from 0 to 6o. The internal consistency is satisfactory $(\alpha=0.80)$ (Brandtstädter \& Renner, 1990). For FGA negative correlations were reported with depression (Brandtstädter \& Renner, I990) and positive correlations with life satisfaction and optimism 
(Brandtstädter \& Renner, I990) and happiness and self-acceptance (Mueller \& Kim, 2004).

\subsection{PROCEDURE}

Five participants were recruited from the rehabilitation ward and eightyfour participants from the health and safety executive. After informed consent was obtained a series of questionnaires was completed by the participants. The interview took place either at the Maastricht University or at the workplace of the participant. The interview started with the collection of demographic questions. To control for possible sequential effects of emotions on the selves, the participants were randomly divided into two groups; the first group started with the Selves Questionnaire followed by the remaining measures. The second group finished the interview with the Selves Questionnaire.

\subsection{STATISTICAL ANALYSIS}

Data of all 89 subjects were used for the analysis. First the data were checked on their distributions and for possible outliers. For data with a skewness $<2$ the square root was used, when skewness $>2$ a $\log _{\mathrm{I}}$ transformation was used. One-way ANOVAs were performed to identify possible order effects in the administration of the questionnaires. Descriptive statistics of the sample and Pearson correlations were carried out to analyze hypothesized associations. Variables were centred prior to the further analysis. A total of four separate hierarchical multiple regression models were constructed to test the hypothesised role of selfdiscrepancies and their interaction with flexible problem solving on two dependent variables, depression (BDI) and trait anxiety (STAI-T). For each dependent variable two models were constructed: one for the actualought self discrepancies and one for the actual-feared discrepancies. In each model both the 'own' and 'other' perspectives were included simultaneously. After controlling for demographic variables, age and gender (step I) and pain characteristics, duration and intensity (step 2), the relevant self discrepancies were entered in step 3. In step 4, flexibility and the interaction terms between flexibility and the relevant selfdiscrepancies were entered. In the case of a significant interaction further analysis using the protocol outlined by Aiken and West was followed (Aiken \& West, 199I). 


\section{Results}

\section{I. DESCRIPTIVE ANALYSIS AND MOOD STATES}

Eighty-nine respondents with WRUED participated in the study, of which $57 \%$ were men with a mean age of $38(S D=10.74)$ and an average duration of pain since onset of 2 years $(S D=0.67)$. Two-thirds of the respondents were highly educated (higher technical and vocational training and university training), all participants were still active at work. Scores on mood states (VAS) were low, indicating that respondents were not currently anxious $(M=0.96 ; S D=0.45)$, $\operatorname{sad}(M=0.68 ; S D=0.49)$ or ashamed $(M=$ I.II; $S D=0.35)$. They were mildly frustrated $(M=3 \mathrm{I} .05 ; S D$ = 22.92), somewhat more proud $(M=5 \mathrm{I.94} ; S D=\mathrm{I} 8.02)$ and alert $(M=$ 58.56; $S D=\mathrm{I} 8.62)$. In contrast, they rated themselves as not very happy $(M$ $=23.52 ; S D=18.76$ ). Table I shows the means and standard deviations for the measures of negative affect, pain, discrepancies, upper-extremity functioning and flexibility. All participants completed the selfquestionnaire and the other questionnaires. There were no effects for the order in which the tests were administered (all $P>.05)$.

\subsection{PAIN AND DISTRESS}

The mean scores on the highest, lowest and actual pain VAS were respectively $M=54.9(S D=23.45), M=7.92(S D=8.5 \mathrm{I})$ and $M=26.00$ (SD $=20.74)$. The composite score of pain intensity was $M=29.6 \mathrm{I}(S D=\mathrm{I} 4.26)$, which suggests somewhat lower pain levels compared to another sample of non-clinical WRUED patients in the Netherlands $(M=4 \mathrm{I} .5 ; S D=25.4)$ (Roelofs et al., 2007). The mean scores on the BDI was $M=7.90$ ( $S D=$ 5.I2), indicating no depression. Mean score on the STAI-T was $M=40$ $(S D=8.88)$. Pain intensity was positively correlated with the BDI $(P<. \mathrm{OI})$ and with the mood states anxious, sad, ashamed, frustration and happiness. Significant correlations ranged from $r=0.24$ to $r=0.47$ ( $P$ $<.05)$.

\section{3·3. UPPER-EXTREMITY FUNCTIONING AND FLEXIBLE-GOAL ADJUSTMENT}

The mean score for upper-extremity functioning was $M=28.08$, indicating that compared with WRUED patients (Pransky, et al., I997) the participants experienced relatively few problems undertaking the activities represented in the UEFS. A mean score of $M=36.89$ on FGA suggests that participants on average did not assimilate their earlier goals and were less flexible compared to a general population sample (Brandtstädter \& Renner, I990). 


\subsection{SELF DISCREPANCIES}

Mean scores on the self discrepancy measure were: the actual-ought own $(M=3.92, S D=0.53)$, actual-ought other $(M=3.62, S D=0.73)$, actualfeared own $(M=1.04, S D=0.28)$, and actual-feared other $(M=2.3 \mathrm{I}, S D=$ 0.94). Higher scores on the actual-ought (both own and other) discrepancies denote less discrepancy between the two selves, whereas higher scores on the actual-feared discrepancies denote smaller discrepancy between the selves. Hardin and Leong reported self discrepancies of healthy Asian Americans and European Americans of respectively $M=2.4 \mathrm{I}(S D=0.73)$ and $M=2.0 \mathrm{I}(S D=0.59)$ for actualought self-discrepancies and respectively $M=\mathrm{I} .89(S D=0.65)$ and $M=$ I.6I $(S D=0.5 \mathrm{I})$ for actual-feared self. Compared to these healthy subjects the self-discrepancies of our population are moderate to small (Hardin \& Leong, 2005). Thus on average the current sample regarded their actual and ought selves as being moderately proximate to each other. In addition the mean value of the actual-feared own discrepancy was almost one, which indicates that the distance between their actual self and the person they fear to become was almost at the maximum possible. However when the perspective of the other was taken the feared self was nearer to the actual self. In contrast, the feared self seen from the viewpoint of a significant other was moderately distant to the actual self. The correlations between the different self-discrepancies are presented in Table I. Except for actual-ought own and actual-feared other, all of the self-discrepancies were significantly related to each other, with correlations varying between $r=0.22$ and $r=0.59$. The negative correlations between ought and feared selves indicate that the smaller the actual-ought discrepancy, the larger the actual-feared discrepancy.

\subsection{SELF DISCREPANCIES AND ITS RELATION TO PAIN, EMOTIONS AND FLEXIBLE-GOAL ADJUSTMENT}

Pearson correlation coefficients showed a significant association between actual-ought own discrepancies and age $(r=0.32$; the older the participant, the smaller the discrepancy between actual-self and ought own self) and between actual-ought other and pain duration $(r=0.28$; the 


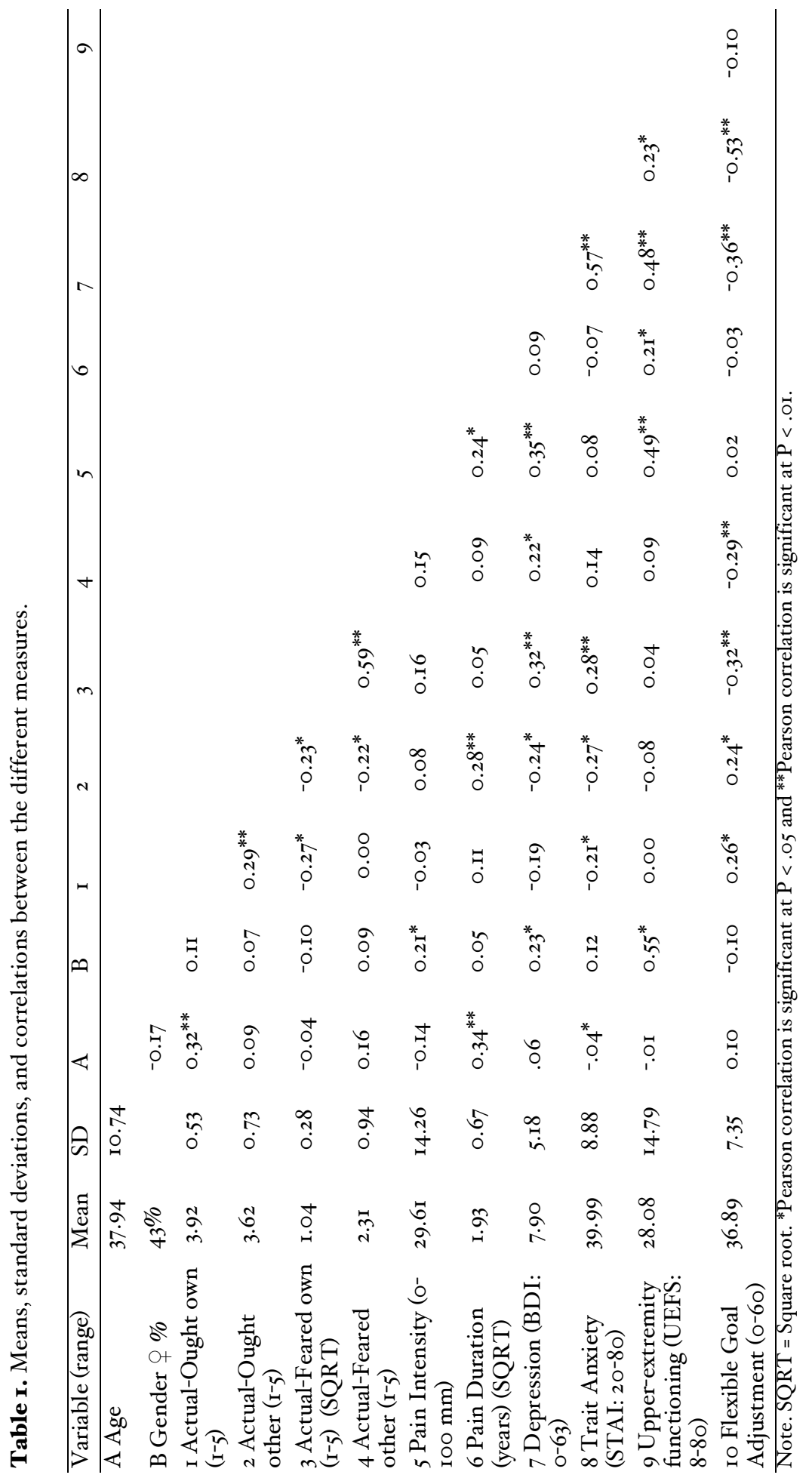


Table 2. Summary of the stepwise multiple regression analyses for depression and selfdiscrepancies, with interaction self-discrepancies $(\mathrm{SeD})$ and flexibility.

\begin{tabular}{|c|c|c|c|c|c|c|}
\hline Model steps & Variables entered & B & $\mathrm{B}$ & SE B & $\mathrm{R}^{2 \mathrm{a}}$ & $\underline{P}$ \\
\hline \multicolumn{7}{|l|}{ Blocks } \\
\hline \multirow[t]{2}{*}{ I. Demographics } & Age & 0.06 & 0.06 & O.II & 0.04 & $n s$ \\
\hline & Gender & 0.21 & $0.4 \mathrm{I}$ & 0.22 & & \\
\hline \multirow[t]{2}{*}{ 2. Pain } & Pain duration & -0.05 & -0.05 & O.I2 & 0.05 & $n s$ \\
\hline & Pain intensity & $0.24^{*}$ & 0.24 & O.II & & \\
\hline \multirow[t]{2}{*}{ 3a.SeD } & Actual-Ought own & -O.I4 & -0.15 & 0.12 & O.II & O.OI \\
\hline & Actual-Ought other & $-0.26^{*}$ & -0.27 & 0.12 & & \\
\hline \multirow[t]{3}{*}{ 4a. SeD * Flexibility } & Actual-Ought own $*$ Flexibility & -0.16 & -0.15 & 0.12 & 0.12 & O.OI \\
\hline & Actual-Ought other $*$ Flexibility & $0.29^{*}$ & 0.30 & 0.13 & & \\
\hline & Flexibility & $-0.32^{*}$ & -0.32 & 0.10 & & \\
\hline \multirow[t]{2}{*}{ 3b.SeD } & Actual-Feared own & $0.33^{*}$ & 0.32 & 0.13 & O.II & 0.05 \\
\hline & Actual-Feared other & $0.03 \mathrm{I}$ & 0.03 & 0.13 & & \\
\hline \multirow[t]{3}{*}{ 4b.SeD $*$ Flexibility } & Actual-Feared own $*$ Flexibility & -0.19 & -0.17 & 0.12 & 0.08 & $n s$ \\
\hline & Actual-Feared Other $*$ Flexibility & 0.07 & 0.080 & 0.14 & & \\
\hline & Flexibility & -0.26 & -0.26 & O.II & & \\
\hline
\end{tabular}

longer the pain, the smaller the discrepancy between actual-self and ought other self). There were no correlations between the other selfdiscrepancies and pain duration and all self-discrepancies and pain intensity, gender and age (see Table r).

In line with the prediction from the Self Discrepancy Theory the first order correlations for the actual-ought self discrepancy and anxiety and for actual-feared self discrepancy and both anxiety and depression were significant. With the current sample size $(n=89)$, a correlation of $r>0.2 \mathrm{I}$ is required for significance at $P<0.05$ : an $r=0.2$ is equivalent to an effect size of $d=0.4 \mathrm{I}$. Overall the relationship between self-discrepancies and measures of emotional adjustment are reflected in a medium effect size. There were significant associations between FGA and all four selfdiscrepancy measures; the more flexible the participants were in adjusting their goals, the smaller the discrepancy between the actual and ought-self (own and other) and the greater the distance between the actual and feared self (own and other). Since there were no significant associations between self-discrepancies and upper-extremity functioning, this variable was not included in the further regression analyses. 
Table 3. Summary of the stepwise multiple regression analyses for anxiety and selfdiscrepancies, with interaction self-discrepancies $(\mathrm{SeD})$ and flexibility.

\begin{tabular}{|c|c|c|c|c|c|c|}
\hline Model steps & Variables entered & $B$ & $\mathrm{~B}$ & SE B & $\mathrm{R}^{2 \mathrm{a}}$ & $\mathrm{P}$ \\
\hline \multicolumn{7}{|l|}{ Blocks } \\
\hline \multirow[t]{2}{*}{ I. Demographics } & Age & -0.02 & -0.02 & O.II & 0.02 & ns \\
\hline & Gender & 0.13 & 0.26 & 0.23 & & \\
\hline \multirow[t]{2}{*}{ 2. Pain } & Pain duration & -0.04 & -0.04 & 0.13 & 0.00 & ns \\
\hline & Pain intensity & 0.07 & 0.07 & 0.12 & & \\
\hline \multirow[t]{2}{*}{ 3a.SeD } & Actual-Ought own & -0.06 & 0.06 & 0.13 & 0.12 & o.or \\
\hline & Actual-Ought other & $-0.33^{* *}$ & -0.34 & 0.13 & & \\
\hline \multirow[t]{3}{*}{ 4a. SeD * Flexibility } & Actual-Ought own $*$ Flexibility & O.OI & O.OI & O.II & 0.25 & 0.00 \\
\hline & Actual-Ought other $*$ Flexibility & O.I4 & O.I4 & 0.12 & & \\
\hline & Flexibility & $-0.53^{* *}$ & -0.53 & O.Io & & \\
\hline \multirow[t]{2}{*}{ 3b.SeD } & Actual-Feared own & $0.29^{*}$ & 0.29 & O.I4 & 0.08 & 0.05 \\
\hline & Actual-Feared other & -0.02 & -0.02 & O.I4 & & \\
\hline \multirow[t]{3}{*}{ 4b.SeD *Flexibility } & Actual-Feared own $*$ Flexibility & -0.09 & -0.08 & O.II & 0.26 & 0.00 \\
\hline & Actual-Feared Other $*$ Flexibility & -0.09 & -O.IO & 0.14 & & \\
\hline & Flexibility & $-0.51^{* *}$ & $-0.5 \mathrm{I}$ & O.II & & \\
\hline
\end{tabular}

Note: ${ }^{2}$ For blocks $2^{-} 4$ the value of the $\mathrm{R}^{2}$ is the incremental $\mathrm{R}^{2}$ value for that block.

\subsection{INTERACTION BETWEEN SELF-DISCREPANCIES, EMOTIONS AND FLEXIBLE-GOAL ADJUSTMENT}

Table 2 shows the results of the stepwise multiple regression analyses for the BDI as the dependent variable and the self-discrepancies as independent variables. In block $I$ and 2 the contribution of the demographics and pain variables were checked. Block 3 specifies the main effect of the self-discrepancies actual-ought own and actual-ought other (model a) and the self-discrepancies actual-feared own and feared other (model b) on depression which showed that actual ought selfdiscrepancies and actual feared self-discrepancies were significantly associated with the BDI score, each explaining iI $\%$ of the variance. This means that participants with larger discrepancies between who they currently are and who they feel obliged to be are more depressed as well as participants with smaller discrepancies between their actual self and the person they fear to become, are more depressed. In this, the contribution of actual ought-other self-discrepancy and the actual fearedown self-discrepancy were significant. In the final block of the regression analyses, the interaction with flexibility was added to the model. For the actual ought other self-discrepancy a statistically significant interaction was found between self-discrepancy and flexible-goal adjustment $(\beta=-$ 
0.29, $S E=0.13, P<0.05$ ); for less flexible respondents, larger ought-other self-discrepancies result in higher scores on the BDI, whereas for high flexible respondents, depression ought other self-discrepancies are not associated with depression. Figure I presents a graphical representation of the interaction between actual-ought self-discrepancies and flexiblegoal adjustment in the prediction of BDI. As can seen, for respondents with low flexible-goal adjustment the relationship between depression and actual ought-other self-discrepancy is negative $(\beta=-0.40, S E=0.14, P$ $=0.014$ ), whereas for respondents who are highly flexible there is a non significant positive association $(\beta=0.16, S E=0.19, P=0.35)$.

Table 3 shows the results for trait anxiety as dependent variable and the self-discrepancy scores as independent scores. In line with the previous analysis, the contribution of the actual-ought other self-discrepancy and the actual-feared own self-discrepancy was significant, explaining respectively ${ }_{12} \%$ and $8 \%$ of the variance. There was no statistical significant interaction between self-discrepancies and flexible-goal adjustment. The significant $\mathrm{R}^{2}$ in step 4 of the models were attributable to the main effects of flexible-goal adjustment $\left(R^{2}=0.067, p<0.05 ; R^{2}=\right.$ $0.235, P<0.0 \mathrm{I})$ for the ought and feared discrepancies respectively.

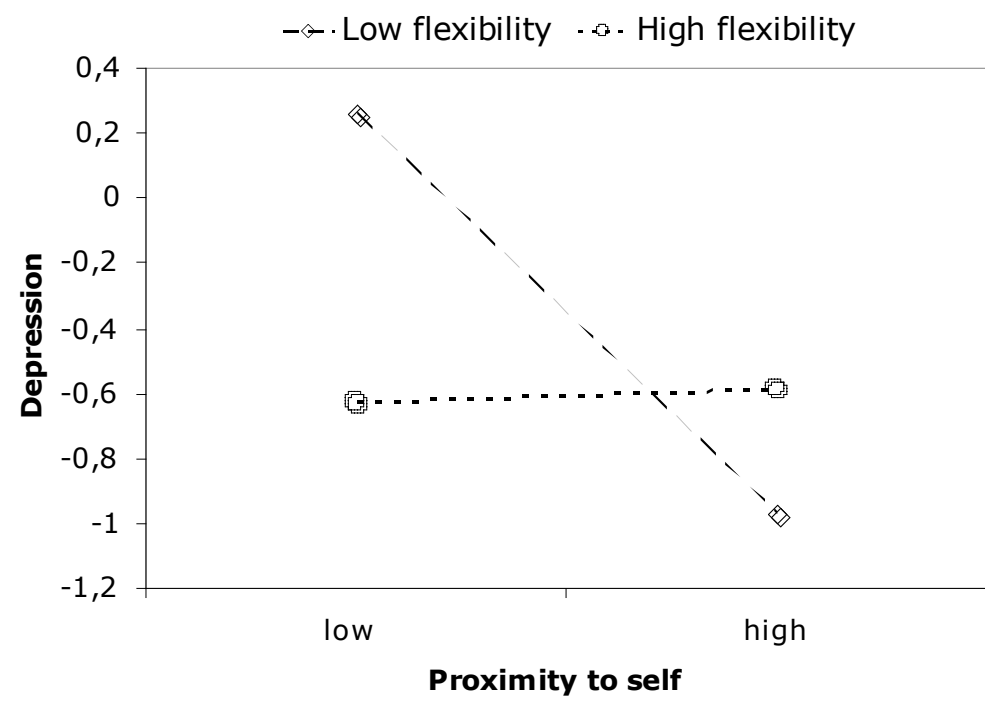

Figure I. Graphical representation of the interaction between proximity to the oughtother self-discrepancy and flexibility in the prediction of depression ( $z$-scores). 


\section{Discussion}

To the best of our knowledge, we believe that this is the first study examining the relationship between self-discrepancies and negative emotions and their explanatory variance in participants with WRUED. The study has several interesting findings. First, as hypothesized selfdiscrepancies were related to negative emotions. Larger ought selfdiscrepancies and smaller feared self-discrepancies were significantly related to more depression and higher anxiety. Second, pain duration, pain intensity and daily functioning, were not related to magnitude of the discrepancies between the actual and the ought self, or to the actual and the feared self-discrepancies. Finally, significant interactions were found between self-discrepancies and flexible-goal adjustment. Compared with the Waters study (Waters, et al., 2004) all self-discrepancies, except for feared-other self discrepancies and ought-own self-discrepancies, were moderately but significantly correlated with each other (correlations ranging from 0.22 and 0.59 ). This indicates that the participants with WRUED are able to distinguish between the four types of selfdiscrepancies, and that each type of self-discrepancies holds a unique aspect of self-discrepancy.

The associations between self-discrepancies and both type of emotions (depression as well as anxiety), are not entirely consistent with the original hypothesis of SDT (Higgins, 1987), but are in line with recent studies (Bruch, et al., 2000; Carver, et al., 1999; Gramzow, 2000), which reported that self-discrepancies not only provoke a distinct type of emotion, but both, agitation-related emotions (e.g. anxiety) as well as dejection-related emotions (e.g.depression). The same was recently observed in a chronic pain population (Waters, et al., 2004). We did not observe the associations between self-discrepancies and pain intensity and pain duration, except for a positive association between pain duration and actual-ought other self-discrepancies; the longer the individual's pain history, the smaller the discrepancy between the actual self and the person one feels obliged to be, seen from the perspective of the significant other. An explanation for this opposite relationship may be found in the acceptance of living with chronic pain, which stands for the willingness to experience the pain without fruitless attempts to control it and to function with the pain (McCracken \& Vowles, 2007; Viane, Crombez, Eccleston, Devulder, \& De Corte, 2004). When a patient finds him/herself in a continuous and usually irreversible situation (such as living with chronic pain), according to the dual-process model of Brandstädter \& Renner, one needs to be flexible enough to change or revalue earlier defined goals or uplift the pain situation (Brandtstädter \& Renner, I990; Brandtstädter \& Rothermund, 2002). Possibly in our sample, the respondent addressed oneself more to a significant other and 
also defined new goals as obliged to fulfill even with the chronic pain. In line with this interpretation, we identified flexible-goal adjustment as a moderator in the relationship between actual-ought other selfdiscrepancies and negative emotions.

Self-discrepancies only gave rise to negative emotions when the participants behaved inflexibly to the consequences of the pain problem only. This implies that in participants with stronger feelings of obligations towards a significant other, certain defensive and tenacious coping mechanisms, such as the urge to control personal goals, overwhelm in the adjustment to the life with pain. The moderating effect did not hold for the actual-feared self-discrepancies, although we observed a relationship between flexible-goal adjustment and actualfeared self-discrepancies. Earlier studies indeed showed that in chronic pain, an inflexible coping style is related to negative emotions (Brandtstädter \& Rothermund, 2002; McCracken \& Vowles, 2007; Schmitz, et al., 1996) and that a flexible, so called accommodative coping style is needed to positively reverse the negative emotions. In this coping style, patients accept that the pain is incurable and personal goals are unattainable unless they disengage from blocked goals and fruitless commitments and reorient themselves towards new and more feasible standards. These results seem to suggest that helping patients approaching their goals in a more flexible way might reduce their selfdiscrepancies and improve their affect and daily functioning. Novel interventions such as Self-System therapy, in which flexibility and its relation to self-discrepant feeling are part of the treatment rationale, are successful in significantly improving psychological well-being (Strauman, Vieth, Merrill, Koldem, et al., 2006). Self-System therapy is designed to improve the patient's ability to self regulate in the service of attaining personal goals.

We hypothesized that less upper extremity functioning would be associated with larger discrepancies between the actual-ought and smaller discrepancies between the actual feared self. Indeed we observed that prolonged experience of pain is related to functioning; however unlike Morley et al (2005), there was a lack of association between daily functioning and self-discrepancies. A possible explanation for this can be found in the measurement instrument which appeared to be unsuitable for this purpose. The UEFS-measure only assessed specific activities of daily living (e.g. to open a can, to open a door, to do the dishes) (Pransky, et al., 1997), whereas the association between disability and selfdiscrepancies is more situated at a higher structure of goals and activities (unable to work, socialize, etc). When a person is unable to open a can, still his higher order goal of being a good parent is within reach. In future studies that examine the relation between self-discrepancies, negative 
emotions and disability, then inclusion of a more appropriate measure of functioning (or disability) is desirable.

Although we made no predictions with respect to the importance of the different perspectives, the results showed that assessing self-discrepancies from different viewpoints is worthwhile in chronic pain. Originally, Higgins' methodology (Higgins, Klein, \& Straumann, 1985) asked patients to generate self-discrepancies from their own perspective and from the perspective of a self-generated significant other. Nevertheless, combining the own and the other perspective in the analysis is consistent with previous self-discrepancy research (Hardin \& Leong, 2005; Higgins, Klein, \& Straumann, 1985). We observed the significant other to be crucial in the discrepancy between the actual and the ought self as well as in the perspective of the actual-feared self discrepancy. Does this mean that the person they are obliged or fear to be is dictated by what they think a significant other demands or thinks? Content analysis of the ought-self in undergraduates revealed that the duties, obligations and responsibilities, resembling the ought self, are indeed mainly based on interpersonal competence and relationships (Bybee, Luthar, Zigler, \& Merisca, 1997). Waters et al (Waters, et al., 2004) who observed this interpersonal perspective in a chronic pain population, argued that in chronic pain the feedback of others (doctors, friends, family, colleagues) is of crucial importance for the view of the self. Maybe this need is fueled by the lack of comprehension and understanding, the feeling of being ignored and belittled, which have often been mentioned in qualitative studies (Lundberg, et al., 2007; Morley \& Eccleston, 2004).

The other viewpoint seemed to be more important in the feared self compared to the own viewpoint, which implies that the person one fears to become is prompted by intrapersonal requirements or fears. But what do chronic pain patients fear? Morley \& Eccleston (2004) inquired chronic pain patients to report about who they feared to become in the future. They discovered five themes of fears, comprising spread of the pain, functional consequences of the pain, possible health needs, financial and social consequences. Although these themes not consequently cluster as intrapersonal, it seems that most themes are oriented towards the own perspective. We did not analyze the content of the selves in this study yet, however, from a clinical point of view paying attention to the content as well as the perspective of the self-discrepancies seems to be worthwhile in future intervention.

The associations reported in this paper were all significant, nevertheless, most correlations were moderate to small $(r=0.2 \mathrm{I}$ to $r=0.59)$. A possible explanation can be found in the population we recruited for this study. We expected this group of participants with WRUED to have larger actual-ought self-discrepancies compared to actual-feared self- 
discrepancies. The ought and feared self-discrepancies observed in this group were respectively moderate to small for actual-ought and large for actual-feared and were even smaller compared to a group of healthy subjects (Hardin \& Leong, 2005). One explanation for these small selfdiscrepancies is that our sample appeared to be less disabled as expected before. The group generally showed marginal scores on depression, agitation-related emotions, and only marginal pain and complaints on upper-extremity functioning. Since this raises questions about the issue of generalizability to all WRUED patients, future studies might include participants with a wider range of functional disability and psychological distress.

To conclude, the results of this study suggest that it might be worthwhile to broaden the perspective of psychological assessment and to incorporate measures of the view of the self. As no causal inferences can be made based on these cross-sectional data, longitudinal studies or studies in which self views are experimentally manipulated, for example using priming techniques are warranted.

\section{ACKNowledgements}

We thank Joop Ruijgrok for referring participants to the study and to the participants for willing to participate. The contribution of Mariëlle Goossens, Hanne Kindermans and Jeanine Verbunt was supported by ZonMW, program Rehabilitation Research, Grant No. 60-60500-98015. Participation of Dr. J. Roelofs was supported by the EFIC Grünenthal Grant (EGG). The contribution of Johan W.S. Vlaeyen was supported by the NWO Social Sciences Research Council of the Netherlands, Grant No. $453^{-} \mathrm{O} 4^{-003}$. The authors are grateful to Leona Blanken for collecting the data. 


\section{|| Chapter 4 ||}

\section{The role of self-discrepancies in the emotional experience and activity patterns of patients with chronic low back pain}

This chapter is published as: Kindermans, H., Huijnen, I., Goossens, M., Roelofs, J., Verbunt, J., Vlaeyen, J. (2OII) "Being" in pain: The role of self-discrepancies in the emotional experience and activity patterns of patients with chronic low back pain. Pain, 152, 403-409. 


\section{Abstract}

Chronic pain not only interferes with daily activities, it may also have a negative impact on the perceived integrity of one's self through selfdiscrepancies. Self-discrepancies are experienced distances between the actual self and self-guides that can exist from 2 perspectives (i.e., own and other). Self-discrepancies are associated with negative mood states and incite self-regulatory behaviour in order to reduce these discrepancies. The present study was aimed at replicating the emotional consequences of self-discrepancies in patients with chronic low back pain, and extending current knowledge of the behavioural consequences of selfdiscrepancies (i.e., behavioural activity patterns such as avoidance and persistence). A cross-sectional design was employed with 83 patients who completed a number of self-report measures. We hypothesized that ideal and ought discrepancies, as well as feared congruencies were associated with depressed and anxious mood. On the behavioural level, a U-shaped relationship was hypothesized between ideal and ought self-discrepancies and persistence behaviour, whereas feared self-discrepancies were hypothesized to be related to avoidance behaviour. Results were partially in line with the hypotheses. With respect to the emotional consequences, feared (own and other) self-discrepancies were predictive of depressive and anxious mood. With regard to activity patterns, results showed a Ushaped relationship between ideal-other self-discrepancies and persistence behaviour and a positive relationship between feared-own self-discrepancies and avoidance behaviour. In contrast to expectations, none of the other self-discrepancies was related to activity patterns. Of interest was that avoidance, but not persistence behaviour, was predictive of higher levels of disability and lower levels of quality of life.

\section{INTRODUCTION}

Pain can interrupt ongoing cognitive and physical tasks, and interferes with daily activities (Eccleston \& Crombez, 1999). This is especially the case when pain is interpreted catastrophically and when pain-related fear has developed (Crombez, Eccleston, Baeyens, \& Eelen, I998; Leeuw, et al., 2007). When pain persists, such as in chronic musculoskeletal pain, the continued interference and associated disability poses a real challenge to patients, which is reflected in low levels of quality of life and negative perception of one's own identity (Lame, Peters, Vlaeyen, Kleef, \& Patijn, 2005; Morley \& Eccleston, 2004). In an attempt to restore daily functioning, patients can alter their performance. This anticipated change in their activity pattern is, however, often unsuccessful and can even be counterproductive. For example, a body of research has shown that pain catastrophizing and pain-related fear might lead to unnecessary 
avoidance of activities and, consequently, to disuse and disability in the long term (Vlaeyen \& Linton, 2000). Besides activity patterns characterized by avoidance, researchers and clinicians have suggested that there is also a group of chronic pain patients with disability complaints who tend to persist in performing activities despite their pain (Hasenbring, Plaas, Fischbein, \& Willburger, 2006; Van Houdenhove \& Neerinckx, 1999; Vlaeyen \& Morley, 2004). So far, there is a lack of empirical evidence explaining why some chronic pain patients persist in activities while others avoid activities.

A possible mechanism explaining both avoidance and persistence behaviour might be derived from the Self-Discrepancy Theory (SDT; Higgins, 1987). SDT explains how self-discrepancies, that is, discrepancies between the actual self (i.e., the person you are now) and the ideal self (i.e., the person you ideally would like to be), the ought self (i.e., the person you feel you ought to be), or the feared self (ie, the person you fear to be) lead to negative emotions and distress (Carver, et al., 1999; Higgins, 1987). Studies in chronic pain populations have shown that selfdiscrepancies are associated with higher levels of depression, anxiety, distress, and pain (Goossens, et al., 2010; Waters, et al., 2004). Besides emotional consequences, self-discrepancies are also thought to be associated with behavioural consequences. That is, self-discrepancies motivate self-regulatory behaviours in order to reduce discrepancies (or enlarge discrepancies, in the case of the feared self) (Boldero \& Francis, 1999; Carver \& Scheier, 1998). The first aim of the present study was to replicate earlier findings and investigate the emotional consequences of self-discrepancies in patients with chronic pain. In line with previous studies (Goossens, et al., 2010; Waters, et al., 2004), we hypothesize that ideal and ought discrepancies and feared congruencies predict depressive and anxious mood. The second aim was to extend the study of selfdiscrepancies in chronic pain patients by examining their explanatory function in activity patterns. We hypothesize that ideal or ought selfdiscrepancies are associated with persistence behaviour because their behaviour is driven by a focus on desired or obliged end states (i.e., ideal or ought self). Yet, persistence behaviour might also be aimed at maintaining an actual-ideal or actual-ought congruency. Therefore, we tested the existence of a U-shaped relationship between ideal and ought self-discrepancies and persistence behaviour. Feared self-congruencies are hypothesized to predict avoidance behaviour because the focus is on an undesired end state (i.e., the feared self). Finally, we hypothesize that both avoidance and persistence are associated with higher levels of disability and inferior quality of life. 


\section{METHODS}

\section{I. RECRUITMENT OF PARTICIPANTS}

The present study took place in the Southern area of the Netherlands. Participants were either referred to the study by their consultant in rehabilitation medicine or responded to the advertisement that appeared in local newspapers. Consultants in rehabilitation medicine were asked to refer patients meeting the inclusion and exclusion criteria for the present study. In cases of patients responding to the advertisement, selection criteria were checked by a consultant in rehabilitation medicine who performed a medical screening according to the clinical guidelines for low back pain of the Dutch College of General Practitioners (Faas, et al., 1996). Participants were eligible for inclusion in the present study if they suffered from non-specific low back pain for at least 3 months, were aged between 18 and 65 years, and had sufficient knowledge of the Dutch language. Participants for whom primary psychiatric treatment was indicated were excluded. For female participants, pregnancy was also an exclusion criterion.

\subsection{MEASURES}

Besides sociodemographics (i.e., gender, age, education level, occupation) and pain-related information (i.e., pain duration), data were obtained for the measurement instruments to follow. Reliability coefficients (Cronbach alpha) of all questionnaires are presented in Table I.

\subsection{Self-discrepancies}

Self-discrepancies were measured by assessing Hardin's Selves Questionnaire (HSQ; Hardin \& Leong, 2005) in the form of a semistructured interview. Participants were asked to generate attributes for each self-guide (ie, ideal, ought, and feared) from 2 perspectives, their own perspective and the internalized perspective of someone who is important to them (e.g., spouse). (Originally, the HSQ assessed the undesired self instead of the feared self. For the purpose of our hypotheses, we revised the description of the undesired self and, in concordance with Carver et al. (I999), modified it to the feared self). More specifically, participants listed 5 attributes they ideally would like to possess (Ideal-own), 5 attributes they feel the important other would ideally like them to possess (Ideal-other), 5 attributes they feel they ought to possess (Ought-own), 5 attributes they think the other feels they ought to possess (Ought-other), 5 attributes they fear to possess (Feared-own), and 5 attributes the other fears they possess (Feared-other). After listing all 30 attributes, participants were asked to rate to which extent each attribute currently describes themselves on a scale from i (does not 
describe me at all) to 5 (completely describes me). Self-discrepancy scores were obtained by summing the discrepancy scores of the 5 attributes. For the ideal and the ought self, lower scores indicated larger discrepancies, reflecting a negative state, while for the feared self, lower scores indicated smaller congruencies and therefore reflect a positive state. The HSQ is a valid and reliable instrument to measure self-discrepancies (Hardin \& Leong, 2005). To permit comparisons with previous studies in which the HSQ was used (Goossens, et al., 2010; Hardin \& Leong, 2005), the scores presented in Table I are the scores per self-guide divided by 5 (i.e., the number of attributes).

\subsubsection{Depression}

The Dutch version of the Beck Depression Inventory II (BDI-II; Beck, Steer, Brown, \& Van der Does, 2002) was utilized to measure depression. Depressive symptomatology is questioned in 2I items with several possible responses and scores ranging from 0 to 3 . Total scores are obtained by summing the item scores, resulting in total scores ranging from o (not depressed at all) to 63 (severely depressed). The BDI-II has sound psychometric properties (Beck, Steer, \& Brown, 1996) and has been found suitable for administration in chronic pain populations (Harris \& D'Eon, 2008).

\subsubsection{Anxiety}

The anxiety subscale of the Hospital Anxiety and Depression Scale (Zigmund \& Snaith, 1983) was used to measure anxiety. The anxiety subscale exists out of 7 items about the frequency of experiencing anxious states on a 4-point scale. The Dutch version of the Hospital Anxiety and Depression Scale has been found to be a reliable and valid instrument (Spinhoven, et al., 1997).

\subsubsection{Activity patterns}

To measure avoidance and persistence behaviour, a recently developed instrument, the Patterns of Activity Measure-Pain (POAM-P; Cane, et al., 2007) was administered. The POAM-P is a 30 -item self-report measure developed to identify 3 activity patterns in patients with chronic pain: avoidance (Io items), overdoing (ie, persistence behaviour; Io items), and pacing (Io items). Yet, because the focus of the present study is on avoidance and persistence, no results regarding the pacing scale will be reported. An example of an avoidance item is "I avoid activities that I know will make my pain worse," while a contrasting item of the overdoing scale is "When I'm doing an activity, I don't stop until it is finished." Participants have to indicate to which extent the item applies to them on a 5 -point scale ranging from 0 (not at all) to 4 (always). Total scores per subscale range from $\mathrm{O}$ to $4 \mathrm{O}$. The 3 -factor structure of the 
Dutch version of the POAM-P has been confirmed and the 3 subscales were found to have high internal consistency (Cronbach alphas ranging from .80 to .94). Significant and meaningful associations with related constructs such as fear of movement and (re)injury, pain catastrophizing, depression, and disability confirmed the validity of the subscales (Kindermans HPJ, Roelofs J, Goossens M, Huijnen IP, Verbunt JA, Vlaeyen J., unpublished manuscript).

\subsubsection{Disability}

Disability was measured with the Roland Disability Questionnaire (RDQ; Roland \& Morris, 1983). The RDQ presents 24 daily activities; participants have to indicate whether their low back pain interferes with the activity (score I) or not (score o). The item scores are summed, leaving total score ranges between $\mathrm{O}$ and 24 , with higher scores reflecting higher levels of disability. The Dutch version of the RDQ is a reliable and valid instrument assessing disability in patients with chronic low back pain (Brouwer et al., 2004).

\subsubsection{Health-related quality of life}

The RAND 36-item Health survey (RAND-36; van der Zee \& Sanderman, 1993) was administered to measure health-related quality of life. The questionnaire comprises 9 subscales measuring both physical and mental health, therefore enabling the computation of a physical health (physical functioning, physical role limitations, general health perception, and pain) and a mental health (social functioning, emotional role limitations, mental health, and vitality) scale, which will be used in the present study. The ninth, I-item subscale, "health change," does not belong to one of the aforementioned scales and will not be reported on. Responses to the items are given on a $3^{-}$or 6-point Likert scale, or with "yes" or "no," depending on the subscale. Psychometric properties of the RAND-36 are satisfactory (van der Zee \& Sanderman, I993; van der Zee, Sanderman, Heyink, \& De Haes, 1996).

\subsubsection{Pain intensity}

Pain intensity was measured on 3 100-mm visual analogue scales (Price, McGrath, Rafii, \& Buckingham, 1983) on which participants had to indicate their "worst pain last week," "least intense pain last week," and "current pain intensity." The average of the scores on these 3 scales was used as a composite score of pain intensity.

\subsection{PROCEDURE AND DESIGN}

Patients who were interested in participation received a participant information letter, and if they responded that they were willing to 
participate, they were then contacted by the researchers. Participants who responded to the advertisement also received a participant information letter and, if willing to participate, they were screened by a consultant in rehabilitation medicine to ensure qualification for the present study. After obtaining written informed consent, participants were invited to come to the University to have the HSQ interview or were interviewed by telephone. Thereafter, participants completed the self-report questionnaires, either on paper or an electronic version presented via Internet. The present study was part of a larger study, which also included daily life assessments and follow-up measurements that will be reported elsewhere. Participants received a gift voucher for their participation and were reimbursed for their travel expenses. The present study was approved by the Medical Ethics Committee of the Maastricht University Medical Centre (MEC 06-3-046) and by the institutions of the rehabilitation units from which patients were referred to the study.

\subsection{STATISTICAL ANALYSIS}

Data preparation involved missing data analyses and checks for normality of the variables, for which the Statistical Package for Social Sciences (SPSS 15.0; SSPS Inc., Chicago, IL) was used. In cases of less then I0\% missing values per (sub-) scale, the missing value was estimated by means of regression techniques. Scales with more then Io\% missing values were dropped from analyses. Two scales, namely the BDI-II and pain duration, did not meet assumptions of normality and were square-root transformed prior to analyses. After transformation, skewness and kurtosis values of both scales were in the acceptable range of $-\mathrm{I}$ and $+\mathrm{I}$. Computations of descriptive information, chi-squared and t-tests, and correlational analyses were carried out in SPSS 15.0. Besides correlational analyses, hierarchical multiple regression analyses were carried out in SPSS to determine the contribution of self-discrepancies to the prediction of negative mood (depression and anxiety) and activity patterns (avoidance and persistence) and the contribution of activity patterns to disability and quality of life. To prevent type I errors due to multiple testing, alpha was set to .oI. 


\section{Results}

\section{I. PARTICIPANTS}

\section{I.I. Participants flow}

A total of II6 participants with chronic nonspecific low back pain participated in the present study. Due to missing data, 33 participants (28\%) were not included in the analyses. Of these 33 participants, one participant did not complete the HSQ interview and 17 did not complete the self-report questionnaires. The remaining 15 participants did complete the HSQ interview and the self-report questionnaires but still had too many missing data (i.e., more than ro\% on the level of individual items) after running missing values analyses. A lack of descriptive information of the 17 participants who did not fill in the questionnaires precluded checking for selective drop-out. The reasons for withdrawal were in most cases unknown, yet some indicated a lack of time due to personal circumstances or experienced the study as too burdensome. In total, 83 participants were included in the analyses, of which $58(70 \%)$ participants were referred to the study by their consultant in rehabilitation medicine and $25(30 \%)$ responded to the advertisements in local newspapers. Participants who responded to the advertisement were older $(\mathrm{M}=52.20$ years, $\mathrm{SE}=\mathrm{I} .94)$ than those referred by their consultant in rehabilitation $(\mathrm{M}=44.4 \mathrm{I}$ years, $\mathrm{SE}=\mathrm{I} .3 \mathrm{I} ; \mathrm{t}(8 \mathrm{I})=3.29, \mathrm{P}=0.00 \mathrm{I})$. There were no significant differences between both samples on the other independent and dependent variables.

\section{I.2. Descriptive information}

Forty-two women and 4I men were included in the analyses. There were no gender differences on the self-report questionnaires. Age ranged from 22 to 65 years, with a mean of 46.76 years $(S D=10.46)$. With respect to education level, the majority of participants received lower secondary professional education or below $(53 \%)$. The rest of the participants received, at maximum, higher general secondary education (31\%) or higher education (13\%). Fifty-three percent were employed (full- or part- $^{-}$ time), $6 \%$ were on sick leave, and $21 \%$ were recipients of disablement insurance benefits. The average duration of the pain complaints was 9.8I years $(\mathrm{SD}=8.93)$ and ranged from 5 months to 39 years. Mean pain intensity, measured on 10o-mm visual analogue scales, was $49.47(\mathrm{SD}=$ 18.73). Means and standard deviations of the scores on the self-report questionnaires are presented in Table $\mathrm{I}$. 


\subsection{SELF-DISCREPANCIES AND EMOTIONAL CONSEQUENCES}

Prior to the hierarchical multiple regression analyses, correlational analyses were carried out to investigate the relationships between the distinct types of self-discrepancies and depression and anxiety (Table I). Results showed that ought-own and feared-own and feared-other discrepancies were significantly related to depression and feared-own and feared-other to anxiety in the expected direction. Pearson correlations ranged from $\mathrm{r}=0.28$ to $\mathrm{r}=0.40$ at $\mathrm{P} \leq 0.0 \mathrm{I}$ (Table $\mathrm{I}$ ). Thus, the closer participants felt to their ought-own, the less depressive mood they experienced. Regarding feared selves, both feared-own and feared-other congruencies were related to depression and anxiety. This means that the closer participants felt to the person they feared to be, or to the person that another feared them to be, the more feelings of depression and anxiety the participant experienced. Feeling close to the ideal (own or other) or ought-other self was not significantly related to depressive or anxious mood.

Hierarchical multiple regression analyses were performed predicting depression and anxiety while controlling for sociodemographic variables (gender and age) in the first block and pain-related variables (pain duration and mean pain intensity) in the second block. Each type of selfdiscrepancy from both perspectives (ideal, ought, and feared) was analyzed separately and was entered in the third block. Ideal-own and ideal-other self-discrepancies were not predictive of depression (respectively, $\beta=-0.25, \mathrm{t}=-2.08, \mathrm{P}=0.04$, and $\beta=-0.06, \mathrm{t}=-0.47, \mathrm{P}=$ 0.64 ) nor anxiety (respectively, $\beta=-0.27, \mathrm{t}=-2 . \mathrm{II}, \mathrm{P}=0.04$, and $\beta=0.00, \mathrm{t}$ $=0.0 \mathrm{I}, \mathrm{P}=0.99)$. Neither were ought-own or ought-other selfdiscrepancies predictive of depression (respectively, $\beta=-0.25, \mathrm{t}=-2.07, \mathrm{P}$ $=0.04$, and $\mathrm{b}=-0.0 \mathrm{I}, \mathrm{t}=-0.12, \mathrm{P}=0.90$ ) or anxiety (respectively, $\beta=-0.19$, $\mathrm{t}=-\mathrm{I} .48, \mathrm{P}=0 . \mathrm{I} 4$, and $\beta=-0.07, \mathrm{t}=-0.58, \mathrm{P}=0.57$ ). Because ought $-\mathrm{own}$, but not ought-other, self-discrepancies were significantly related to depression in the correlational analyses, separate regression analyses were run for the ought- own predicting depression. Yet, ought-own selfdiscrepancies were not predictive of depression while controlling for sociodemographic and pain-related variables $(\beta=-0.25, \mathrm{t}=-2.5 \mathrm{O}, \mathrm{P}=0.02)$. 


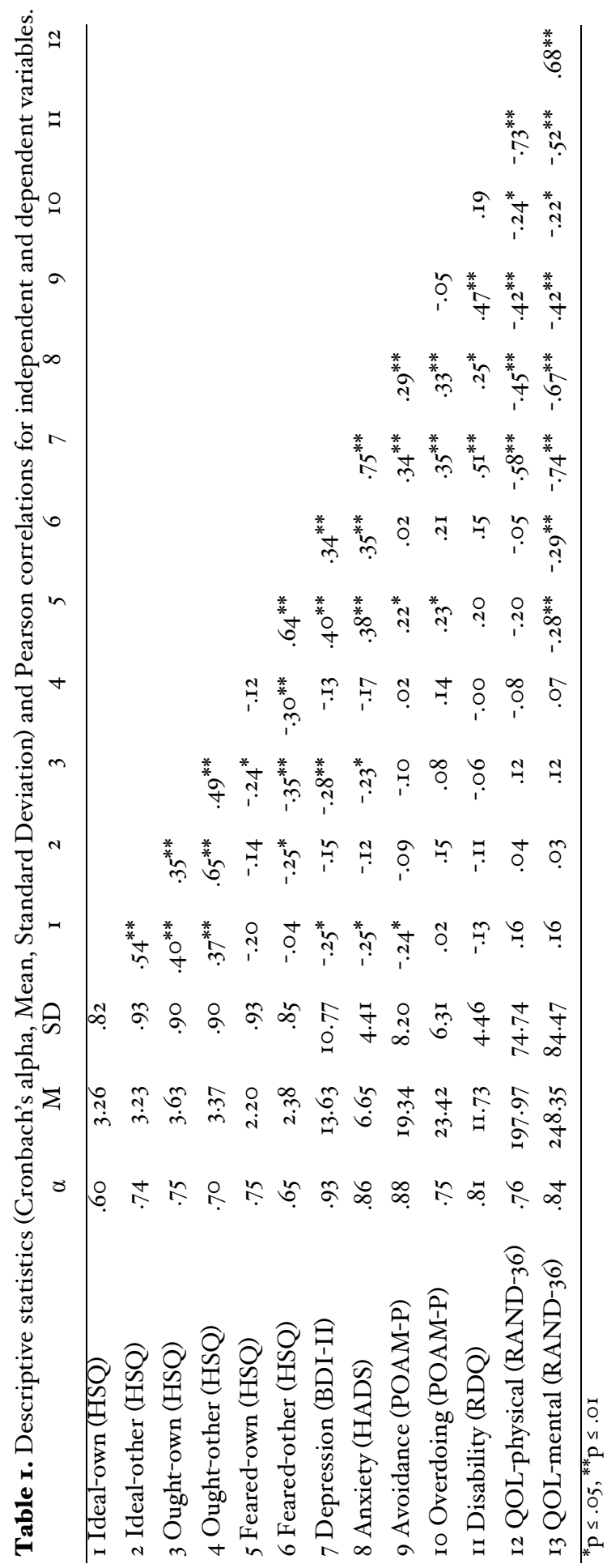


Further, as can be seen in Table 2, the addition of feared-own and fearedother self-discrepancies (block 3a) to the prediction of depression and anxiety resulted in a significant $\mathrm{F}$ change, while the predictors themselves did not reach statistical significance. Because this might indicate a type II error at the predictor level, regression analyses were conducted for the feared-own and the feared-other self-discrepancy separately (block $3 \mathrm{~b}$ and 3c). Results demonstrated that both feared-own and feared-other selfdiscrepancies were significant predictors of depression and anxiety over and beyond the contribution of sociodemographic and pain-related variables (Table 2). So, feeling far away from the feared self was predictive of lower levels of depression and anxiety.

Table 2. Summary of hierarchical regression analyses for feared self-discrepancies predicting depression and anxiety while controlling for socio-demographic and painrelated variables.

\begin{tabular}{|c|c|c|c|c|c|c|c|c|}
\hline Dependent & Blocks & Variables & $\mathrm{B}$ & SE B & $\beta$ & $\Delta \mathrm{R}^{2}$ & $\Delta \mathrm{F}$ & $p \Delta \mathrm{F}$ \\
\hline \multirow{8}{*}{$\begin{array}{l}\text { Depression } \\
\text { (BDI) }\end{array}$} & \multirow[t]{2}{*}{$\mathrm{I}$} & Gender &.- .17 & .23 & -.08 & \multirow[t]{2}{*}{. $\mathrm{OI}$} & \multirow[t]{2}{*}{.29} & \multirow[t]{2}{*}{ ns } \\
\hline & & Age & -.02 & .12 &.$- \mathrm{OI}$ & & & \\
\hline & \multirow[t]{2}{*}{2} & Pain duration & .06 & .II & .06 & \multirow[t]{2}{*}{. $\mathrm{I} 6$} & \multirow[t]{2}{*}{7.68} & \multirow[t]{2}{*}{$\leq .001$} \\
\hline & & Mean pain intensity & .42 &. $\mathrm{II}$ & $.40^{*}$ & & & \\
\hline & \multirow[t]{2}{*}{$3 a$} & Feared-own & .25 & .14 & .24 & \multirow[t]{2}{*}{.14} & \multirow[t]{2}{*}{$7 \cdot 95$} & \multirow[t]{2}{*}{$\leq . \mathrm{OOI}$} \\
\hline & & Feared-other & .20 & .13 & .19 & & & \\
\hline & $3 b$ & Feared-own & .38 & .II & $.36^{*}$ & .12 & $13 \cdot 32$ & $\leq . \mathrm{OOI}$ \\
\hline & $3 \mathrm{c}$ & Feared-other & .35 &. $\mathrm{IO}$ & $.34^{*}$ &. $\mathrm{II}$ & 12.08 & $\leq . \mathrm{OOI}$ \\
\hline \multirow{8}{*}{$\begin{array}{l}\text { Anxiety } \\
\text { (HADS) }\end{array}$} & \multirow[t]{2}{*}{ I } & Gender & -.05 & .23 & -.02 & \multirow[t]{2}{*}{.OI } & \multirow[t]{2}{*}{0.23} & \multirow[t]{2}{*}{$\mathrm{ns}$} \\
\hline & & Age & -.08 & .12 & -.07 & & & \\
\hline & \multirow[t]{2}{*}{2} & Pain duration &.$- \mathrm{OI}$ & .12 &.$- \mathrm{OI}$ & \multirow[t]{2}{*}{.07} & \multirow[t]{2}{*}{2.90} & \multirow[t]{2}{*}{ ns } \\
\hline & & Mean pain intensity & .27 &. $\mathrm{II}$ & .26 & & & \\
\hline & \multirow[t]{2}{*}{$3 a$} & Feared-own & .25 & .14 & .23 & \multirow[t]{2}{*}{.15} & \multirow[t]{2}{*}{$7 \cdot 57$} & \multirow[t]{2}{*}{$\leq . \mathrm{OOI}$} \\
\hline & & Feared-other & .22 & .14 & $.2 \mathrm{I}$ & & & \\
\hline & $3 \mathrm{~b}$ & Feared-own & .39 &.$I I$ & $.37^{*}$ & .13 & 12.38 & $\leq . \mathrm{OOI}$ \\
\hline & $3 c$ & Feared-other & .37 &. $\mathrm{II}$ & $.36^{*}$ & .12 & II. 88 & $\leq .001$ \\
\hline
\end{tabular}

Note.BDI $=$ Beck Depression Inventory.HADS $=$ Hospital Anxiety and Depression Scale. ${ }^{*} \mathrm{p} \leq$ 0.0oI.

\subsection{SELF-DISCREPANCIES AND ACTIVITY PATTERNS, DISABILITY, AND QUALITY OF LIFE}

Results from the correlational analyses (Table I) did not show significant associations between self-discrepancies and activity patterns, yet they did 
show associations between avoidance behaviour on the one hand, and disability and quality of life (physical and mental) on the other hand. In contrast, persistence behaviour was not significantly related to disability or quality of life.

To further test the contribution of self-discrepancies to activity patterns, 3 hierarchical multiple regression analyses were carried out. In all regression analyses, sociodemographic variables (gender and age) were entered in the first block and pain-related variables (pain duration and pain intensity) in the second block. To explain persistence behaviour, ideal-own and ideal-other self-discrepancies were entered in the third block and, in a second regression analysis, replaced by ought-own and ought-other self-discrepancies. In the fourth block, the quadratic terms of the self-discrepancies were added to test the U-shaped relationship. There were no significant main effects of self-discrepancies on persistence behaviour. However, the quadratic term of the ideal-other significantly predicted persistence behaviour (Table 3 ). This means that participants who felt close to their ideal-other as well as those who felt far away from their ideal-other, both showed higher levels of persistence behaviour (Figure I).

With regard to ought self-discrepancies, neither the quadratic terms of the ought-own self-discrepancy, nor ought-other self-discrepancy were significant predictors of persistence behaviour (respectively, $\beta=0.05, t=$ $0.39, \mathrm{P}=0.70$, and $\beta=0.14, \mathrm{t}=\mathrm{I} .08, \mathrm{P}=0.29$ ). In the regression analysis with avoidance behaviour as the dependent variable, the feared-own and feared-other were entered in the third block. Results showed that the closer participants felt to the person they feared to be, the more likely they were to exert avoidance behaviour (Table 3). In line with aforementioned analyses, the feared-own (block $3 \mathrm{~b}$ ) and the feared-other (block 3c) were also tested separately. As presented in Table 3, the fearedown was no longer a significant predictor of avoidance when the effect of the feared-other was not controlled for. 


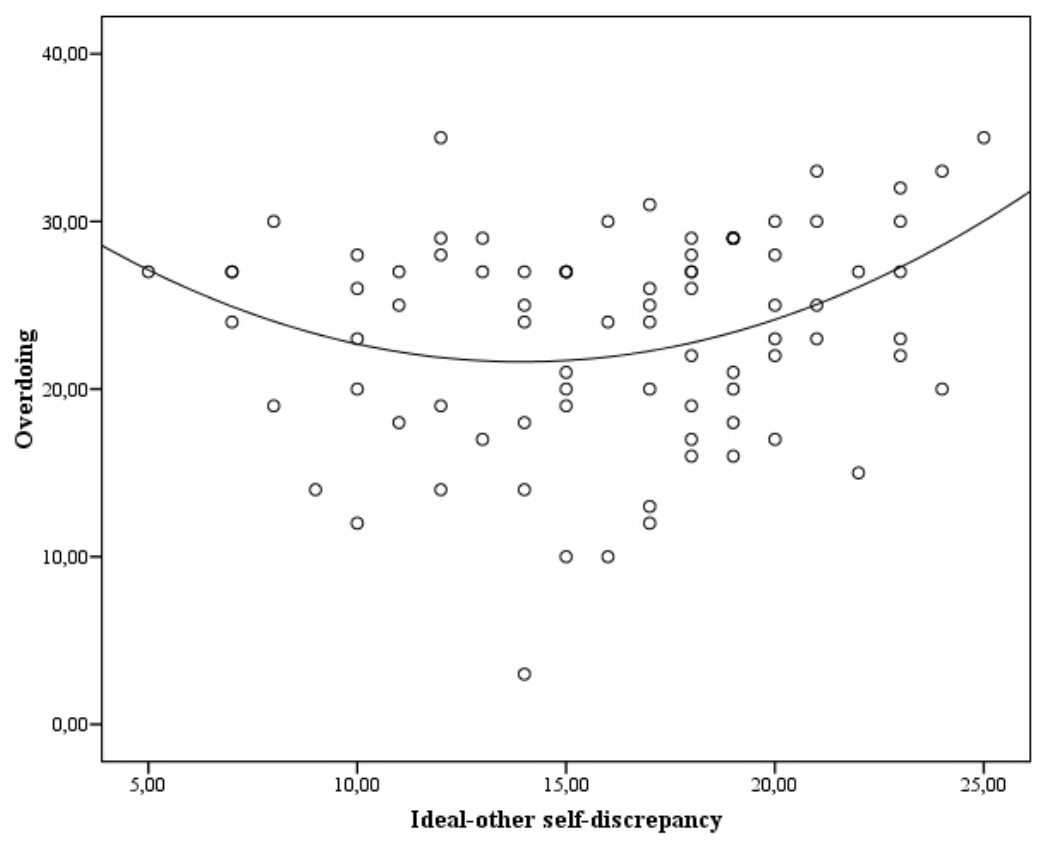

Figure I. The relationship between overdoing and ideal-other self-discrepancies.

Hypotheses concerning the prediction of disability and quality of life from activity patterns were also tested with hierarchical regression analyses for each activity pattern separately (Table 4). In line with aforementioned analyses, sociodemographic and pain-related variables were controlled for in the first 2 blocks. In the third block, either persistence or avoidance behaviour was entered. Results showed that avoidance but not persistence behaviour was a significant predictor of disability and mental and physical quality of life. 
Table 3. Summary of hierarchical regression analyses for self-discrepancies predicting overdoing and avoidance while controlling for socio-demographic and pain-related variables.

\begin{tabular}{|c|c|c|c|c|c|c|c|c|}
\hline Dependent & Blocks & Variables & $\mathrm{B}$ & SE B & $\beta$ & $\Delta \mathrm{R}^{2}$ & $\Delta \mathrm{F}$ & $p \Delta \mathrm{F}$ \\
\hline \multirow{8}{*}{$\begin{array}{l}\text { Overdoing } \\
\text { (POAM-P) }\end{array}$} & \multirow[t]{2}{*}{$\mathrm{I}$} & Gender & -.02 & $.2 \mathrm{I}$ &.$- \mathrm{OI}$ & \multirow[t]{2}{*}{. $\mathrm{OI}$} & \multirow[t]{2}{*}{.29} & \multirow[t]{2}{*}{$\mathrm{ns}$} \\
\hline & & Age & -.08 &.$I I$ & -.08 & & & \\
\hline & \multirow[t]{2}{*}{2} & Pain duration & -.00 &. $\mathrm{II}$ & -.00 & \multirow[t]{2}{*}{.05} & \multirow[t]{2}{*}{2.04} & \multirow[t]{2}{*}{ ns } \\
\hline & & $\begin{array}{l}\text { Mean pain } \\
\text { intensity }\end{array}$ & .22 &. $\mathrm{II}$ & .22 & & & \\
\hline & \multirow[t]{2}{*}{3} & Ideal-own & -.06 &. $\mathrm{I} 2$ & -.06 & \multirow[t]{2}{*}{.03} & \multirow[t]{2}{*}{ I.II } & \multirow[t]{2}{*}{ ns } \\
\hline & & Ideal-other & .24 &. $\mathrm{I} 2$ & .25 & & & \\
\hline & \multirow[t]{2}{*}{4} & Ideal-own ${ }^{2}$ & .00 &. $\mathrm{OI}$ & .09 & \multirow[t]{2}{*}{. $\mathrm{IO}$} & \multirow[t]{2}{*}{4.69} & \multirow[t]{2}{*}{$\leq$.OI } \\
\hline & & Ideal-other $^{2}$ &. $\mathrm{OI}$ &. $\mathrm{OI}$ & $.30^{*}$ & & & \\
\hline \multirow{8}{*}{$\begin{array}{l}\text { Avoidance } \\
\text { (POAM-P) }\end{array}$} & \multirow[t]{2}{*}{ I } & Gender & .16 & .22 & .08 & \multirow[t]{2}{*}{. $\mathrm{OI}$} & \multirow[t]{2}{*}{.36} & \multirow[t]{2}{*}{ ns } \\
\hline & & Age & -.06 & .12 & -.06 & & & \\
\hline & \multirow[t]{2}{*}{2} & Pain duration & .19 & .12 & .19 & \multirow[t]{2}{*}{.05} & \multirow[t]{2}{*}{ I. 88} & \multirow[t]{2}{*}{ ns } \\
\hline & & $\begin{array}{l}\text { Mean pain } \\
\text { intensity }\end{array}$ & .13 &. $\mathrm{II}$ & .13 & & & \\
\hline & \multirow[t]{2}{*}{$3 a$} & Feared-own & .40 & .15 & $.39^{*}$ & \multirow[t]{2}{*}{.08} & \multirow[t]{2}{*}{3.69} & \multirow[t]{2}{*}{ ns } \\
\hline & & Feared-other & -.20 &. $\mathrm{I} 4$ & -.20 & & & \\
\hline & $3 \mathrm{~b}$ & Feared-own & .26 &. $\mathrm{II}$ & .26 & .06 & 5.29 & ns \\
\hline & $3 \mathrm{c}$ & Feared-other & .04 &. II & .04 & .00 & .I4 & ns \\
\hline
\end{tabular}

Note. POAM-P $=$ Patterns of Activity Measure-Pain. ${ }^{*} \mathrm{p} \leq 0.0 \mathrm{I}$. 
Table 4. Summary of hierarchical regression analyses for activity patterns predicting disability and quality of life (QOL) while controlling for socio-demographic and painrelated variables.

\begin{tabular}{|c|c|c|c|c|c|c|c|c|}
\hline Dependent & \multirow{2}{*}{\multicolumn{2}{|c|}{$\begin{array}{l}\text { Blocks Variables } \\
\text { I } \quad \text { Gender }\end{array}$}} & \multirow{2}{*}{$\begin{array}{l}\mathrm{B} \\
-.09\end{array}$} & \multirow{2}{*}{$\begin{array}{l}\text { SE B } \\
.22\end{array}$} & \multirow{2}{*}{$\begin{array}{l}\beta \\
-.05\end{array}$} & \multirow{2}{*}{$\frac{\Delta \mathrm{R}^{2}}{.0 O}$} & \multirow{2}{*}{$\frac{\Delta \mathrm{F}}{. \mathrm{IO}}$} & \multirow{2}{*}{$\frac{p \Delta \mathrm{F}}{\mathrm{ns}}$} \\
\hline \multirow{6}{*}{$\begin{array}{l}\text { Disability } \\
\text { (RDQ) }\end{array}$} & & & & & & & & \\
\hline & & Age & -.01 &. $\mathrm{II}$ & -.01 & & & \\
\hline & 2 & Pain duration & -.00 &. $\mathrm{IO}$ & -.00 & .29 & I6.00 & $p<.001$ \\
\hline & & $\begin{array}{l}\text { Mean pain } \\
\text { intensity }\end{array}$ & .52 & .09 & $.54^{*}$ & & & \\
\hline & $3 a$ & Overdoing & .07 &. $\mathrm{IO}$ & .07 & .00 & .55 & ns \\
\hline & $3 \mathrm{~b}$ & Avoidance & $.4 \mathrm{I}$ & .08 & $.43^{*}$ & .17 & $25 . \mathrm{II}$ & $p<. \mathrm{OOI}$ \\
\hline \multirow{6}{*}{$\begin{array}{l}\text { Physical QOL } \\
\text { (RAND-36) }\end{array}$} & & Gender & .18 & $.2 \mathrm{I}$ & .09 & .07 & 3.01 & ns \\
\hline & & Age & .24 &. $\mathrm{II}$ & .24 & & & \\
\hline & 2 & Pain duration & -.03 & .09 & -.03 & .40 & 29.39 & $p<.00 \mathrm{I}$ \\
\hline & & $\begin{array}{l}\text { Mean pain } \\
\text { intensity }\end{array}$ & -.63 & .08 & $-.64^{*}$ & & & \\
\hline & $3 a$ & Overdoing & -.09 & .09 & -.09 &. $\mathrm{OI}$ & I.O4 & ns \\
\hline & $3 b$ & Avoidance & -.34 & .07 & $-.35^{*}$ & .12 & 21.30 & $p<$. oOI \\
\hline \multirow{6}{*}{$\begin{array}{l}\text { Mental QOL } \\
\text { (RAND-36) }\end{array}$} & I & Gender & .19 & .23 & .09 & .03 & I.OI & ns \\
\hline & & Age &. $\mathrm{I} 2$ & .12 &. $\mathrm{I} 2$ & & & \\
\hline & 2 & Pain duration & -.09 &. $\mathrm{II}$ & -.09 & .23 & II.9O & $p<. \mathrm{OOI}$ \\
\hline & & $\begin{array}{l}\text { Mean pain } \\
\text { intensity }\end{array}$ & -.49 &. $\mathrm{IO}$ & $-.47^{*}$ & & & \\
\hline & $3 a$ & Overdoing & -.15 &. $\mathrm{IO}$ & -.14 &. $\mathrm{OI}$ & $\mathrm{I} .23$ & ns \\
\hline & $3 \mathrm{~b}$ & Avoidance & -.38 & .09 & $-.37^{*}$ & .13 & 15.89 & $p<$. OOI \\
\hline
\end{tabular}

Note. RDQ = Roland Disability Questionnaire. ${ }^{*} \mathrm{p}<0.00 \mathrm{I}$.

\section{Discussion}

The aim of the present study was twofold. The first aim was to inspect the emotional consequences of self-discrepancies in patients with chronic pain. The second aim was to extend the study of self-discrepancies in patients with chronic pain by testing self-discrepancies' value in predicting self-reported activity patterns and, as a consequence of these activity patterns, disability levels and quality of life. With regard to the first aim of the study, results showed that feared (own and other) selfdiscrepancies were indeed related to emotional distress. Yet, ought and ideal (own or other) self-discrepancies were not. Regarding the second aim, results showed that the feared-own, but not the feared-other, was associated with avoidance. Furthermore, a U-shaped relationship between the ideal-other and persistence behaviour was demonstrated. 
Finally, avoidance, but not persistence, behaviour contributed to higher levels of disability and diminished mental and physical health.

Based on the present results, emotional distress appears strongly related to the experienced proximity to the feared self, because this was associated with and predictive of both anxiety and depression. This is also in line with findings from Goossens and colleagues (2010), who studied patients with chronic pain in the upper extremities and found that patients who felt close to their feared self reported higher levels of depression and anxiety. In contrast with Waters and colleagues (2004), who studied chronic low back pain patients, ideal (own and other) selfdiscrepancies were not related to depression nor anxiety in the present study. Further, ought-own self-discrepancies were related to depression but this relationship was no longer significant after controlling for sociodemographic and pain-related variables. The finding that oughtother self-discrepancies were not related to anxiety or depression is in contrast with previous studies, demonstrating detrimental consequences of ought self-discrepancies, including depressed and anxious mood, in chronic pain patients (Goossens, et al., 20IO; Waters, et al., 2004). The present results might originate from the dynamics between different types of self-discrepancies. Carver and colleagues (1999) already suggested that proximity to the feared self might minimize the importance of approaching desired end states, such as the ideal and ought self, because of the salience of the feared self. This is also supported by other studies, showing that the undesired self, which is closely related to the feared self, is a better predictor of well-being-related constructs (Ogilvie, I987; Phillips, Silvia, \& Paradise, 2007). It might be that the feared self was also more salient to participants in the present study.

With respect to behavioural consequences of self-discrepancies, ideal and ought self-discrepancies were hypothesized to be related to persistence behaviour. Results showed that patients who felt close to their idealother as well as those who experienced great discrepancies between their actual and ideal-other, both showed higher levels of persistence behaviour. For the participants who feel discrepant from their ideal-other self, persistence behaviour might be an (unsuccessful) attempt to get closer to their ideal self. For those who feel close to their ideal self, persistence behaviour may reflect the possibility to continue their daily activities despite pain, and in that case, persistence behaviour may be inversely related to disability. This ambiguity may be one of the reasons why there is no straightforward relationship between persistence behaviour and disability levels. While our hypothesis on the U-shaped relationship between self-discrepancies and persistence behaviour was restricted to the ideal-other, this finding sheds new light on the functional meaning of persistence behaviour when considering selfdiscrepancies. 
With regard to avoidance behaviour, results demonstrating feared-own self-discrepancies were related to avoidance. It is noteworthy that fearedother self-discrepancies acted as a suppressor variable in the regression analysis because the effect of the feared-own was significant only while controlling for the feared-other. Nevertheless, the present results showed that participants who felt close to their feared self from their own perspective also reported more avoidance behaviour. In a similar vein, avoidance behaviour as predicted in the fear-avoidance model is also the consequence of fears, yet on a more basic "do-level." The object of fear in the present study, namely becoming someone you do not want to be, acts on a higher-order "be-level" but seems to have similar consequences. This means that the feared self may be understood in terms of an antigoal and, as antigoals are likely to instigate safety behaviour (Mansell, 2005), in patients with chronic pain it is likely that this leads to a tendency to avoid activities. In other words, this is the first study showing that the validity of fear-avoidance models appears to generalize to the level of perceived self and identity.

In general, the level of measurement of self-discrepancies might play a role with regard to the limited results between self-discrepancies and activity patterns. Self-discrepancies are higher-order constructs, meaning that they are the result of cognitive higher-order processes, in which an individual reflects on his or her self. A content analysis of selfdiscrepancies has also shown that the ideal, ought, and feared selves concern general attributes mostly related to the interpersonal domain (eg, honest) (Kindermans, et al., 20IO). Activity levels, on the other hand, are lower-order constructs measured at a behavioural level, and relate to the intrapersonal domain (eg, doing household chores). In order to overcome this conceptual distance, self-discrepancies might be measured on a lower level by, for example, focusing on activities. It might be discussed, however, to what extent this operationalization justifies the use of the term self-discrepancies instead of activity-discrepancies.

Partly in line with our hypotheses, the current results demonstrated that avoidance behaviour was predictive of higher levels of disability and diminished quality of life. Yet persistence behaviour was not. The results are, however, in line with findings of previous studies on activity patterns (Hasenbring, Hallner, \& Rusu, 2009b; McCracken \& Samuel, 2007) in which no detrimental effects of persistence behaviour were found. In the study of McCracken and Samuel (2007), persistence behaviour was unrelated to disability. Moreover, Hasenbring and colleagues (Hasenbring, Hallner, \& Rusu, 2009b) found that persistence behaviour was associated with lower levels of disability. It is noteworthy that in these 3 studies, 3 different measurement instruments were used to assess persistence behaviour. It is possible that, despite the agreement in the 
theoretical conceptualization of persistence behaviour, different items might tap into different aspects of persistence behaviour. For example, an item focusing on "being highly active" versus an item focusing on "experiencing increased pain as a consequence of being highly active" might be differentially related to disability. The finding of the present study that persistence behaviour was related to being close to, as well as being far away from, the ideal-other self, adds up to the importance of taking a closer look at the concept of persistence behaviour.

Future studies should be attentive to the dynamics between types of selfdiscrepancies, but might also consider focusing on one type of selfdiscrepancy in order to gain more insight into direct effects on emotional or behavioural outcomes. Furthermore, the perspective on the self should not be neglected as different results emerge from self-discrepancies from the "own" perspective versus self-discrepancies from the "other" perspective. It might be interesting for future studies to also consider the relationship between the patient and his or her significant other, as listed in the self-discrepancy interview, because this might be of importance for the strength of the self-discrepancy. For the study of the role of selfdiscrepancies in activity patterns, future studies might consider possible mediating or moderating variables. For example, flexible-goal adjustment has been shown to be protective against negative emotions despite the presence of self-discrepancies (Goossens, et al., 20IO).

The integration of self-discrepancies in the explanatory mechanism behind emotional and behavioural consequences of chronic pain might have clinical implications. Clinicians should keep in mind that patients may be burdened by fears not only at the level of activities but also at the level of being. Chronic pain patients might benefit from clinical interventions targeting the way patients see themselves and working with the personal goals they set for themselves, which are defined in the ideal and ought self. Self-system therapy, which is derived from SDT, has previously been employed in the treatment of depression and has shown promising results (Strauman, Vieth, Merrill, Kolden, et al., 2006; Vieth, et al., 2003).

The shortcomings of the present study, being that the results rely on selfreport and as the design was cross-sectional, no causal relationships could be confirmed, imply that future studies should focus on longitudinal designs to examine associations in time and experimentally testing selfdiscrepancies in patients with chronic pain. It would be interesting to experimentally activate specific self-discrepancies and determine under controlled circumstances whether and how they influence pain behaviour. Furthermore, caution is needed with respect to generalizing present findings to other pain populations because the present study involved a relatively homogeneous group of chronic low back pain patients only. 
Considering that this is the first study to investigate this relationship, it is difficult to be conclusive about the role of self-discrepancies in the activity patterns of chronic pain patients. Nevertheless, the present results add to the importance of studying the feared self in patients with chronic pain and to consider both emotional and behavioural consequences, as the feared-own was related to avoidance. On the other hand, ideal self-discrepancies might be important in the light of explaining persistence behaviour. Yet, based on present results, the ought self might be less relevant in explaining emotional or behavioural consequences. Importantly, avoidance but not persistence behaviour appeared to predict disability and diminished quality of life.

\section{ACKNOWLEDgments}

The authors wish to thank Stephen Morley for the interesting and fruitful discussions on the study of self-discrepancies in patients with chronic pain. We are also grateful to Erik Schouten and Gerard van Breukelen for their statistical assistance and to Astrid Dello, Truus Uijen, and Sita van Riet for their help in data collection and organization. The study was supported by the Council for Medical and Health Research of the Netherlands (ZON-MW), Grant No. I4350042. The contribution of Johan W.S. Vlaeyen was supported by the NWO Social Sciences Research Council of The Netherlands, Grant No. 453-04-003. Participation of Dr. Roelofs was supported by the EFIC-Grünenthal Grant (EGG). The authors have no conflict of interest with regard to the present study. 


\section{|| Chapter $5 \|$}

\section{Activity patterns in chronic pain: underlying dimensions and associations with disability and depressed mood}

This chapter is published as: Kindermans, H., Roelofs, J., Goossens, M., Huijnen, I., Verbunt, J., Vlaeyen, J. (20II). Activity patterns in chronic pain: underlying dimensions and associations with disability and depressed mood. The Journal of Pain, I2, I049-1058. 


\section{Abstract}

Activity patterns are believed to play an important role in the development and perpetuation of chronic pain. So far, three important activity patterns have been studied: avoidance behaviour, persistence behaviour, and pacing behaviour. Yet, empirical evidence is limited and inconclusive about the relationships between these activity patterns and important outcomes. Therefore, the present study was aimed at identifying activity patterns by means of factor analyses and determining their relationship with disability and depressive symptomatology in participants with chronic pain $(N=$ 132). Items across different measurement instruments pertaining one particular activity patterns were aggregated, and submitted to factor analysis. Results from three separate factor analyses revealed six distinct activity patterns, i.e. pain avoidance, activity avoidance, task-contingent persistence, excessive persistence, pain-contingent persistence, and pacing. In line with our hypotheses, pain $^{-}$and activity avoidance, and excessive persistence were related to higher levels of disability and depressive symptomatology. In contrast to hypotheses, pacing was associated with worse outcomes as well. Interestingly, task-contingent persistence was related to lower levels of disability and depressive symptomatology. When controlling for pain and the other activity patterns, excessive persistence and activity avoidance were the most detrimental in terms of relations with depressed mood or disability. Task-contingent persistence appeared to be the least detrimental.

\section{INTRODUCTION}

Recent cognitive-behavioural models on pain-related disability assume that activity patterns such as avoidance, persistence, and pacing play a central role in the development and maintenance of chronic pain (Hasenbring, et al., 2006; Nielson, et al., 2001; Vlaeyen \& Morley, 2004). According to the fear-avoidance model, avoidance behaviour is associated with fear of movement and pain catastrophizing resulting in disability and numerous studies have confirmed the detrimental effects of avoidance behaviour on disability and depression (Leeuw, et al., 2007).

Activity persistence despite pain is characterized by higher levels or more fluctuating levels of activity and is believed to have detrimental effects on disability as well through overuse (Bousema, Verbunt, Seelen, Vlaeyen, \& Knottnerus, 2007; Hasenbring, 2000; Van Houdenhove \& Neerinckx, I999; Vlaeyen \& Morley, 2004). Based on original premises on persistence behaviour, a positive relationship with disability would be expected. However, empirical evidence on persistence behaviour and 
disability is scarce, and the few studies available found persistence behaviour to be associated with lower, instead of higher, levels of disability (Hasenbring, et al., 2009b; McCracken \& Samuel, 2007). A possible explanation for this finding might be that these patients indeed feel less disabled, despite a higher level of pain intensity (Hasenbring, Hallner, \& Rusu, 2009a).

In contrast to avoidance and persistence behaviour, pacing has been introduced as an adaptive behavioural strategy and is a core element in operant pain management programmes (Birkholtz, et al., 2004; Philips \& Rachman, 1996). Pacing strategies may include breaking tasks into smaller, manageable pieces, taking frequent short rests, speeding up or slowing down (contrasting a patient's habitual activity), maintaining a steady pace or using a timer to counteract pain-contingent activity (Birkholtz, et al., 2004; Nielson, et al., 200I). Despite the widely accepted view of pacing as functional behaviour, empirical evidence is lagging behind its widespread use as a clinical tool. Whereas earlier studies found pacing to be related to lower levels of disability (Nielson, et al., 200I), this has not been confirmed in recent studies (Karsdorp \& Vlaeyen, 2009; McCracken \& Samuel, 2007). Although there is some discussion on how pacing is currently defined (Gill \& Brown, 2009), pacing, as conceptualized by Nielson and colleagues (200I) and McCracken and Samuel (2007), would be expected to be associated with diminished levels of disability. Thus, apart from the necessity of a clear definition, the current inconclusive results call for closer inspection of the dimensionality of pacing as it is currently operationalized and its relations to disability and depressive symptomatology.

Considering that patients may adopt several behavioural strategies instead of restricting to one activity pattern, McCracken and Samuel (2007) studied clusters of distinct activity patterns. Results indicated that those patients with high levels of avoidance behaviour and those with high levels of both avoidance and persistence behaviour were the least functional group in terms of disability. However, the detrimental consequences of unique activity patterns remain unclear. Moreover, the fact that overall findings on activity patterns are ambiguous might indicate the existence of underlying dimensions. The present study was aimed at identifying important activity patterns across various self-report measures of activity patterns in participants with chronic pain, and at determining their relationship with disability and depressive symptomatology. It was hypothesized that activity patterns characterised by avoidance or persistence behaviour would be equally detrimental as reflected in positive relationships with disability and depressive symptomatology. In contrast, pacing-based activity patterns are hypothesized to be functional and thus, negatively related to disability and depressive symptomatology. 


\section{METHODS}

\section{I PARTICIPANTS AND PROCEDURE}

The present study included $\mathrm{I} 32$ participants $(\mathrm{M}: \mathrm{F}=45: 87)$, all recruited through advertisements in local newspapers. Participants were eligible for inclusion if they suffered from musculoskeletal pain for longer than three months and had fluency in the Dutch language. For female participants, pregnancy was an exclusion criterion. After obtaining informed consent, participants filled out the questionnaires either on paper or via internet. Participants were aged between 18 and 69 with a mean age of $45.62(\mathrm{SD}=$ I2.I8). The duration of the pain complaints ranged from 5 months to 40 years $(\mathrm{M}=\mathrm{I} 46.82, \mathrm{SD}=\mathrm{I} 2 \mathrm{O} .23)$. Primary pain complaints included lower back pain $(52.7 \%)$, shoulder pain $(6.9 \%)$, upper limb pain $(5.3 \%)$, lower limb pain ( $13 \%)$, pain in the cervical region $(9.2 \%)$ pain in the thoracic region $(3.1 \%)$, and other regions $(9.9 \%)$. The minority of all participants (37.I \%) were working part or full time. The present study was approved by the psychology faculty Ethical Committee of Maastricht University.

\subsection{MEASURES}

\section{The Patterns Of Activity Measure-Pain (POAM-P)}

The POAM-P was developed by Cane and colleagues (2007) and translated into Dutch. The Dutch version of the POAM-P was submitted to a back-translation into English, and subsequently approved by the authors of the original version. The POAM-P is a 30 -item self-report questionnaire, measuring three activity patterns in patients with chronic pain, namely avoidance, overdoing (i.e. behavioural persistence), and pacing. Each subscale comprises io statements. The instructions are as follows: "People who have pain use different ways to do their daily activities. Think about how you usually do your daily activities." Participants have to indicate to which extent the statement applies to them on a five point scale ranging from o (not at all) to 4 (always). For each subscale, a separate total score is obtained by summing the scores per item which results in total score ranges from $O$ to 40 . Initial reliability and validity checks of the Dutch version of the POAM-P were satisfactory (Kindermans, et al., 2009).

The Pain and Activity Relations Questionnaire (PAR2)

The PARQ (McCracken \& Samuel, 2007) is a 2I-item self-report questionnaire, also measuring three activity patterns labelled as avoidance (8 items), pacing (6 items) and confronting ( 7 items). The subscale confronting measures a behavioural persistence activity pattern comparable to the overdoing subscale of the POAM-P. Participants have 
to rate each statement on a six-point scale ranging from o (never) to 5 (always). Total scores are obtained by summing the scores on the items per subscale resulting in total scores ranging from $\mathrm{O}$ to $4 \mathrm{O}$ (avoidance), $\mathrm{O}$ to 30 (pacing), and o to 35 (confronting). Initial reliability and validity checks were satisfactory (McCracken \& Samuel, 2007).

\section{Behavioural Responses to Illness 2uestionnaire (BRIQ)}

The BRIQ is a $2 \mathrm{I}^{-}$item self-report questionnaire developed to measure behavioural responses of patients in an acute phase of illness (Spence, Moss-Morris, \& Chalder, 2005). The questionnaire comprises four subscales, namely all-or-nothing behaviour (6 items), limiting behaviour (7 items), emotional support seeking (4 items), and practical support seeking (4 items). In the present study, only 'all-or-nothing behaviour' and 'limiting behaviour' were selected, as these subscales measure behavioural persistence and avoidance behaviour respectively. Items are answered on a 5 -point scale ranging from I (not at all) to 5 (every day), indicating the frequency of the stated behaviour for the participant. Total scores are obtained by summing the scores on the items for each subscale separately. Total scores range from 6 to 30 (all-or-nothing) and 7 to 35 (limiting). Although the BRIQ was originally developed for patients in an acute phase of illness, inspection of the items indicated that the questionnaire was also suitable for administration in a chronic pain population without modification. Psychometric properties of the BRIQ are satisfactory (Spence, et al., 2005). The BRIQ was translated into Dutch and the back translation was approved by the original authors.

\section{Chronic Pain Coping Inventory (CPCI)}

Coping strategies were measured by the CPCI (Jensen, Turner, Romano, \& Strom, 1995). The original CPCI comprises 64 items in eight subscales. Each subscale assesses a particular strategy to cope with pain, namely guarding (9 items), resting (7 items), asking for assistance (4 items), task persistence (6 items), relaxation (7 items), exercise/stretch (I2 items), coping self-statements (II items) and seeking social support (8 items). Participants have to indicate how many days they adopted the particular coping strategy the past week on an 8-point scale ranging from 0 to 7 days. Nielson and colleagues (200I) added a pacing subscale (6 items) to the original CPCI. In the present study, only the subscales task persistence and pacing were used since these subscales reflect how participants deal with their activities in the presence of pain. Total scores are obtained by summing the scores on the items for each subscale separately. Total scores range from $\mathrm{O}$ to 42 for task persistence and pacing. Psychometric properties of the Dutch version of the CPCI with addition of the pacing scale are adequate (Karsdorp \& Vlaeyen, 2009; Nielson, et al., 200I). 


\section{Pain intensity}

Three Ioomm visual analogue scales were administered to assess pain intensity (Price et al., 1983). Participants were asked to indicate their "worst pain last week", "least intense pain last week," and "current pain intensity." The average of the scores on these three scales was used as a composite score of pain intensity. Higher scores denote higher pain intensity.

\section{Beck Depression Inventory - second edition (BDI-II)}

The Dutch version of the BDI-II (Beck, Steer, Brown, \& Van der Does, 2002) was used to measure depressive symptomatology. The BDI-II comprises $2 \mathrm{I}$ items, assessing depressive symptomatology. Scores per item range from $\mathrm{O}$ to 3 , with higher scores reflecting severer depressive states. Item scores are summed to obtain an overall total score ranging from $\mathrm{O}$ (not depressed at all) to 63 (severely depressed). The BDI-II is suitable for administration in chronic pain populations and has sound psychometric properties (Beck, et al., 1996; Harris \& D'Eon, 2008).

\section{Pain Disability Index (PDI)}

The PDI (Pollard, 1984) was used to measure disability. The PDI is a short self-report questionnaire consisting of 7 items, which measures participants' functioning within 7 domains (e.g. social activities). Participants are asked to rate to which extent the pain has an influence on each domain on an II-point Likert scale. Total scores range from $\mathrm{O}$ (not disabled) to 70 (severely disabled). Psychometric properties of the PDI are satisfactory (Tait, Chibnall, \& Krause, 1990).

\subsection{STATISTICAL ANALYSES}

Statistical analyses were carried out with Predictive Analytics SoftWare (PASW I8.o). First, missing data were inspected and in case of less then IO percent missing values at the item level of each (sub)scale, missing values were imputed by means of regression analysis techniques. In regression imputation, the missing value is estimated based on how the participant scored on the other items of that (sub)scale and how other participants scored on the respective item. In total, 8 missing values were imputed. (Sub)scales with more then ro percent missing values were omitted from analyses resulting in sample size ranges from $\mathrm{N}=127$ to $\mathrm{N}=$ 132. Normality of all variables was checked by inspecting the skewness and kurtosis, which should range between $+\mathrm{I}$ and $-\mathrm{I}$.

For informative reasons, descriptives and results from correlational analyses from the original subscales are provided since these are the subscales used by clinicians and researchers. 
To investigate possible underlying dimensions, separate joint exploratory factor analyses were run for each activity pattern (avoidance, persistence, and pacing). That is, all items across the different measurement instruments pertaining to an activity patterns were aggregated. For avoidance behaviour, these included a total of 25 items coming from the avoidance subscales of the POAM-P and the PARQ, and the items of the limiting behaviour subscale of the BRIQ. For persistence behaviour, items of the overdoing subscale of the POAM-P, the confronting subscale of the PARQ, the all-or-nothing subscale of the BRIQ, and the task peristence subscale of the CPCI were aggregated, resulting in a total of 29 items. Finally, to study pacing behaviour, the pacing items of the POAM-P, PARQ, and CPCI were aggregated, which resulted in a total of 22 items.

For each set of activity pattern items (avoidance, persistence, and pacing), the number of factors that had to be retained from the factor analyses was determined by visual inspection of the scree plot and by means of parallel analysis (O'Connor, 2000). Parallel analysis involves the generation of a random dataset with an equal number of observations and variables as the original data. Next, average eigenvalues are computed based on random correlation matrices. These random eigenvalues are compared with the eigenvalues from the factor analysis on the original data. If the eigenvalue of the factor analysis is larger than the (parallel) random eigenvalue, it can be concluded that the eigenvalue represents a real factor. If the eigenvalue from the factor analysis is smaller than the random eigenvalue, this is considered to be due to sampling error (Hayton, Allen, \& Scarpello, 2004).

Subsequently, principal components analyses with direct oblimin rotation were carried out with the predetermined number of factors to be retained based on the scree plot and parallel analysis. Delta was kept to o to prevent high correlations between factors. Items with a factor loading above .50 and that did not have cross-loadings above .40 on other factors, were retained for that factor. Internal consistency of the subscales was checked by assessing reliability coefficients (Cronbach's alphas).

Correlational analyses were carried out to examine associations between activity patterns, depressive symptomatology, and disability. Finally, regression analyses were conducted to determine the relative contribution of the activity patterns to the explanation of depressive symptomatology and disability while controlling for pain intensity. 


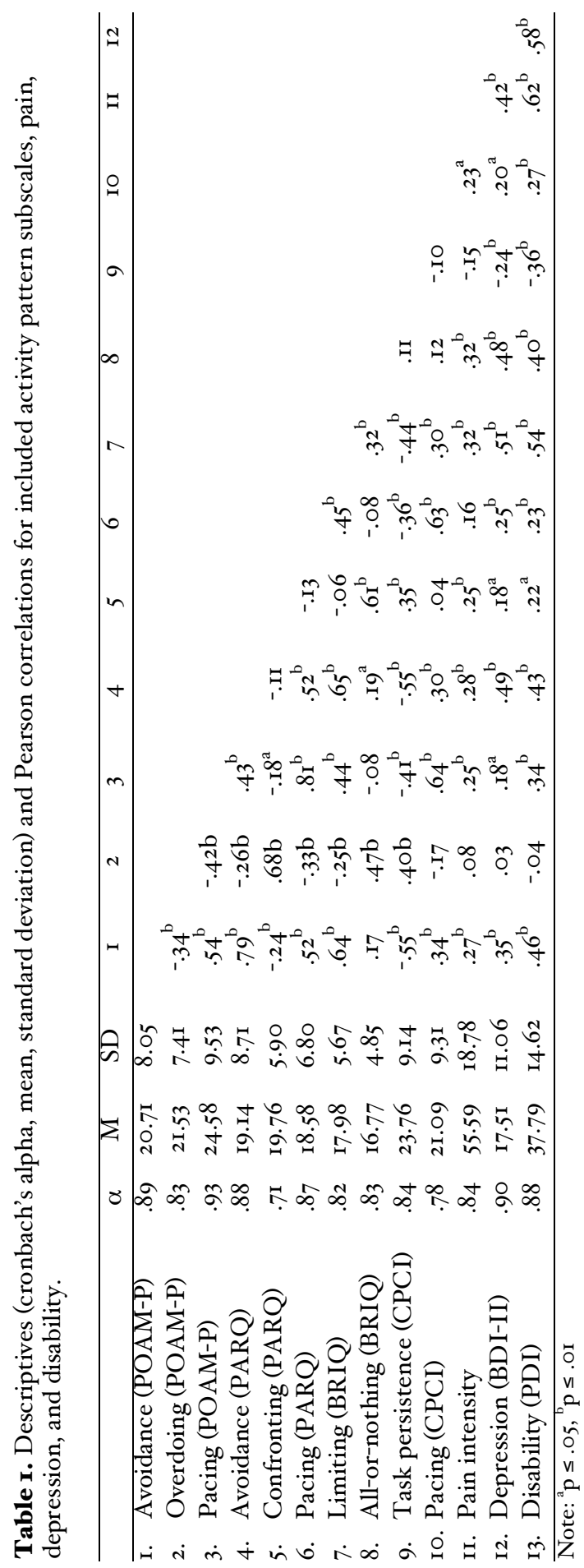




\section{Results}

Before addressing the main findings, some general comments need to be made. First, significant gender differences were found on pain duration with males reporting a longer duration of pain than females $(\mathrm{t}(\mathrm{I} 3 \mathrm{O})=2.23$, $\mathrm{p}<.05)$. Second, the total score of the BDI-II was not normally distributed as indicated by skewness and kurtosis values, which were outside the acceptable range of $-I$ and + I. The BDI-II scores were therefore square-root transformed, which was successful in 'normalizing' the BDI-II scores. Descriptives and Pearson correlations for the original activity patterns subscales, pain intensity, depressed mood, and disability are presented in Table $\mathrm{I}$.

\section{Avoidance behaviour}

First, the number of factors to be retained was determined. The eigenvalues generated by the parallel analyses (i.e. random eigenvalues) were compared with the eigenvalues generated by factor analyses. For the third factor, the random eigenvalue (I.63) was larger then the eigenvalue from the factor analyses (I.38) while for the first two factors the random eigenvalues were smaller (I.90 < I0.35; I.75 < I.95), meaning that a twofactor solution should be retained. Visual inspection of the scree plot confirmed a two-factor solution. Accordingly, a principal components analysis with direct oblimin rotation was carried out with two factors. Communalities of the items ranged between .30 and .64 and the total variance explained by the two factors was $49 \%$. The correlation between the two factors was .6o. The items with their loadings on the two factors are presented in Table 2. The items belonging to the first factor reflect avoidance behaviour in the presence or anticipation of changes in pain (e.g. worsening pain). Because of the focus on pain, this factor was labelled 'Pain avoidance'. The items of the second factor are more focussed at avoidance being a consequence of being in pain and also at the content of the avoidance behaviour itself (e.g. putting parts of life on hold). This factor was labelled 'Activity avoidance'. For further analyses, those items with factor loadings above .50 were retained for the corresponding factor. As a result, pain avoidance included $\mathrm{I} 2$ and activity avoidance 9 items. The remaining 4 items were omitted from further analyses. Cronbach's alphas of the pain and activity avoidance factors were respectively .92 and .86 , indicating high internal consistency of the factors. 


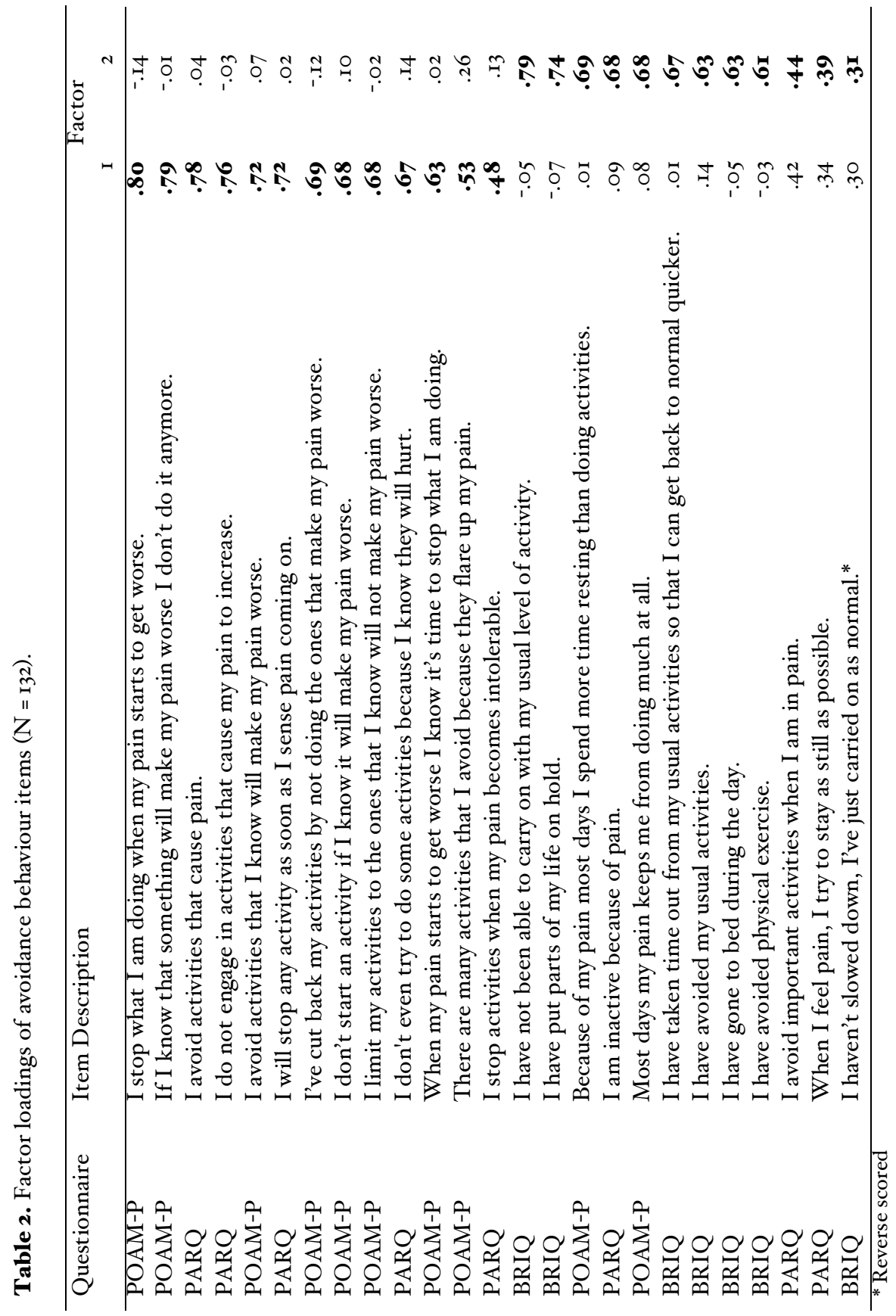




\section{Persistence behaviour}

Parallel analyses generated the following first four random eigenvalues: 2.15 , I.95, I.8I, and I.7I, while the first four eigenvalues from factor analyses were 8.09, 4.13, 2.50, and I.62. For the fourth factor, the random eigenvalue was larger than the eigenvalue from factor analyses, indicating a three-factor structure. Visual inspection of the scree plot confirmed a three-factor structure. Communalities ranged between .3I and .70 and the three factors accounted for $5 \mathrm{I} \%$ of the total variance. Correlations between the factors were .I9 (factor I and 2), .27 (factor 2 and 3), and .II (factor I and 3). The factor loadings of the items are presented in Table 3. The first factor encompassed items pertaining to behavioural persistence for purposes of finishing tasks or activities despite pain. For this reason, the first factor was labelled as 'Task-contingent persistence'. The second factor contains items in which behavioural persistence is regarded as doing too much, not respecting one's physical limits and experiencing the rebound effect of heightened activity levels. Consequently, the second factor was labelled 'Excessive persistence'. The items belonging to the third factor mostly refer to the level of experienced pain as the determinant of the performed behaviour. This factor is labelled as 'Pain' contingent persistence'. Based on the .50 cut-off for items' factor loadings, task-contingent persistence included $\mathrm{I}_{3}$, excessive persistence 7 , and pain-contingent persistence 6 items. Cronbach's alphas of the three factors were respectively $.89, .84$, and $.8 \mathrm{I}$, indicating good internal consistency.

\section{Pacing behaviour}

Parallel analyses (ro.80 > 1.82; 1.66 < 1.67) and the scree plot indicated pacing behaviour to be unidimensional. Communalities ranged between .56 and .80 and the single factor accounted for $49 \%$ of the total variance. The items and their factor loadings are presented in Table 4. Internal consistency of the factor was high (Cronbach's alpha $=.94$ ).

\section{Relationships between activity patterns, depressive symptomatology, and disability}

As presented in Table 5, correlational analyses were carried out to examine the relationship between activity patterns and depressive symptomatology and disability. Based on the results from the aforementioned analyses, six activity patterns were included, namely pain avoidance, activity avoidance, task-contingent persistence, excessive persistence, pain-contingent persistence, and pacing. 


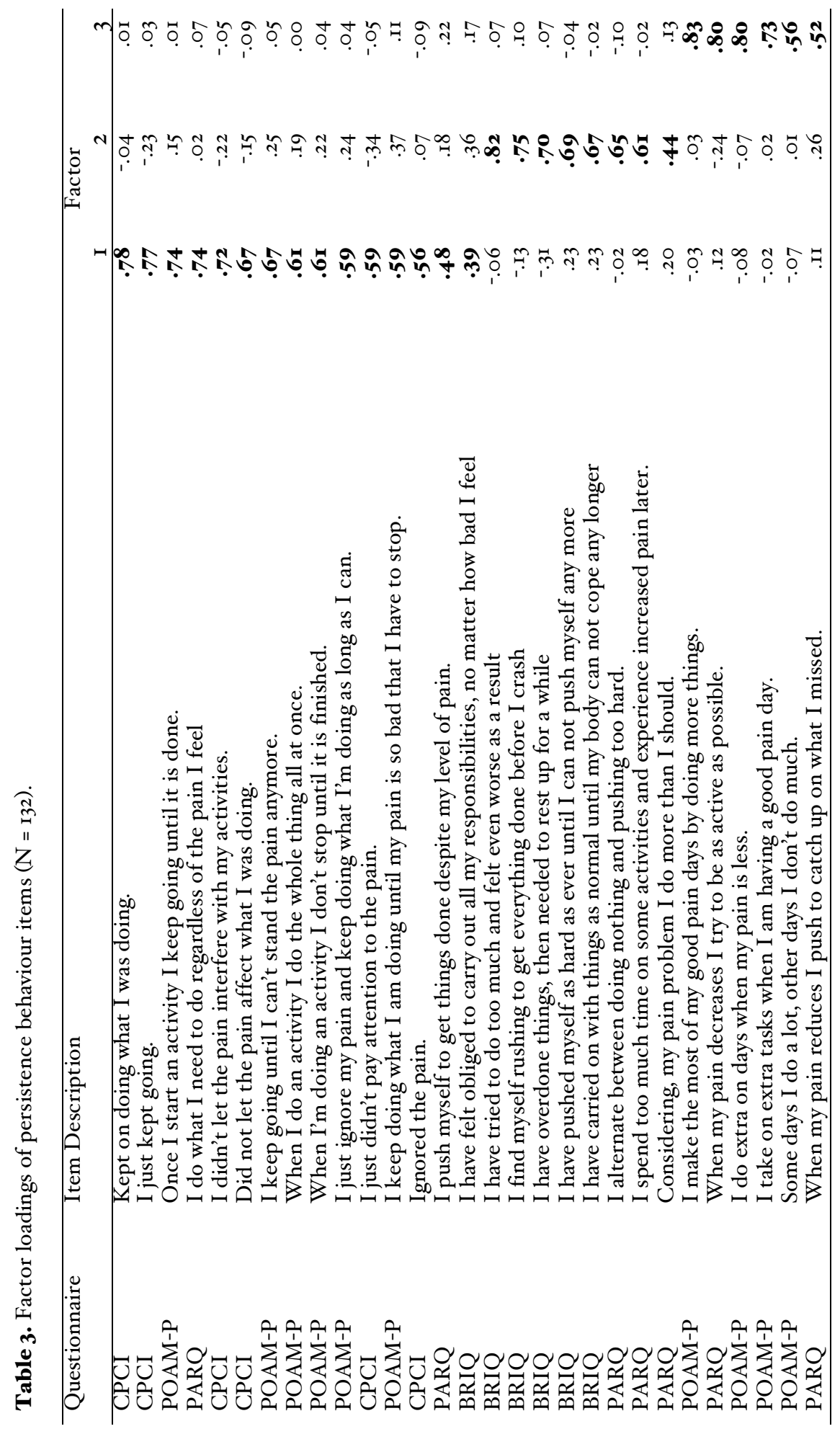


As demonstrated in Table 5 , it is noteworthy that pacing was positively related to both avoidance behaviours, yet negatively related to taskcontingent persistence. Further, activity avoidance was negatively related to task-contingent persistence but positively to excessive persistence.

Table 5. Pearson correlations between activity patterns, depressed mood, and disability.

\begin{tabular}{llrrrrrr}
\hline & $\mathrm{I}$ & 2 & 3 & 4 & 5 & 6 & 7 \\
\hline I. Pain avoidance & & & & & & & \\
2. Activity avoidance & $.63^{\mathrm{b}}$ & & & & & & \\
3. Task-contingent persistence & $-.58^{\mathrm{b}}$ & $-.46^{\mathrm{b}}$ & & & & & \\
4. Excessive persistence & .15 & $.47^{\mathrm{b}}$ & $.23^{\mathrm{a}}$ & & & & \\
5. Pain-contingent persistence & -.04 &. $\mathrm{II}$ &. $\mathrm{I} 4$ & $.30^{\mathrm{b}}$ & & & \\
6. Pacing & $.52^{\mathrm{b}}$ & $.45^{\mathrm{b}}$ & $-.49^{\mathrm{b}}$ & -.02 & .09 & & \\
7. Depression (BDI-II) & $.37^{\mathrm{b}}$ & $.56^{\mathrm{b}}$ & -.18 & $.50^{\mathrm{b}}$ & .06 & $.24^{\mathrm{a}}$ & \\
8. Disability (PDI) & $.34^{\mathrm{b}}$ & $.67^{\mathrm{b}}$ & $-.32^{\mathrm{b}}$ & $.43^{\mathrm{b}}$ & .15 & $.34^{\mathrm{b}}$ & $.58^{\mathrm{b}}$ \\
\hline Note: ${ }^{\mathrm{a}} \mathrm{p} \leq . \mathrm{OI},{ }^{\mathrm{b}} \mathrm{p} \leq . \mathrm{OOI}$ & & & & & & &
\end{tabular}

With regard to the relationship between activity patterns and depressive symptomatology, the analysis revealed that pain avoidance, activity avoidance, and pacing were positively related to depressive symptomatology. Whereas excessive persistence was also positively related to depressive symptomatology, task- and pain-contingent persistence were not. Furthermore, all activity patterns were related to disability, except for pain-contingent persistence showing no relationship with disability and task-contingent persistence which was negatively related to disability.

Finally, separate regression analyses were conducted with activity patterns predicting depressive symptomatology and disability, controlled for pain intensity (see Table 6). In both regression analyses, pain intensity and excessive persistence were significant predictors of depressive symptomatology and disability. With regard to the prediction of disability, activity avoidance and task-contingent persistence were also significant predictors. Yet, higher task-contingent persistence was, in contrast to higher excessive persistence or activity avoidance, predictive of lower levels of disability. 
Table 6. Summary of regression analyses for activity patterns predicting depressed mood and disability controlled for pain intensity.

\begin{tabular}{|c|c|c|c|c|c|c|c|c|}
\hline Dependent & & Variables & $\bar{B}$ & \multicolumn{2}{|c|}{$\mathrm{SE} \mathrm{B} \beta$} & \multicolumn{3}{|c|}{$\Delta \mathrm{R}^{2} \Delta \mathrm{F} \quad p \Delta \mathrm{F}$} \\
\hline \multirow[t]{7}{*}{ Depression (BDI-II } & & Pain intensity &. $\mathrm{OI}$ &. $\mathrm{OI}$ & $.20^{\mathrm{a}}$ & .18 & 28.32 & $p<.001$ \\
\hline & 2 & Pain avoidance & .02 &. $\mathrm{OI}$ & .12 & .26 & 9.14 & $p<$. OOI \\
\hline & & Activity avoidance & .04 & .02 & $.2 \mathrm{I}$ & & & \\
\hline & & Task-contingent persistenc & -.01 &. OI & -.06 & & & \\
\hline & & Excessive persistence & .09 & .02 & $.36^{\mathrm{b}}$ & & & \\
\hline & & Pain-contingent persistenct & -.03 & .02 & -.10 & & & \\
\hline & & Pacing & .00 &. $\mathrm{OI}$ & .03 & & & \\
\hline \multirow[t]{7}{*}{ Disability (PDI) } & I & Pain intensity & $.3 \mathrm{I}$ & .05 & $.40^{\mathrm{b}}$ & .39 & 80.08 & $p<.001$ \\
\hline & 2 & Pain avoidance &.$- \mathrm{II}$ & .12 & -.08 & $.2 \mathrm{I}$ & I0.49 & $p<.001$ \\
\hline & & Activity avoidance & .69 & .19 & $.36^{\mathrm{b}}$ & & & \\
\hline & & Task-contingent persistenc & -.19 & .09 & $-.18^{a}$ & & & \\
\hline & & Excessive persistence & .43 & $.2 \mathrm{I}$ & $.17^{\mathrm{a}}$ & & & \\
\hline & & Pain-contingent persistenct & -.02 & .18 & $-.0 I$ & & & \\
\hline & & Pacing & .02 & .05 & .03 & & & \\
\hline
\end{tabular}

Note. BDI-II $=$ Beck Depression Inventory-II, PDI $=$ Pain Disability Index, ${ }^{a} \mathrm{p}<0.05,{ }^{b} \mathrm{p}<0.00 \mathrm{I}$.

\section{Discussion}

The aim of the present study was to identify underlying dimensions of activity patterns in chronic pain and determine the contribution of these activity patterns to explained variance in disability and depressive symptomatology. Results can be summarized as follows. Two factors underlying behavioural avoidance, namely pain avoidance and activity avoidance, were identified and three persistence behaviour factors, namely task-contingent, excessive pain-contingent, and excessive persistence. Pacing emerged as a single factor. In line with the hypotheses, both pain and activity avoidance were related to higher levels of depressive symptomatology and disability. Regarding persistence behaviour, excessive persistence was positively related to depressive symptomatology and disability, yet, pain-contingent persistence was not. Remarkably, task-contingent persistence was found to be negatively related to disability and thus associated with better outcomes. In contrast to our hypotheses, pacing was related to higher levels of disability and depressive symptomatology. Further analyses demonstrated that, of all activity patterns, excessive persistence showed the strongest relationship with depressed mood. Activity avoidance, excessive persistence, and task- 
contingent showed the strongest relationships with disability. Yet, in contrast to excessive persistence and activity persistence, task-contingent was associated with better, instead of worse, outcome.

The present results suggest that avoidance behaviour comprises two underlying types of avoidance, namely pain avoidance and activity avoidance. Pain avoidance reflects avoidance or escape behaviour aimed at minimizing or preventing pain experience. While the avoidance behaviour in activity avoidance also relates to pain, in this case, pain refers to the patients' condition rather than the (fluctuating) pain experience. Also, the activity avoidance factor seems to reflect more generalized avoidance behaviour. To our knowledge, this is the first study reporting on these dimensions of avoidance behaviour. Yet, within the study of attention processes in pain, it has been demonstrated that attention to pain may also encompass two underlying dimensions. Besides the more general 'attention to pain', a second dimension with items pertaining to 'attention to changes in pain' was identified (Roelofs, Peters, McCracken, \& Vlaeyen, 2003). It might be that pain avoidance is closely related to attention to changes in pain since pain avoidance, in contrast to activity avoidance, also includes items aimed at minimizing changes (i.e. worsening) of pain. Despite the possible conceptual differences, in line with hypotheses, the pattern of results for pain- and activity avoidance was similar, in that both were related to higher levels of disability and depressive symptomatology. Yet, when controlling for the other activity patterns and pain intensity, only activity avoidance remained a statistically significant predictor of disability. Possibly, the stronger relationship between activity avoidance, compared to pain avoidance, and disability might stem from the more general avoidance of activities as described by the activity avoidance items. Overall, present results are in line with the body of research on the dysfunctional nature of avoidance behaviour in patients with chronic pain (Leeuw, et al., 2007).

With regard to persistence behaviour, three types of persistence were identified. That is, task-contingent persistence (e.g., focusing on 'getting the job done'), pain-contingent persistence (e.g., activity levels depend upon the level of pain with activity fluctuations over time as a result), and excessive persistence (e.g., focusing on exertion and the detrimental consequences). Interestingly, only excessive persistence was related to higher levels of depressive symptomatology and disability and remained significant after controlling for other activity patterns and pain intensity. Pain-contingent persistence was not related to depressive symptomatology or disability and, remarkably, task-contingent persistence was related to lower disability levels, also after controlling for other activity patterns and pain intensity. Based on these results, it seems that only excessive persistence entails persistence behaviour, as the construct was initially intended (i.e. dysfunctional persistence in activities 
despite pain). In addition, task-contingent persistence seems to reflect that type of persistence behaviour that was initially intended to be measured solely by the task persistence scale of the CPCI (Jensen, et al., 1995). The present results, indicating the existence of functional as well as dysfunctional types of persistence behaviour, highlight the importance of carefully selecting the appropriate measurement instrument for future studies. Furthermore, the fact that persistence behaviour may be multidimensional provides a sound explanation for previous findings. Considering that McCracken and Samuel (McCracken \& Samuel, 2007) and Hasenbring and colleagues (Hasenbring, et al., 2009b) may not have measured excessive persistence, a negative relationship with disability may indeed be expected.

Finally, pacing was found to be unidimensional. In contrast with hypotheses, pacing was related to higher levels of disability and depressive symptomatology. In trying to explain these findings, it is noteworthy that pacing was closely related to pain and activity avoidance, and negatively related to task-contingent persistence. This seems to suggest that pacing, as it is currently measured, might reflect a (hidden) form of avoidance behaviour. These findings are in line with previous studies, such as those reported by McCracken and Samuel (McCracken \& Samuel, 2007) demonstrating that pacing was also significantly related to avoidance and both were positively related to disability. Also, in the study from Karsdorp and Vlaeyen (2009), pacing was positively related to disability and physical impairment. Yet, Nielson and colleagues (Nielson, et al., 200I) demonstrated that pacing did predict lower levels of physical impairment. As a consequence of earlier findings (Karsdorp \& Vlaeyen, 2009; McCracken \& Samuel, 2007), pacing as adaptive behaviour and as a core element of pain management strategies has been put under critical examination. Although there are valid arguments to do so, also coming from the present study, it should be kept in mind that these critical notes on pacing largely originate from correlational studies incorporating selfreport questionnaires as also put forward by Jensen (Jensen, 2009). Moreover, whereas the measurement of pacing was initiated to study its effectiveness in pain management programs, thus far, most studies did not study it as such (Gill \& Brown, 2009; Nielson, et al., 200I). It is possible that, without controlled clinical guidance, pacing strategies are used by patients as avoidance strategies. Yet, even within a clinical context, it is not hard to imagine, that from a patient's perspective, pacing behaviour might implicate some compromises and result in the subjective experience of being more disabled. Although pacing might indeed be considered an adequate strategy to cope with the current situation being in pain, it can also be perceived by patients as limiting compared to the activity levels they had before pain-onset. A primary issue in the study of pacing and its effects is a lack of agreement on the definition of pacing (Gill \& Brown, 2009). In contrast with earlier 
writings on pacing (e.g., Gil, Ross, \& Keefe, I988), Nielson and colleagues (Nielson, et al., 200I) explicitly decided to define and operationalize pacing by the behavioural strategies patients adopt (i.e. the form) regardless of its function, namely increased activity tolerance. Yet, visual inspection of the six pacing items of the CPCI showed that one item did subtly refer to increased activity tolerance (i.e. "I was able to do more...") and one item might have been interpreted as such due to its ambiguous nature (i.e. "...I could still get a lot done..."). Further, the pacing items of the CPCI are also focused on being active independent of pain, which, in this case, refers to the function of pacing. The pacing items of the PARQ also include the notion of pain but these may be too closely related to avoidance (e.g. "I stop activities before pain becomes too great and return to them later"). The pacing items of the POAM-P do not explicitly include the function of pacing nor include references to pain (except for the instructions), but purely focus on the form of the behaviour (e.g. taking breaks, breaking tasks into parts). Thus, in line with McCracken and colleagues (McCracken \& Samuel, 2007), three elements should be considered when defining or measuring pacing: its function (increased activity tolerance), its form (the behavioural strategies), and how pain is framed. The finding of the present study that pacing was unidimensional, however, indicates that these elements do not reflect different dimensions.

In the present study, activity avoidance, task-contingent persistence, and excessive persistence showed the strongest relationships with disability or depressive symptomatology. Regarding avoidance behaviour, more research is needed to investigate whether there are indeed two dimensions underlying avoidance and, if this is the case, whether this has implications for clinical practice. It could be that the focus of exposurebased treatment programmes might be different for patients who mainly display pain-, instead of activity-, avoidance. Patients with high levels of excessive persistence, on the other hand, might benefit from cognitive behavioural treatment including response prevention strategies, a method that is often used in treatment of patients with obsessive compulsive disorder (Rowa, et al., 2007). This way, patients might shift from maladaptive persistence behaviour to adaptive, task-related, persistence behaviour. The present study failed to demonstrate the, presumably, functional character of pacing. Yet, it is questionable whether this is possible to determine, given the current operationalizations of pacing, in a context different from that of the clinical practise. Future research should determine whether present results are a consequence of the dysfunctional nature or imprecise operationalization of pacing. In general, it is encouraging that studies have started to investigate tailored treatment (including pacing strategies) based on distinctions between activity patterns characterized by avoidance versus persistence. Although 
these studies are challenging (Vlaeyen \& Morley, in press), the results are promising (van Koulil, et al., 2008; van Koulil, et al., 20IO).

It could be criticized that the relations among activity avoidance, excessive persistence, disability, and depressive symptomatology might be inflated given the apparent negative connotations of the behavioural items. For example, the excessive persistence item "I have tried to do too much and felt even worse as a result" comprises the appraisal of doing too much and its detrimental consequence. Furthermore, the activity avoidance item "I have put parts of my life at hold" might show some item-overlap with disability. Nevertheless, if these scales would be measuring the same constructs, correlation coefficients between the activity patterns and disability and depressive symptomatology would be, corrected for attenuation, unacceptable high, which was not the case.

Some limitations with regard to the present study should be kept in mind. With respect to the rather small sample size, this might result in high standard errors of the factor correlations, which may impact on the stability of the factor structure. However, the factor structure in the current study was clear and interpretable. Nevertheless, cross-validation is necessary to ensure the stability of the activity patterns. Furthermore, the present study included a non-clinical sample of participants with chronic pain. It is unclear how representative this sample is of the population of individuals in The Netherlands who have chronic pain. Therefore, cross-validation in a clinical sample is warranted to enhance generalizability. A more general limitation of the present study refers to the administration of activity patterns by self-report. Given the fact that patients may under- or overestimate their behavioural performance (e.g., Huijnen, Verbunt, Peters, Delespaul, et al., 2010), results from selfreported activity patterns, alike all results from self-report, should be interpreted with caution. Furthermore, activity patterns, as investigated in the present study, reflect habitual ways of dealing with activities. This method, however, does not take situational differences at an individual level into account. For example, someone who scores high on avoidance behaviour might show persistence behaviour on certain activities or under certain circumstances. Results of the present study should therefore be interpretated with caution, as they do not provide information at an individual level. Cluster analyses methods, such as adopted by McCracken and colleagues (McCracken \& Samuel, 2007), are more designated to study such phenomena.

In sum, the present study provided support for the existence of several important activity patterns in participants with chronic pain. Results showed that pain avoidance, activity avoidance, excessive persistence, and pacing were related to higher levels of disability and depressive symptomatology. Of these, activity avoidance and excessive persistence 
showed the strongest relations with disability and depressive symptomatology. In contrast, task-contingent persistence was related to lower levels of disability. Increased understanding of activity patterns might help to improve tailored care for patients with chronic pain.

\section{ACKNOWLEDGEMENTS}

The authors wish to thank Douglas Cane for his valuable contribution to this study and Charlene Akse for her help in collecting the data.

\section{Disclosures}

The present study was supported by the Council for Medical and Health Research of the Netherlands (Zon-MW), Grant nr. I4350042. Contribution of Johan W.S. Vlaeyen was supported by the NWO Social Sciences Research Council of The Netherlands, Grant nr. 453-04-003. Participation of Dr. Roelofs was supported by the EFIC-Grünenthal Grant (EGG). The authors report no conflicts of interest. 



\section{|| Chapter 6 ||}

The effects of ideal, ought, and feared selfguides on task performance 


$$
106
$$




\section{INTRODUCTION}

Essential to the process of self-regulation are the standards to which individuals compare themselves and in reference to which they evaluate themselves (Higgins, Strauman, \& Klein, 1986). Theories of the self often incorporate this emphasis on self-standards as an integral part of the self. Higgins (1987) described the self as consisting of three basic domains on which two standpoints exist, the 'own' standpoint and the standpoint of significant others. The three basic domains of the self are the actual self and two distinct types of self-guides: the ideal self and the ought self. The actual self corresponds to what is often referred to as the self-concept, which represents the attributes a person (or a significant other) believes they actually possess. The ideal self and the ought self function as selfevaluative standards or guides for behaviour. The ideal self is a representation of the traits or attributes a person would ideally like to possess, whereas the ought self is a representation of the traits or attributes a person believes they should possess. When combining each basic domain with each standpoint on the self, six basic self-state representations arise: actual/own, actual/other, ideal/own, ideal/other, ought/own, and ought/other. Which standpoint is most salient may differ from person to person and from situation to situation (Higgins, 1987 ).

When self-guides are perceived by the individual to be discrepant from the actual self, psychological discomfort occurs. Higgins (1987) stated that discrepancies between the actual and the ideal self are associated with dejection-related emotions (e.g. disappointment, dissatisfaction, frustration, shame, embarrassment), whereas discrepancies between the actual and the ought self are related to agitation (e.g. fear, nervousness, guilt, self-contempt). A number of correlational and experimental studies have found evidence for the hypothesised relations between the type of self-discrepancy and distinct types of emotions (Boldero \& Francis, 1999, 2000; Higgins, 1989b; Higgins, Bond, Klein, \& Strauman, I986b; Scott \& O'Hara, I993; Strauman, I989; Strauman \& Higgins, 1988). However, several studies have failed to confirm unique relations between selfdiscrepancies and agitation/dejection-related emotions (Bruch, et al., 2000; Carver, et al., I999; Gramzow, et al., 2000; Ozgul, Heubeck, Ward, \& Wilkinson, 2003; Tangney, et al., 1998). Higgins (1999b) proposed that the next set of research questions should be 'when', instead of 'whether', the predicted effects occur. A possible explanation for these contradictory findings may be found by considering a different type of self-representation: the kind of person that an individual does not want to be.

Ogilvie (1987) drew attention to the undesired self as "a neglected variable in personality research". When comparing discrepancies regarding the 
ideal self with those regarding the undesired self, Ogilvie found the latter to be a better predictor of life satisfaction (Ogilvie, I987; Ogilvie \& Clark, 1992). In addition, Carver et al. (I999) studied a related construct, the feared self. These authors observed significant associations between the feared self and dejection-related emotions as well as with agitationrelated emotions. In addition, they reported that when ideal and feared discrepancies were controlled for statistically, the association between actual:ought discrepancies and agitation weakened. Carver et al. (1999) concluded that when one is too close to her/his feared self, an avoidance motivation is elicited, which is more important than the motivation for approaching the ought self. These findings were successfully replicated by Heppen and Ogilvie (2003), using a different measure of selfdiscrepancies.

Building on the aforementioned findings, Carver (200I; 2006) suggested two bipolar dimensions of affective experience which are dependent of the rate of progress in approach or avoidance. In an approach process, the feeling that one is making progress elicits feelings of elation and eagerness whereas the feeling that one is not making progress elicits sadness and depression. In an avoidance process, making progress elicits relief and calmness whereas not making progress causes fear and anxiety. Thus, Carver and Scheier's control theory offered an alternative perspective on the relations between perceived self-discrepancy and the emotional states that result. That is, whereas in self-discrepancy theory the type of self-guide determines the emotions that result from selfevaluation, in control theory the valence of the emotion is a function of rate of discrepancy reduction relative to an expected rate. Carver (200I) also suggested that the reason that sadness often relates strongly to anxiety might be the co-occurrence of threat and failure.

Thus, one important difference between self-discrepancy theory and control theory involves the interpretation of the reference value used in self-evaluation. In self-discrepancy theory, the reference value is a standard to which the self is compared. This standard reflects the attributes one wants or ought to possess in the present and thus a discrepancy between the actual and the ideal or the ought self will cause negative emotions (Boldero \& Francis, 2002). In control theory, reference values are goals, which can be accomplished in the future. One can compare the actual self to this goal but this does not necessarily cause negative emotions; instead, the experience of self-discrepancy may even coexist with positive emotions.

An important aspect of self-discrepancy theory is that individuals are motivated to reduce self-discrepancies. The ideal and the ought self represent distinct categories of desired end-states, but differ with regard to the strategies people employ to reach that end-state. More specifically, 
which type of discrepancy-reducing strategy is used depends upon the type of self-guide (Higgins, 1996, 1997a). These ideas are captured in regulatory focus theory (Higgins, 1996, 1997a). According to RFT, two regulatory systems can be distinguished: the promotion system, pertaining to accomplishments, hopes and aspirations and thus associated with the ideal self, and the prevention system, aimed at safety, duties, and obligations, associated with the ought self. In a promotion state, the individual is focused on the presence or absence of positive outcomes and adopts the strategy of "making good things happen" by seeking to match her/his actual behaviour with an ideal guide. In contrast, a prevention state involves a focus on the presence or absence of negative outcomes and adopting a strategy of "keeping bad things from happening" by seeking to avoid a mismatch between actual behaviour and an ought guide. Furthermore, promotion is characterized by eagerness to attain advancement and gains, while prevention is characterized by a vigilance to assure safety and non-losses.

From a control theory perspective, Carver and colleagues (2001; 1998) made a distinction between the approach system, in which the aim is to approach desired outcomes, and an avoidance system, in which the aim is to avoid undesired outcomes (by avoidance, escape, or withdrawal). Control theory thereby places a greater emphasis on the attributes that one does not want to possess. These attributes are represented within the feared self, which is related to but distinct from the ought self. According to RFT, both promotion and prevention are focused on positive endstates, with the primary differences being the strategies used to attain that end-state and the affect associated with goal pursuit. Carver and colleagues (200I; 1998) also suggested that the ought self has a dualmotive quality. That is, the ought self represents the attributes one believes one ought to possess, and such attributes may be associated at times with a fear of becoming the kind of person that one is not supposed to be. From a developmental perspective, it has been suggested that the ought self may be derived in part from experiences of punishment during childhood (Carver et al., I999), and a prospective longitudinal study indicated that maternal punishment behaviours at age 3 predicted strength of orientation to ought guides at age 6 (Manian, Papadakis, Strauman, \& Essex, 2006).

So, one might conclude that whereas both the ideal and the ought self are associated with discrepancy reduction in pursuit of a positive end-state, the feared self is associated with discrepancy enlargement in order to avoid a negative end-state. While both the ought and the feared self might be driven by fear, the ought self gives a direction for the individual in terms of what to approach in order to fulfill responsibilities and attain safety. The feared self only gives meaning to what must be avoided. That is, both the promotion and prevention systems (and by inference, the 
ideal and ought selves) involve discrepancy-reducing feedback loops, whereas the feared self involves discrepancy-enlarging feedback loops. Approaching the ideal involves promotion strategies, whereas approaching the ought involves prevention strategies; in addition, avoidance of the feared self involves prevention strategies.

These distinctions are potentially important for understanding the basic motivational processes that underlie self-regulation. As noted, selfdiscrepancy theory and control theory differ with regard to nature of the reference value involved in self-regulation. Consequently, the two theories offer distinct perspectives on what motivates individuals to evaluate themselves, and ultimately, what motivates them to reduce perceived self-discrepancies. Within self-discrepancy theory, standards are the reference values, and possessing an actual self that is too far from the ideal and ought selves causes distress. In turn, this distress is what motivates the individual to reduce the discrepancies. Within control theory, self-discrepancies do not necessarily cause negative emotions and thus do not motivate discrepancy-reduction. Rather, the discrepancy itself instigates approach (or avoidance) behaviour (Boldero \& Francis, 2002).

Surprisingly, in contrast to the numerous studies on the emotional consequences of self-discrepancies, fewer studies have examined the selfregulatory consequences of perceived self-discrepancy. However, there have been some studies conducted on the differential effects of promotion versus prevention orientation on task performance. It was demonstrated that promotion-oriented individuals tend to persist more on an anagrams task (operationalized as time spent on an unsolvable anagram or number of responses on a solvable anagram following an unsolvable) in which they experience difficulties, compared to prevention-oriented individuals, who tend to disengage from the task so that they will make no more errors (Crowe \& Higgins, 1997; Roney, Higgins, \& Shah, 1995). Yet, in the case that explicit feedback is given, preventers in contrast to promoters will perform better after failure feedback. Promoters, on the other hand, perform better after success feedback (Forster, Grant, Idson, \& Higgins, 200I; Idson \& Higgins, 2000). To our knowledge, there are no studies in which the selfregulatory consequences of a feared self congruency have been investigated alongside ideal and ought self-discrepancies. In general, it is known that anti-goals are not adaptive because they draw the individual away from certain experiences and toward safety, rather than toward positive goals (Mansell, 2005).

The present study replicates and extends the study by Crowe and Higgins (1997) to test the effect of self-guide priming on task performance. In addition to priming the ideal and ought self, a feared self priming 
condition also is included. The aim of the present study is to take a first step in investigating the relationship between the feared self and individual differences in promotion and prevention regulatory focus. In line with Crowe and Higgins (1997), we hypothesize that participants who are primed with their ideal self will persist on a goal-directed task longer then participants who are primed with their ought self. Furthermore, we expect ideal and ought primed participants to persist longer compared to those primed with a feared self.

\section{METHOD}

\section{I PARTICIPANTS AND DESIGN}

Ninety-six Maastricht University undergraduates participated in the study. One participant misunderstood the anagrams task and as a result that subject's data were not included in the analyses, leaving a total of 95 participants ( 8 male, 87 female). Age ranged from i8 to 27 years $(M=$ 2I.OI, $\mathrm{SD}=2.04$ ). A between-subjects design with three conditions (Ideal Self vs. Ought Self vs. Feared Self priming) was employed. The Ideal and Ought conditions both included 32 participants and the Feared condition included 3I participants.

\subsection{MATERIALS}

\section{Verbal Fluency}

The FAS verbal fluency test (Borkowski, Benton, \& Spreen, 1967) was administered to allow us to control for verbal fluency when analyzing the data from the anagrams task. In the FAS test, participants are asked to name as many words as possible that start with a given letter (F, A, S). For each letter, participants are given one minute. The responses were recorded with a Dictaphone to enhance scoring. For each correct word, which started with the given letter and named within the given minute, participants scored one point.

\section{Chronic Self-Discrepancies}

Our primary interest in the study was the effect of situational induced self-regulatory focus. As a consequence, we wanted to control for participants' chronic self-discrepancies. Self-discrepancies were measured by asking participants to list four characteristics they ideally wanted to possess (ideal), believed they should or ought to possess (ought), or feared to possess (feared). Next, participants were asked to indicate on a scale from 0 to 4 to what extent they wanted to possess, should possess, or 
feared to possess the characteristic and to what extent they actually possessed the characteristic. Self-discrepancy scores were operationalized as the difference between their first rating (extent) and their second rating (actual). Higher scores on the ideal or ought self-discrepancy measure denote greater chronic self-discrepancy, whereas higher scores on the feared self-discrepancy measure denote lower chronic selfdiscrepancy (i.e., greater distance between the participant's actual characteristics and the type of person they fear being).

\section{Regulatory Focus Priming}

In line with Higgins, Roney, Crowe and Hymes (1994), regulatory focus was primed by asking participants to write a short essay. Participants were given 5 minutes to write the essay. In the Ideal condition the instructions were:

Describe how your hopes and aspirations are different now from what they were when you were growing up. In other words, what accomplishments would you ideally like to meet at this point in your life? What accomplishments did you ideally want to meet when you were a child?

In the Ought condition, "hopes and aspirations" were replaced with "duties and obligations", "accomplishments" with "responsibilities", and "ideally" was replaced with "ought". The instructions for the Feared condition were based upon the work of Carver and colleagues (1999) and Oyserman and Markus (1990). The instructions were as follows:

Describe how your worries and fears are different now from what they were when you were growing up. In other words, which failures would you think you have to avoid at this point in your life? What failures did you fear to meet when you were a child?

\section{Anagrams Task}

To measure task persistence, participants were asked to complete an anagrams task, which was similar to the anagrams task used in the Crowe and Higgins (1997) study. The first three anagrams had three solutions, the fourth anagram was unsolvable, and the fifth anagram had five solutions. There were no time restrictions and participants were informed that each anagram could have multiple solutions or no solution. The number of responses as well as the time participants spend on each anagram was recorded. Prior to the start of the anagrams task, 
participants received two practice anagrams. In the present study, the anagrams task included multiple blocks of five anagrams. After each block of five anagrams, a message appeared on the screen, informing participants that they could choose to take another set of five anagrams and that the score on their last block would count. There were ten blocks of five anagrams. The set-up of the anagrams was equal in all blocks. Thus, in addition to the number of responses and the time spend on the anagrams, a third measure of task persistence was included, namely the number of blocks completed.

\subsection{Procedure}

Participants were recruited through advertisements and were told they would be participating in a study of "verbal intelligence and personality". They were invited to the lab and after obtaining informed consent, the verbal fluency test was administered and participants were asked to complete the self-discrepancy measure on a computer. Next, participants received the Regulatory Focus Priming task. They were randomly assigned to one of the three priming conditions (Ideal vs. Ought vs. Feared). The anagrams task followed immediately after the priming. At the end of the experiment, participants were debriefed and received course credit or were paid for their participation.

\subsection{DATA ANALYSES}

There were three classes of dependent variables: the number of blocks participants completed, the time they spend on each anagram, and the number of responses on each anagram. Verbal fluency and ideal, ought, and feared self-discrepancy measures were entered as covariates in all analyses. First, overall task persistence effects were tested. Analysis of covariance (ANCOVA) was used to test differences among the priming conditions on the number of blocks participants completed. Also, two separate repeated measures ANCOVAs were conducted to test for differences between the priming conditions on the time spent on the first five anagrams and the number of responses on the first four solvable anagrams. Thus, repeated measures ANCOVAs were restricted to the first block of anagrams. Second, task persistence related to the failure experience on the unsolvable anagram was analyzed. Two separate ANCOVAs were conducted to test for differences between the priming conditions on time spent on the unsolvable anagram (anagram 4) and on the number of responses on the anagram following the unsolvable anagram (anagram 5). 


\section{Results}

Prior to analyses, data were examined with reference to assumptions of normality. The number of blocks and time variables were positively skewed and therefore log transformed to obtain skewness and kurtosis values between the range of $-\mathrm{I}$ and $+\mathrm{I}$. Verbal fluency and self-discrepancy measures (ideal, ought, and feared) were standardized prior to being included as covariates in all analyses. Due to technical issues, two participants had missing data on the three self-discrepancy measures. These were imputed with the mean of the observed values for each variable.

There were no differences among the priming conditions on the verbal fluency or self-discrepancy measures. Also, there were no differences among the priming conditions on the number of words written in the priming essay.

\section{Overall Task Persistence}

Means and standard deviations of the three classes of (untransformed) dependent variables per priming condition are presented in Table $\mathrm{I}$. There were no significant differences among the priming conditions on the number of blocks participants completed $(\mathrm{F}(2,88)<\mathrm{I}$, ns). However, there was a significant association between magnitude of ought selfdiscrepancy and number of blocks completed (F (I, 88) $=6.2 \mathrm{I}, \mathrm{p}<.05, \eta \mathrm{p} 2$ $=.06, \beta=. \mathrm{I} 7$ ). The interaction between priming condition and ought selfdiscrepancy was not significant, indicating homogeneity of regression slopes between ought self-discrepancy and the number of blocks within each priming condition. Repeated measures ANCOVA revealed no significant differences among priming conditions on the time spent on the first five anagrams $(\mathrm{F}(2,88)<\mathrm{I}$, ns). In this analysis, both verbal fluency $(\mathrm{F}(\mathrm{I}, 88)=6.7 \mathrm{I}, \mathrm{p}<.05, \eta \mathrm{p} 2=.07)$ and ideal self-discrepancy $(\mathrm{F}(\mathrm{I}$, $88)=4.14, \mathrm{p}<.05, \eta \mathrm{p} 2=.05)$ were significant predictors. More specifically, lower levels of verbal fluency and greater discrepancies between actual and ideal self were associated with spending more time over the first five anagrams. There were no significant interactions between priming condition and covariates. Repeated measures ANCOVA on the number of responses to the solvable anagrams in the first block also revealed no significant differences among priming conditions $(\mathrm{F}(2,88)=2.4 \mathrm{I}, \mathrm{p}=. \mathrm{IO})$. Verbal fluency again was a significant predictor $(\mathrm{F}(\mathrm{I}, 88)=4.35, \mathrm{p}<.05, \eta \mathrm{p} 2=.05)$ in that higher levels of verbal fluency were associated with more responses; fluency did not significantly interact with priming condition. 


\section{Failure-Related Task Persistence}

ANOVAs did not reveal significant differences between the priming conditions on the time spent on the unsolvable anagram of the first block $(\mathrm{F}(2,88)<\mathrm{I}$, ns) or the number of responses on the fifth and final anagram in the first block $(F(2,88)=1.68, \mathrm{p}=. \mathrm{I} 9)$. There was a significant effect of ought self-discrepancy $(\mathrm{F}(\mathrm{I}, 88)=4.02, \mathrm{p}<.05, \eta \mathrm{p} 2=.04, \beta=-$ $. \mathrm{I} 7)$ and feared self-discrepancy $(\mathrm{F}(\mathrm{I}, 88)=7.4 \mathrm{I}, \mathrm{p}<.05, \eta \mathrm{p} 2=.08, \beta=.20)$ on the time spent on the unsolvable anagram. No significant interactions were observed.

Table I. Means and standard deviations for dependent variables per condition.

\begin{tabular}{|c|c|c|c|c|}
\hline & & $\begin{array}{c}\text { Ideal } \\
\text { condition }\end{array}$ & $\begin{array}{c}\text { Ought } \\
\text { condition }\end{array}$ & $\begin{array}{c}\text { Feared } \\
\text { condition }\end{array}$ \\
\hline Number of blocks & & $2.50(\mathrm{I} .32)$ & $2.50(\mathrm{I} .48)$ & $2.13(.92)$ \\
\hline \multirow[t]{5}{*}{ Time } & Anagram I & $9.73(.54)$ & $9.76(.40)$ & $9.72(.42)$ \\
\hline & Anagram 2 & $9.6 \mathrm{I}(.42)$ & $9.7 \mathrm{I}(.48)$ & $9.53(.46)$ \\
\hline & Anagram 3 & $10.07(.54)$ & IO.I8 (.6I) & IO.I4 (.59) \\
\hline & Anagram 4 & I0.30 (.62) & $10.47(.63)$ & I0.37 (.75) \\
\hline & Anagram 5 & $9.97(.65)$ & I0.13 (.59) & $10.09(.67)$ \\
\hline \multirow[t]{5}{*}{ Number of responses } & Anagram I & $2.47(.72)$ & $2.34(.65)$ & $2.61(.92)$ \\
\hline & Anagram 2 & $2.13(.79)$ & $2.59(.67)$ & $2.39(.62)$ \\
\hline & Anagram 3 & $.69(.69)$ & $.75(.67)$ & $.90(.87)$ \\
\hline & Anagram 4 & $.09(.30)$ & .25 (I.O8) &. $\mathrm{IO}(.30)$ \\
\hline & Anagram 5 & I.69 (I.00) & $\mathrm{I} .84(\mathrm{I} .22)$ & $2.16(.86)$ \\
\hline
\end{tabular}

\section{Discussion}

The aim of the present study was to test the differential effects of situationally induced self-regulatory focus on task performance. Novel to the present investigation was the study of the effects of feared self priming, in addition to ideal and ought self-guides. The present study failed to demonstrate significant differences among the priming conditions on anagram task performance. Noticeably, verbal fluency and chronic self-discrepancies were significantly associated with task performance. The more verbally fluent participants were, the less time they spend on the anagrams and the more solutions they provided to the anagrams. Regarding the results for chronic self-discrepancies, a less consistent picture emerged. Greater chronic actual:ideal discrepancies were associated with spending more time over the first five anagrams. 
Greater chronic actual:ought discrepancies were associated with completing more blocks and spending less time on the unsolvable anagram. Also, feeling closer to the feared self was associated with spending less time on the unsolvable anagram. Taken together, these results might reflect chronic differences in eagerness-based strategies, in case of the actual:ideal self-discrepancies, versus vigilant strategies, in case of actual:ought and feared self-discrepancies. The fact that actual:ought discrepancies were associated with completing more blocks might seem a less vigilant strategy. Yet, participants were led to believe that the experiment was about verbal intelligence and had been informed that in the anagrams task, their score on the last block they completed would count. Considered this way, completing more blocks might not have felt as a risk but rather as an opportunity to avoid loss. Nevertheless, these results were unexpected given the fact that participants were primed in order to induce a situational regulatory focus, independent of their chronic regulatory focus. Possible reasons for the lack of the hypothesized effects will be discussed below.

First and foremost, a plausible reason for the lack of significant differences among the priming conditions might be that the effects of assessing chronic self-discrepancies on anagram task performance reflected an unintended priming effect. In the present study, the measurement of the self-discrepancies and the self-guide priming took place in a single session, starting with the self-discrepancy measurement. Yet, in line with other studies (Idson \& Higgins, 2000), it might have been better to assess the self-discrepancy measure at least I week prior to the experimental session. As such, the self-discrepancy assessment may have had the unintended effect of priming self-regulatory cognition, which in turn may have interfered with the situational regulatory focus priming and complicated the interpretation of our findings.

In the present study, regulatory focus was manipulated by asking participants to write about their past (ideal, ought, or feared) goals and how these have changed over time into their current goals. While the inclusion of feared goals was novel in the present study, the method, involving ideal and ought goals, has been used in several other studies and has been an effective means of inducing promotion or prevention states respectively (Freitas \& Higgins, 2002; Freitas, Liberman, \& Higgins, 2002; Higgins, et al., 1994). There are also other, comparable, methods that have been successfully employed to induce regulatory focus. In one method, participants are asked to simply describe their current ideal or ought goals (Freitas \& Higgins, 2002). Another method is to ask participants about past regulatory successes from either a promotion focus or prevention focus (Higgins, et al., 200I). There are, however, no reasons to assume that these alternative methods are fundamentally superior to the method used in the present study. All three methods are 
comparable to the extent that they involve a manipulation of regulatory focus by priming ideal and oughts independent of subsequent tasks within the experiment.

In contrast, other studies have used task-specific framing techniques to induce regulatory focus (Higgins \& Spiegel, 2004; Shah \& Higgins, I997; Shah, Higgins, \& Friedman, 1998). In these methods, the instructions of the experimental task are framed according to the desired priming condition (promotion or prevention). It is possible that task-specific framing techniques are preferable to task-independent methods of inducing regulatory focus. In the present study and the study of Crowe and Higgins (1997), the aim was to test the effects of regulatory focus on a specific task. Whereas Crowe and Higgins (1997), who did find effects from regulatory focus, used a task-specific framing technique, in the present study a task-independent priming method was used. It would be interesting to study the effects of regulatory focus on task persistence by using framing techniques. This, however, poses some theoretical as well as methodological challenges. While there is evidence that priming with ideal or ought goals induces a promotion versus prevention state respectively, feared selves have not yet been directly associated with regulatory focus. It might be anticipated that self-regulation based on the feared self, similar to the ought self, involves a focus on the presence or absence of negative outcomes. Yet, in contrast to the ought self, regulation based on the feared self would be associated with a strategy to avoid a match between the actual self and a feared attribute, instead of to avoid a mismatch between the actual self and an ought guide. Thus, both the ought and the feared self involve an avoidance strategy but the ought self is associated with approach-oriented prevention and the feared self with avoidance-oriented prevention.

In retrospect, another possible reason for the lack of hypothesized effects might be related to the nature of the task. In line with Crowe and Higgins (1997), participants were presented a task in which they experienced difficulty or failure (stemming from the unsolvable anagram). Whereas it could be hypothesized that a prevention focus will lead to a vigilant strategy and thus a worse performance (generating fewer responses to protect against making errors) compared to a promotion focus, a prevention focus might also be associated with greater persistence under these circumstances. More specifically, to those in a prevention focus, tasks might be experienced as a necessity or obligation (Higgins, 1997a). In this case, those in a prevention focus might persevere on the unsolvable anagram if the goal of the task is highly valued. Furthermore, it has also been shown that whereas promotion-oriented individuals perform better after success feedback, prevention-oriented individuals do so after failure feedback (Forster, et al., 200I; Idson \& Higgins, 2000). Since no explicit feedback was provided in the present 
experiment, the effects of the failure on the unsolvable anagram might have operated in a similar way. The finding that chronic actual:ought discrepancies were associated with completing more blocks is in line with the aforementioned hypotheses. This pattern was not observed for chronic actual:feared discrepancies, perhaps indicating differences in regulatory consequences stemming from priming of ought vs. feared selfguides. In consideration of these alternative hypotheses, the current findings might be a consequence of the equivocal nature of the task. More specifically, differential effects might be expected dependent of the subjective interpretation of the unsolvable anagram as failure (signalling the individual to do better) or difficult (signalling the individual to be more careful). While Crowe and Higgins (I997) used a similar anagrams task and found results in line with hypotheses based on the interpretation of the unsolvable anagram as being difficult, it might be better for future studies to select a univocal task and leaving no room for interpretation. In summary, the present study was aimed at testing the differential effects of situationally induced ideal, ought, and feared discrepancies on task performance. However, no differences were found among priming conditions. Of interest was, however, that chronic actual:ideal discrepancies were associated with an eagerness-based strategy, while chronic actual:ought discrepancies and actual:feared congruencies were associated with vigilance-based strategies. Follow-up studies are necessary to thoroughly investigate differential effects of promotion versus prevention on task performance and, importantly, possible differential effects from prevention of a mismatch with the ought self versus prevention of a match with the feared self. 
|| Chapter 7 ||

General discussion 
The present thesis sought to shed light on psychological processes related to the self to increase understanding of the detrimental effects of chronic pain, as reflected in negative emotional well-being, disability, and diminished quality of life. Central to the present thesis was the investigation of the hypothesized model as depicted in Figure I. Discrepancies between the actual self (the person you are now) and three important self-guides were studied. Namely, the ideal self (the person you ideally would like to be), the ought self (the person you feel you ought to be), and the feared self (the person you are afraid of being), all from two perspectives (own and other). Three different activity patterns were investigated, namely avoidance, persistence and pacing behaviour. In addition, the relationship between self-discrepancies and emotional wellbeing was expected to be moderated by the degree of flexibility in adjusting goals. Furthermore, ideal and ought self-discrepancies were expected to be associated with persistence and feared self-discrepancies with avoidance behaviour. Both avoidance and persistence behaviour were hypothesized to be associated with heightened levels of disability and diminished quality of life, in contrast to pacing (which is not depicted in the model).

Several studies were conducted to substantiate (parts of) the model. In this final chapter, results will be discussed and integrated in the light of previous work and the hypotheses outlined in the introduction. Also, future directions, limitations, and clinical implications will be considered.

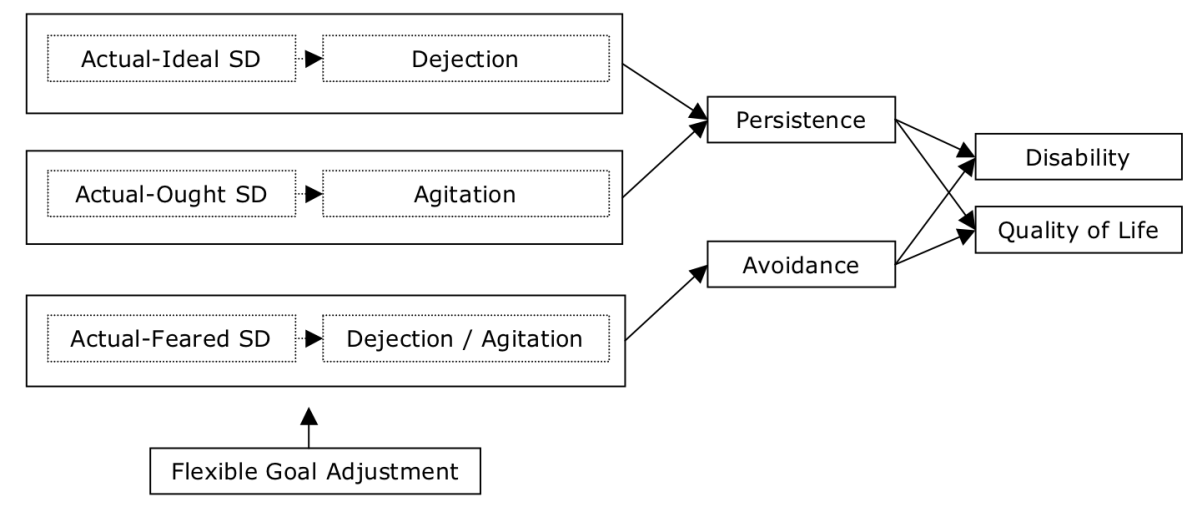

Figure r. A self-discrepancy model for chronic pain

\section{SELF-DISCREPANCIES}

The content of the self-guides (ideal, ought, and feared) as well as the level of discrepancy between the actual self and the self-guides were 
investigated in order to disentangle their influence on disability and distress in the context of chronic pain. An integration and discussion of the results is provided below. To the benefit of future research, an important question pertaining to the study of self-discrepancies in patients with chronic pain is: "how specific do we need to be?" This question is considered with regard to the content, the hypotheses on associations with negative mood, and the closely related concept of selfpain-enmeshment.

\section{I.I THE CONTENT OF SELF-DISCREPANCIES}

Given the limited knowledge of the content of desired or undesired selves of patients with chronic pain (Morley \& Eccleston, 2004), a content analysis was performed on ideal, ought, and feared self-guides of patients with chronic low back pain (Chapter 2). The majority of attributes patients ideally wanted, felt they ought or feared to posses could be categorized under interpersonal attributes (e.g. friendly) and, secondary to that, under well-being related attributes (e.g. healthy). We found that as patients reported a higher level of well-being related attributes as part of their ought self, they also felt more disabled (Chapter 2). As this was a correlation study, no causal inferences were made. Those who strongly feel they need to be for example healthy might feel more disabled due to the comparison with this high standard. On the other hand, the self-regulatory system of patients who feel very disabled is likely to be highly involved with being healthy. Future studies including an experimental manipulation of self-guides might shed more light on the causality of this relationship.

In the present thesis, only the frame of the attributes (ideal, ought, feared) has been considered as a predictor of activity patterns. The content of these selves may however also be a useful source of information with regard to predicting activity patterns since these give direct input to the self-regulatory behaviours. Considered this way, the relationship between the content of the self, in addition to the degree of experienced discrepancy between selves, and detrimental outcomes such as disability, might be mediated by activity patterns. Possibly, two general domains may be important to patients with chronic pain. The first domain might include those self-guides that relate to self-integrity and a second domain might include self-guides involved with preservance of physical integrity. It would be interesting to see which domains are most prevalent across self-guides in patients with chronic pain and to investigate how these might influence lower order goals and pain behaviours. For example, some patients might have high ideals on physical integrity ("being pain-free") and as a consequence might persist in searching for solutions for their pain. This is however different from 
the measurement of pain-specific or activity-related self-discrepancies which can be criticized for not assessing discrepancies between selves (Vangronsveld, et al., 20Io). Yet, these ideas can also be applied to the study of goals in patients with chronic pain (Karsdorp, Nijst, Goossens, \& Vlaeyen, 20IO; Karsdorp \& Vlaeyen, 2OII). Moreover, it is possible that goals at a less abstract level than the level of self-guides, comprise a more pronounciated and thus more relevant content relevant to behaviour (Grant \& Gelety, 2009).

\section{I.2 SELF-DISCREPANCIES AND NEGATIVE EMOTIONS}

In the field of chronic pain, Waters and colleagues (2004) were the first to study self-discrepancies. In line with Higgins (1987), their study showed that actual:ideal self-discrepancies were related to depressed mood in patients with chronic low back pain. Psychological distress appeared to be related to both ideal and ought-other self-discrepancies. In the present thesis, the relationship between self-discrepancies and negative emotions was investigated in two studies involving patients with Work Related Upper Extremity pain (Chapter 3) and chronic low back pain (Chapter 4 ). The study described in chapter 4 of the present thesis, did not demonstrate significant associations between ideal (own nor other) or ought-other self-discrepancies and negative mood, but showed that ought-own self-discrepancies were related to depressed mood, and not anxious mood. Yet, after controlling for socio-demographic and painrelated variables this association was no longer significant. In chapter 3 , ideal self-discrepancies were not assessed but ought self-discrepancies were, and the results demonstrated that ought-other self-discrepancies were related to depressed and anxious mood and ought own to anxious mood. It is noteworthy though, that in chapter 4 , in the zero-order correlations, the ideal own was related to depressed and anxious mood and the ought-own also to anxious mood at $\mathrm{p}<0.05$. Yet, alpha was set to . OI to prevent type I errors due to multiple testing. This might indicate that seemingly mixed results may, at least in part, be a consequence of different statistical approaches. Another possible reason for differential findings might be due to the differences in measurement instruments to assess self-discrepancies and emotional well-being. Nevertheless, the results from the studies in both chapters did not confirm the unique relationships between self-discrepancies and negative mood as described in the self-discrepancy theory. Interestingly, Morley and colleagues (2005) studied hoped-for selves in patients with chronic pain. They found that especially the conditional hoped-for selves, which are the hoped-for selves that according to the patient could only be achieved in absence of pain, were important in the light of depressed mood. 
When Higgins (1987) introduced the Self-discrepancy theory, it was presented as a theory relating the self with affect. A crucial element of the original theory is that specific self-discrepancies, namely ideal and ought, lead to specific negative emotions, respectively dejection and agitation. Over the years, these specific relations have extensively been studied. Most of the studies were conducted in healthy participants and demonstrated mixed results. Some found support for the hypothesized relations while others found relationships with agitation and dejection but these were not unique, and others did not find relations with negative emotions (for a review see Phillips \& Silvia, 20ıo). In the field of social and personality psychology, these mixed results have led to an increased focus on possible subgroups. For example, the level of self-monitoring has shown to moderate the relationship between self-discrepancies and experienced distress. More specifically, associations between selfdiscrepancies and emotions are stronger for individuals high in self monitoring or self-awareness and for these individuals, self-discrepancies from the perspective from the important other are more salient (Gonnerman, Parker, Lavine, \& Huff, 2000; Phillips \& Silvia, 2005). In the light of the current thesis, the answer to the question "how specific do we need to be?" with regard to relationships between ideal and ought self-discrepancies and negative mood probably may depend on the context. For the studies described above, which included chronic pain samples, the fact that self-discrepancies were related to negative mood transcends the question whether they were related to specific negative emotions. Of importance is that both the ideal and the ought were associated with emotional well-being.

With regard to the feared self, no specificity was hypothesized. Both studies, described in chapter 3 and 4 demonstrated that feeling close to the feared self was associated with higher levels of depressed and anxious mood, with the exception of a lack of significant association between the feared-other and anxious mood in patients with work-related upper extremity pain. These findings are in line with Carver and colleagues (I999) and lend support to previous studies showing that closeness to undesired selves might be a better predictor of emotional well-being than distance from desired selves (Ogilvie, 1987). Yet, feared-for selves (discrepancies and conditional) as studied by Morley and colleagues (2005) and Sutherland and Morley (2008) did not show significant associations with negative mood. These feared-for selves stem from the possible selves theory and reflect future feared-for selves (Markus \& Nurius, 1986). This temporal focus is the main difference between possible selves and self-discrepancies. The feared self as studied in the present thesis also represents the person you are afraid of becoming (future-oriented) but also includes the person you would not like to be now. Possibly, future feared-for selves have less effect on current mood compared to present feared-for selves. 
Based on the aforementioned results increased specificity with regard to types of self-discrepancies is warranted. Differentiation between ideal, ought and feared selves, and also between perspectives (own and other), seems justified, not only given the differences in content between selfdiscrepancies, but also given the distinct associations with negative emotions and behavioural consequences.

\section{I.3 FEELING ENMESHED VERSUS FEELING DISCREPANT}

In the present thesis, self-discrepancies were studied independently of the extent to which participants felt the attainment (or avoidance) of their desired (or undesired) self-guides was affected by their pain. Some studies looking into the self in pain have focused on specific effects of pain on the self by studying role loss due to pain or enmeshment (Harris, et al., 2003; Morley, et al., 2005; Sutherland \& Morley, 2008; Vangronsveld, et al., 2010). Self-pain-enmeshment refers to the state in which pain and illness schemas are incorporated in to the self-schema (Pincus \& Morley, 200I). In these studies, the additional value of conditional future selves to simple future self-discrepancies was demonstrated in the prediction of well-being related outcomes such as depressed mood in chronic pain (Morley, et al., 2005; Sutherland \& Morley, 2008). It was shown in a sub-acute sample of patients with painful neck injury that over a three-week period, self-discrepancies remained stable whereas the level of enmeshment decreased (Vangronsveld, et al., 2010). These results might raise questions about the stability and changeability of self-discrepancies. Yet, it is not surprising that, given the short period of time, the pain condition did not affect the structure of the self in this otherwise healthy sample of participants. Also, there is evidence that in healthy persons the content of the selfdiscrepancies changes over time but not the degree of experienced discrepancy (Strauman, 1996). However, there are indications that in samples of clinically depressed patients discrepancy rates might vary with the course of the disorder and, more importantly, with treatment (Crane, et al., 2008; Fairbrother \& Moretti, I998; Strauman, et al., 200I).

In sum, it is plausible that a measure of the degree to which the self is affected by pain, due to its specificity and sensitivity, is a better predictor of well-being-related outcomes evoked by pain. In this sense, the painenmeshment model could also be applied to the study of selfdiscrepancies when the focus is on the detrimental effects of pain on the self. Still, the degree of the self that is enmeshed is only meaningful to the degree of the self that is not. Considered this way, self-discrepancy theory might be a more useful framework than the pain-enmeshment model to predict overall well-being and self-regulatory behaviours. 


\section{ACtivity Patterns}

In the transition from acute to chronic pain as well as in the perpetuation of chronic pain, a pivotal role is assigned to how patients manage their daily activities, more specifically whether they avoid activities due to pain (avoidance behaviour) or persist in activities despite pain (persistence behaviour) (Hasenbring \& Verbunt, 2010; Vlaeyen \& Linton, 2000; Vlaeyen \& Morley, 2004). To counteract dysfunctional cycles of activity and rest, pain management programs often include pacing (Birkholtz, et al., 2004). However, while there is accumulating evidence corroborating the detrimental role of avoidance behaviour (e.g., Leeuw, et al., 2007; Chapter 5), dysfunctional persistence behaviour as well as pacing behaviour are rather poorly understood. As a consequence, a detailed discussion on the latter two activity patterns is provided below.

\section{I WHAT IS PERSISTENCE BEHAVIOUR?}

The study of persistence behaviour as a dysfunctional activity pattern in patients with chronic pain is a rather new approach. Confronting oneself with the pain and persisting on tasks was mainly considered as adaptive behaviour opposed to avoidance behaviour (Jensen, et al., I995; Vlaeyen, et al., 1995; Vlaeyen \& Linton, 2000). Yet, the past decade researchers have started to conceptualize persistence behaviour as a risk factor for chronic pain and study its possibly detrimental effects on disability and well-being (e.g., Chapter 4, 5; Hasenbring, et al., 2009b; Hasenbring \& Verbunt, 20IO; McCracken \& Samuel, 2007; Van Houdenhove \& Neerinckx, 1999; van Koulil, Kraaimaat, et al., 2008; Vlaeyen \& Morley, 2004).

In the present thesis, we found that persistence behaviour was not associated with disability or quality of life in patients with chronic low back pain (Chapter 4 ). Although these findings are in contrast with our hypotheses, they are in line with results from other studies (e.g., Hasenbring, et al., 2009b; Huijnen, et al., 20II; McCracken \& Samuel, 2007). Remarkably, in contrast with the hypotheses of the present thesis, Hasenbring and colleagues (2009b) expected and demonstrated persistence behaviour to be negatively associated with disability. From their perspective, these patients may feel less disabled because they are still active, yet at the expense of increases in pain. Nevertheless, the present results call the validity of the concept "dysfunctional persistence behaviour" into question.

The study described in chapter 5 on the underlying dimensions of activity patterns, among which persistence behaviour, helps to clarify some recent findings. Three factors underlying persistence behaviour were found. The 
factors were labelled task-contingent, pain-contingent, and excessive persistence. Interestingly, these factors were differentially related to disability and depressed mood. Namely, only excessive persistence was associated with higher levels of disability and depressed mood whereas task-contingent persistence was associated with lower levels of disability. Pain-contingent persistence was not related with disability or depressed mood. From the results it can be concluded that only excessive persistence reflects dysfunctional persistence while task-contingent persistence appeared adaptive. Since current measures to assess persistence behaviour incorporate a mix of these three types of persistence might help to understand why, so far, no empirical evidence was found for dysfunctional persistence. It would however be premature to conclude that dysfunctional persistence behaviour does exist but research simply failed at measuring it. Thus far, the available results do not exclude that persistence behaviour is only in the perception of the patient and not an objectively measurable and distinct activity pattern. Considered this way, excessive persistence would not be the cause of increased pain but rather an ad hoc interpretation of the patient to explain increased pain experience.

Objective accelerometry data from patients with chronic low back pain have demonstrated that the mean activity levels of patients do not differ from those of healthy individuals, which might indicate the presence of (high versus low) activity-related subgroups (Bousema, et al., 2007; van Weering, Vollenbroek-Hutten, Tonis, \& Hermens, 2009; Verbunt, et al., 200I). However, researchers have not been able to demonstrate that the objectively measured activity level differed between patients characterized by avoidance versus persistence, yet, persisters showed longer uptime and felt more disabled compared to functional performers (Huijnen, Verbunt, Peters, Smeets, et al., 2010). Noteworthy, the POAM-P was used to define persisters which might have biased the results in that the persistence subscale of the POAM-P does not include excessive persistence (Chapter 5 ).

Cluster analyses incorporating measures of avoidance, pacing, and persistence indicated that high persistence in combination with low avoidance and low pacing was associated with positive outcomes (McCracken \& Samuel, 2007). This however does not necessarily contradict the idea that persistence behaviour is dysfunctional, but it might nuance the idea of constant persistence. With regard to this, the time frame might be relevant. It has been proposed that persistence behaviour cannot be sustained over time and might eventually lead to avoidance behaviour (Hasenbring, et al., 2009b). However, the finding that persistence behaviour was not negatively associated with pain duration does not support this idea (Hasenbring, et al., 2009b). There is however evidence for the dysfunctional nature of activity patterns 
characterized by extreme fluctuations (Huijnen, Verbunt, Roelofs, Goossens, \& Peters, 2009; McCracken \& Samuel, 2007). Furthermore, for persisters a positive relationship was found between self-reported activity and subsequent pain levels whereas these were not associated in avoiders, which might indicate a sawtooth pattern of activity in persisters (Huijnen, Verbunt, Peters, Smeets, et al., 20IO).

Put together, the aforementioned results indicate that dysfunctional persistence behaviour constitutes high activity alternated with periods of rest. This idea also corresponds with the results from the present study, since it can be expected that patients with highly fluctuating activity patterns would score high on excessive task persistence. There are also indications that the periods of rest are a consequence of increased pain which are, at least according to the patient, a consequence of high activity. The crucial difference between avoidance and dysfunctional persistence thus lies in whether or not persisters are truly more active. To resolve these issues, future studies employing objective measures of activity in combination with subjective reports are paramount. Furthermore, to objectify the difference between dysfunctional persistence versus adaptive (task-contingent) persistence, objective knowledge on the detrimental consequences of overactivity are necessary since this makes the difference in how patients should be treated. More specifically, if overactivity is detrimental (and this might also differ between types of chronic pain complaints), patients may benefit from adopting pacing strategies, if it is not, letting pain determine activity might better be discouraged. To some extent, this would mean that the statement that pain no longer has a signal value in chronic pain needs reexamination. That is, pain might signal overactivity.

\subsection{PACING}

Pacing strategies are often employed in pain management programs and have been put forward as intervention strategies to counteract the paincontingent activity-rest cycle with the aim to increase activity levels of chronic pain patients (Birkholtz, et al., 2004; Brown, 2002). Yet, in contrast to these original aims, the results on pacing are mixed and pacing has shown close resemblance with avoidance (Chapter 5; Karsdorp \& Vlaeyen, 2009; McCracken \& Samuel, 2007; Nielson, et al., 200I). In the present thesis, pacing, measured as a coping strategy, was found to be a one-dimensional construct and related to higher levels of disability and depression and, importantly, to avoidance behaviour. Yet, pacing was not statistically predictive of disability or depression after controlling for pain intensity and other activity patterns (Chapter 5). 
There are at least two important issues that need attention with regard to the measurement of pacing. First, there is a lack of a clear definition of pacing (Gill \& Brown, 2009). Three elements seem crucial to define and measure pacing, namely the function, the form, and how pain is framed (Chapter 5; McCracken \& Samuel, 2007). Dependent on the patient's baseline activity pattern, avoidance versus dysfunctional persistence (assuming that these exist), the function of pacing would be to respectively increase or balance activity. Taken together, the function is to stabilize the activity-rest cycle in order to increase functioning. Based on the beneficial results for task persistence (Chapter 5; Jensen, et al., 1995) and early suggestions by Birkholtz and colleagues (2004), the form of pacing might include task-contingent persistence. In consideration of its close resemblance with avoidance behaviour, it might not be beneficial to teach patients that pain can be used as a determinant for activity pacing. We recommend in future studies to include pacing items that contain possible reasons for slowing down or taking breaks. It may help to identify whether patients are using pacing independent of pain, or use pacing to avoid pain.

Secondly, the context might play an important role in pacing. That is, pacing measured as an intervention strategy in a clinical context might show different results from pacing measured in a sample of chronic pain patients without clinical guidance. This clinical guidance might be crucial to ensure that pacing strategies are correctly employed with the aim to increase activity levels. Without clinical guidance, pacing may reflect coping attempts by the patient who holds the belief that pain is a consequence of (over)activity and instead of leading to increased activity levels, this might result in lowered activity levels.

A profound evaluation of the effectiveness of pacing requires not only a clear definition, a valid and reliable measurement tool, or an assessment in a clinical context, but also insights into the role of different activity patterns (such as dysfunctional persistence behaviour) in the maintenance of chronic pain. Without these requirements being met, the evaluation of pacing is not only hampered but also seems nonsensical.

\section{UNDERSTANDING DISTINCT ACTIVITY PATTERNS}

\section{I FROM BEING TO DOING: A SELF-DISCREPANCY MODEL FOR CHRONIC PAIN}

Thus far, explanatory models for activity patterns in chronic pain patients have focused on the levels of interruption or interference. In the present thesis, the explanation of activity patterns was approached from the level 
of identity. Building on self-regulation models, activity patterns were considered to be the consequence of regulation, based on selfdiscrepancies. It was expected that a focus on the ideal or ought self would be associated with persistence, whereas a focus on the feared self would be related to avoidance behaviour. Two studies, a cross-sectional (Chapter 4) and an experimental study (Chapter 6), presented in the current thesis tested the hypothesized relationships. A brief summary, organized by hypothesis, of the results is provided below followed by an integrated discussion.

Overall, the relationship between the ideal self and persistence behaviour was a consistent finding, yet comprised mixed results on whether congruencies or discrepancies were related to persistence. Results from the cross-sectional study in patients with chronic low back pain demonstrated a u-shaped relationship between ideal-other, but not idealown self-discrepancies and self-reported persistence, Thus, patients who felt close to their ideal-other self as well as those who felt distant from their ideal-other self, both reported higher levels of persistence behaviour (Chapter 4). Yet, feeling close to the ideal-other, but not ideal-own, self was found to be related to higher levels of objectively assessed persistence behaviour. Moreover, moving further away from the ideal-own, but not the ideal-other, over time was associated with an increase in objectively assessed persistence behaviour. Also, moving closer to the ideal-own was associated with a decrease in persistence behaviour (Huijnen, et al., 20II). Interestingly, in the experimental study comprising healthy subjects described in chapter 6, greater chronic ideal discrepancies were associated with task persistence.

As suggested, patients who feel close to their ideal self might persist by means of maintaining this congruency. Patients who feel distant from their ideal self might (unsuccessfully) persist in activities to narrow (reduce) the discrepancy. This might explain the mixed results on the relationship between discrepancies and persistence. However, an increase in discrepancy between the actual and the ideal self could be expected to be linearly associated with an increase in persistence behaviour which was also demonstrated. Thus, over time, a pattern as depicted in Figure 2 was found. This process resembles the idea of coasting as a consequence of positive affect, meaning that effort decreases when postive affect is experienced due to a higher progress rate to the goal then expected. Yet, coasting has a contradictory character since it might imply that positive affect leads to less effort and thus possibly less positive affect (Carver, 2004; Carver \& Scheier, 1998, 2008). In line with this, the fluctuating pattern contradicts the idea of self-congruency maintenance since there is no point in time in which feeling close to the ideal self is associated with persistence. With regard to the $\mathrm{u}$-shaped relationship between the ideal-own and persistence behaviour it is plausible that this result reflects 
the existence of dysfunctional versus functional persistence. This is likely given the fact that the persistence subscale of the POAM-P seems to include mostly pain- and task-contingent persistence, instead of excessive persistence (chapter 5). Still, this does not explain the contrasting findings from the experiment (chapter 6) and the study of Huijnen and colleagues (2OII).

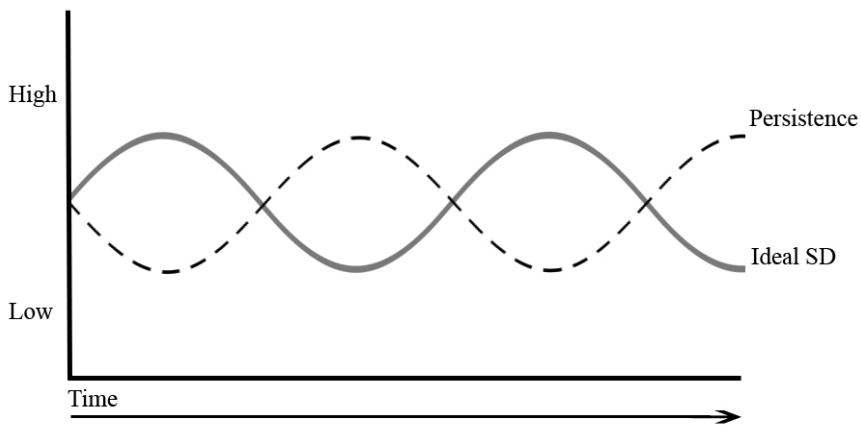

Figure 2. Possible relations between ideal self-discrepancies (Ideal SD) and persistence behaviour over time

For the ought self, no relations were found with persistence behaviour in chapter 4 or in the study by Huijnen and colleagues (20II). In the experimental study however, greater chronic ought discrepancies were associated with task persistence. That is, greater ought discrepancies were associated with completing more blocks of anagrams but also with spending less time on an unsovable anagram. Taken together, it was concluded that these results reflected a vigilant strategy, meaning that participants did strive for obtaining a good result but did not take risks. In chronic pain patients, it would intuitively be expected that ought selfdiscrepancies are strong predictors of activities despite pain. Also, building on Higgins (I987) who stated that "oughts" might feel as necessities, this might be expected. It is possible that the POAM-P did not measure the type of persistence behaviour that is associated with ought self-discrepancies. As a consequence, it remains to be determined whether ought self-discrepancies are associated with excessive task persistence and how this relates to objectively assessed activity levels.

With respect to the feared self, a linear relation between feared-own selfcongruencies and self-reported avoidance behaviour was demonstrated (Chapter 4). Thus, the closer patients felt to their the feared-own, the higher levels of avoidance behaviour they reported. Huijnen and colleagues (20II) however did not find evidence on the relationship between the feared self and objectively assessed activity levels as a proxy measure for avoidance behaviour. Yet, in the experimental study, feeling closer to the feared self was associated with fewer task persistence as 
measured by spending less time on the unsolvable anagram, again reflecting a vigilant strategy (Chapter 6).

The observed relations between feared self-discrepancies and avoidance are in line with expectations and relate to hypotheses in fear-avoidance models (e.g., Vlaeyen \& Linton, 2000). Yet, important about this finding is that behaviour may not only be a consequence of fears at the level of programs or sequences but also at the level of system concepts or principles as organized within Carver and Scheiers goal hierarchy.

In sum, it can be concluded that there is some promising evidence on the relationships between self-discrepancies and avoidance and persistence behaviour. Yet, at least five issues require further attention. First, it is not clear why discrepancies and congruencies with regard to the same selfguide show different patterns of results. In general, it is assumed that those self-guides which are most discrepant from the actual self, are the most accessible and available and instigate self-regulatory behaviour (Higgins, 1987). It would however be interesting to study interactions between self-discrepancies to answer questions such as: What are the consequences of being more focused on ideals versus oughts? Or what are the consequences of feeling close to the feared on regulation based on oughts? Second, differential results were demonstrated between own and other perspectives. It remains to be determined whether these are robust findings. Third, self-discrepancies and persistence and avoidance behaviour were differentially operationalized in the aforementioned studies which impedes the interpretation of the results. Fourth, in the hypothesized model (Figure I) persistence behaviour was conceptualized as dysfunctional behaviour. Yet, none of the studies described above have captured the dysfunctional character of persistence. This might imply that ideal-related behaviour reflected functional self-regulation which might be effective in decreasing discrepancies between the actual and the ideal self. Fifth, while some hypotheses were confirmed, many were not and when effects were found, they were rather weak. A possible explanation for these results possibly is the conceptual distance between higher order self-discrepancies and lower order activities, which invites to consider mediating constructs, such as promotion and prevention strategies.

In consideration of the obtained results, it seems worthwile to carry on with the proposed self-discrepancy model guided by the aforementioned issues. Based on the results, a model may also be considered in which ideal-based self-regulation is beneficial, due to its possible associations with functional persistence. Ought and feared-based self-regulation might still be conceived as detrimental, based on possible relations with, respectively, dysfunctional persistence or avoidance behaviour. 


\subsection{INTERRUPTION, INTERFERENCE, AND IDENTITY: AN INTEGRATED PERSPECTIVE}

As outlined in the introduction, several models have been proposed to explain why individuals with chronic pain display certain activity patterns. The model proposed in the present thesis was unique in the sense that the activity patterns were predicted from an identity perspective. The additional value of considering self-discrepancies in patients with chronic pain is that it takes the effects of chronic pain on being into account and that it places behaviour in a broader self-relevant context. Whereas both the adapted mood-as-input model (Karsdorp, et al., 20IO; Karsdorp \& Vlaeyen, 20II; Vlaeyen \& Morley, 2004) and the avoidance-endurance model (Hasenbring, et al., 2009b; Hasenbring \& Verbunt, 20IO) incorporate the role of higher order goals, they do not take identity-related goals into account. Instead, these models operate on the level of interference. The proposed models are not concurrent but rather complementary. Thus, processes associated with fear-avoidance responses, as described by Hasenbring and colleagues (Hasenbring, et al., 2009b; Hasenbring \& Verbunt, 2010) and building on evidence from the fear-avoidance model (Leeuw, et al., 2007; Vlaeyen \& Linton, 2000), might coexist with and are possibly fuelled by fears at the level of identity. That is, fear for exacerbated pain might increase as a function of the degree to which the person feels exacerbated pain increases closeness to their feared self. A relationship which is probably mediated by antigoals such as "not being able to do the household", which might be subordinate to "being dependent". Also, persistence related responses such as thought suppression and distraction (Hasenbring, et al., 2009b; Hasenbring \& Verbunt, 20IO) might operate in alignment with the pursuit of ideal or ought selves. With regard to the application of the mood-as-input model in chronic pain, which predicts that differences in persistence behaviour results from interactions between mood (negative versus positive) and stop rules (feel-like-discontinuing versus as-many-ascan), negative mood stemming from self-discrepancies might also be considered. Yet, the study of the mood-as-input model in chronic pain has slightly shifted to studying goals (labelled achievement versus hedonic) instead of stop rules (Karsdorp \& Vlaeyen, 20II) which creates novel opportunities for the study of these goals in association with identity-related goals. A possible hypotheses would be that ideal and/or ought self-guides are more involved with achievement goals whereas feared self-guides might comprise hedonic goals.

As a consequence of the multitude of possible (theoretical) links, the integration of these models should be encouraged which will lead to a better understanding of negative outcomes associated with chronic pain. 


\section{A MOTIVATIONAL APPROACH TO BEING IN PAIN}

A recent trend in chronic pain research is the growing interest in (affective) motivational determinants, conveyed as non-pain related goals for pain-related outcomes (Karoly \& Lecci, 1997; Karoly, et al., 2008; Karoly \& Ruehlman, 1996; Schrooten \& Vlaeyen, 2010; Van Damme, et al., 2008; Vlaeyen, et al., 2009). Whereas the present thesis was focused on processes at the level of identity rather than concrete goals, these processes also include motivational aspects or in other words, selfregulatory processes. From a goal-hierarchical approach (Carver \& Scheier, I998; Powers, 1973), self-regulation based on self-guides can be considered as superordinate to self-regulation of concrete goals. A disadvantage of the study of higher order goals as predictors of behaviour is that these might be too abstract. Also, it might be questioned whether results from studies such as described in the current thesis should be employed to encourage higher order goal striving in patients since this might be too difficult, less effective, and has been associated with lower levels of well-being (Emmons, I992; Gollwitzer, I999). On the other hand, patients might have shifted to goal pursuit at lower levels, or in other words from a focus on the be-level to a do-level (Emmons, I992; Morley \& Eccleston, 2004). It can be argued that regained insights into higherorder goals help to define lower order goals and provide meaningfulness to these goals. Finally, motivational models stress the role of the context in which pain occurs. The experience of pain might act as an interfering factor in goal-pursuit but may also lead to increased pain-related avoidance goals. Instead of focussing on pain avoidance (e.g. pain relief by using medication), patients might benefit from increased focus on positive, approach goals that might enhance well-being (Hamilton, Karoly, \& Kitzman, 2004; McCracken, 2010; McCracken \& Velleman, 20IO; Van Damme, et al., 2008). In the current thesis, this has not been directly studied, however the self-discrepancy model might be a useful framework to study relations between pain and (self-related) goals.

In essence, the current thesis adds to the study of chronic pain by looking beyond levels of interruption and interference and taking non-painrelated motivational processes into account.

\section{Limitations}

Although the present thesis adds to an increased understanding of "being" in pain, some limitations should be taken into account. The following general limitations of the present thesis should be considered. All of the studies described in the present thesis, expect for the study in chapter 6 , were cross-sectional questionnaire studies. This imposes at 
least two important limitations tied to results from the present thesis. First, no assertions can be made on causal relationships between selfdiscrepancies, emotional well-being, activity patterns, disability, and quality of life. Thus far, it remains unclear whether self-discrepancies instigate or result from negative mood and activity patterns. Second, all the results rely on self-report by patients. Especially with regard to measuring activity patterns, we do not know whether patients are doing what they say they are doing. Experimental designs and objective measures of patient's behaviour are needed to counteract these limitations. Furthermore, two studies in the present thesis included a true clinical sample, while the other samples existed out of non-clinical participants with chronic pain or healthy subjects. Cross-validation of the results in other clinical samples with different complaints is warranted.

\section{CLINICAL IMPLICATIONS}

Several authors have put forward that the "self" should be integrated into pain management programs (e.g. Bernardes \& Lima, 20ıо; Crowe, et al., 20IO). Yet, it has also been recognized that there is limited empirical evidence on the role of the self and identity in patients with chronic pain (Aldrich \& Eccleston, 2000). It is encouraging that in the past decade the systematic study of the self in chronic pain has grown (e.g. Morley, et al., 2005 ). Although the present thesis shows some promising results and may contribute to the on-going study of the self in pain, direct clinical implications are however premature. Nevertheless, some considerations and directions for future clinical implementation can be inferred.

In general, the employment of the ideal, ought and feared self (in comparison with the actual self) might serve as a useful framework to work with in clinical practise. In essence, two processes (similar to assimilation and accommodation) can be identified in resolving selfdiscrepancies, namely moving the actual self closer to the desired self or changing the content of the desired to match with the actual self. Whereas the first process is generally considered to be effective selfregulation, helping chronic pain patients to get closer to their desired self does not per se constitute effective treatment. Only when the patients' desired self is attainable self-regulation towards the desired self may be encouraged. If it is not, effective treatment may also include adapting dysfunctional self-guides to realistic standards. Furthermore, it can also be questioned how accurate a patients perception of his actual self is.

In line with the aforementioned processes, a future direction to improve the emotional well-being in patients with chronic pain might involve the enhancement of accommodative coping and more specifically flexible 
goal adjustment (Brandtstädter \& Renner, I990; Schmitz, et al., I996; Van Damme, et al., 2008). The results described in chapter 3 support this view as flexible-goal adjustment moderated the effect of ought-other selfdiscrepancies on depression. Nevertheless, while flexible-goal adjustment was also correlated with other self-discrepancies, there were no other significant interactions. Possibly a direct approach to self-discrepancies, such as Self-system therapy (Vieth, et al., 2003), might be more effective. Self-system therapy (Vieth, et al., 2003) was developed on the basis of regulatory focus theory, and is aimed at increasing the successful pursuit of promotion goals versus prevention goals. This rationale is based on the premise that depressed patients have a chronic ideal discrepancy and are high in promotion failure (Strauman, 2002). Self-system therapy has shown to lead to positive outcomes in depressed patients (Strauman, Vieth, et al., 2006). Whereas self-system therapy is primarily aimed at changing mood in patients with chronic pain, it is also likely to be effective in changing activity patterns through the ecouragement of pursuing positive goals. Yet, as mentioned before, more research is needed to obtain insights into how promotion and prevention strategies operate in patients with chronic pain and how these affect activity patterns.

Additionally, it may be worthwhile to consider how and whether contemporary psychological interventions such as exposure in vivo therapy, acceptance and commitment therapy, or mindfulness are effective in tackling dysfunctional processes in patients with chronic pain at the level of identity, such as resolving self-discrepancies or changing maladaptive self-guides.

Exposure in vivo which is specifically aimed activity increments by targeting pain-related fears could possibly have beneficial effects on selfdiscrepancies through bottom-up pathways. That is, an increase in functional ability might contribute to the attainment of desired or escape from undesired selves. Yet, in line with views of Self-determination theory (Deci \& Ryan, 2002), health-related behavioural change might be more easily maintained when the behavioural change is motivated by autonomous motivation. Autonomous motivation includes integrated regulation in which "a person not only values a behaviour, but has also aligned it with other central values and lifestyle patterns" (p. 3, Ryan, Patrick, Deci, \& Williams, 2008). During exposure in vivo the therapist can also encourage this but it is not a central aim. It might however be important in the treatment of chronic pain conditions to aid patients in readjustment and redefinition of their "self" and goals (Karoly, et al., 2008; Walton, Macdermid, \& Nielson, 20IO).

Acceptance and commitment therapy is increasingly being applied to and studied in the context of chronic pain. The central aim of acceptance and 
commitment therapy is to increase psychological flexibility in patients. Psychological flexibility constitutes elements such as acceptance, contact with the present moment, and values-based committed action (Dahl, Wilson, Luciano, \& Hayes, 2005). In treatment, value-based action is increased by helping patients to define life directions, separating values from pressures, defining life activities consistent with these directions, identifying barriers, teaching methods to diminish these barriers, and fostering larger patterns valued actions (Dahl, et al., 2005). There is also evidence that higher levels of value-based action are related to positive outcomes such as lower disability in patients with chronic pain (McCracken \& Gutierrez-Martinez, 20II; McCracken \& Yang, 2006). Since self-discrepancies are different from but closely related to values (Leikas, Lönnqvist, Verkasalo, \& Lindeman, 2009; Sutherland \& Morley, 2008), the process of working with self-discrepancies might resemble the aforementioned method of increasing value-based action. In addition, increasing value-based action might also decrease self-discrepancies. It would be interesting to see how these values relate to self-discrepancies in patients with chronic pain and how change in either one of these is related to each other and emotional and behavioural outcomes.

Mindfulness, which is also an element of self-system therapy and acceptance and commitment therapy, has also shown to have beneficial effects for patients with chronic pain (e.g., Kabat-Zinn, Lipworth, \& Burney, 1985; Morone, Greco, \& Weiner, 2008). Mindfulness meditation was found to enhance self-regulatory processes and thereby protect against mood disorders (Brown \& Ryan, 2003; Feltman, Robinson, \& Ode, 2009; Jimenez, Niles, \& Park, 2010). Moreover, mindfulness based cognitive therapy for recovered depressed patients led to an increase in perceived closeness to the ideal self and the abandonment of maladaptive ideals (Crane, et al., 2008).

The abovementioned findings encourage research on the associations between contemporary psychological interventions and self-discrepancies but do not exclude the possibility that patients might benefit from a treatment module in which self-discrepancies are directly addressed. Probably, optimal treatment will consist of a combination of effective treatment modules, tailored to the patient's specific needs. Future research is necessary to determine whether a separate self-discrepancybased module should be part of this.

\section{Conclusion}

In the present thesis support was found for the role of self-discrepancies in explaining emotional well-being in patients with chronic pain. 
Furthermore, promising albeit limited support was found for a model in which self-discrepancies predict persistence versus avoidance behaviour. With regard to activity patterns, the detrimental nature of avoidance behaviour was confirmed, yet, there appear to be several dimensions underlying persistence behaviour which include both adaptive and dysfunctional forms of persistence. Pacing was not found to be associated with positive outcomes in the present thesis.

The results of the present thesis may contribute to an increased understanding of processes at the level of identity in chronic pain, and several starting points for future research are provided to further disentangle the relationships between self-discrepancies and emotional and behavioural outcomes in chronic pain. 
Summary 
In chapter $\mathbf{I}$ a general introduction is provided on the role of psychosocial factors as important outcomes and predictors in chronic pain. Chapter I introduces the study of the self in chronic pain and presents the theoretical and empirical framework for the study of emotional and behavioural consequences of self-discrepancies in chronic pain. With regard to the behavioural consequences, three activity patterns, namely avoidance, persistence, and pacing behaviour, are discussed which are believed to play a pivotal role in the development and perpetuation of chronic pain.

In chapter 2 the content of the self-guides (ideal, ought, and feared self) and its associations with disability and depression were investigated in eighty patients with chronic non-specific low back pain. It was hypothesized that the self-guides of patients would be characterized by pain and health-related selves. Content analyses led to a classification of the content of the self-guides in eight domains: interpersonal attributes, personal abilities, well-being (physical, emotional, and psychological), close interpersonal relationships, self-expression abilities, achievementrelated attributes, physical appearance, and religion. Across all selfguides, interpersonal attributes were most frequently mentioned, followed by well-being related attributes. Comparisons between selfguides demonstrated that the ideal self was characterized by intrapersonal attributes in contrast to ought and feared self-guides, which were more focused on interpersonal attributes. Since the hypothesized pain and health-related attributes were part of the more general well-being category, relations between specific pain and health related attributes and disability could no be tested. Yet, patients with higher levels of disability did mention more well-being related attributes as part of the person they felt they ought to be while controlling for gender, age, pain duration and intensity. The content of the self-guides was not related to depressive symptomatology.

In chapter 3 relationships between self-discrepancies (ought and feared) and emotional well-being were studied in eighty-nine participants with Work Related Upper Extremity Pain. It was hypothesized that feeling distant from the ought self would be related with anxious mood and feeling close to the feared self to both depressed and anxious mood. Furthermore, these relationships were expected to be moderated by the extent to which participants were able to flexibly adjust their goals. Hierarchical regression analyses (controlling for demographic and painrelated variables) indicated that ought-other and feared-own selfdiscrepancies were associated with depressed and anxious mood. Furthermore, the relationship between ought other self-discrepancies and depressed mood was moderated by flexible goal adjustment. More specifically, for participants who were less flexible, ought other selfdiscrepancies were related with depressed mood, whereas for those who 
were highly flexible, this was not the case. There were no interactions between flexible goal adjustment and the other self-discrepancies or for the prediction of anxious mood.

Chapter 4 presents a study in which the role of self-discrepancies in emotional well-being and activity patterns was studied in eighty-three patients with chronic non-specific low back pain.

A U-shaped relationship was predicted between ideal and ought selfdiscrepancies on the one hand and persistence behaviour on the other hand. Regarding the feared self, it was expected that feeling close to the feared self would be associated with avoidance behaviour. Also, persistence and avoidance behaviour were expected to be associated with disability and diminished quality of life. Multiple regression analyses demonstrated that feeling close to as well as distant from the ideal-other was associated with persistence behaviour. Furthermore, feeling close to the feared-own was related to higher levels of avoidance behaviour. No other relationships between self-discrepancies and activity patterns in patients with chronic pain were found. In addition, multiple regression analyses, controlling for socio-demographic and pain-related variables, showed that avoidance behaviour but not persistence behaviour was associated with higher levels of disability and lower mental and physical quality of life.

In chapter 5 activity patterns were extensively studied. Participants with chronic pain completed several questionnaires measuring avoidance, persistence, and pacing. In addition, pain intensity, depressive symptomatology and disability were administered. First, separate factor analyses were run across all items measuring similar activity patterns. Six factors underlying the activity patterns were identified: pain avoidance and activity avoidance (based on all avoidance-related items), taskcontingent, pain-contingent, and excessive persistence (based on all persistence-related items), and pacing. Subsequent regression analyses demonstrated that, while controlling for pain intensity and the other activity patterns, only excessive persistence and activity avoidance were related to depressed mood and disability. Task-contingent persistence was associated with lower levels of disability.

In chapter 6 predictions concerning the effects of self-discrepancies on persistence behaviour, were experimentally studied in a sample of healthy participants. A between subjects design was employed with three conditions (Ideal versus Ought versus Feared). Persistence was measured by the performance (time spend and number of responses) on an anagrams task. It was expected that participants primed with ideal or ought selves would persist longer on an anagrams task than those primed with their feared self. Yet, results did not show any differences between the conditions on task persistence. There were, however, associations 
between ought and feared self-discrepancies at the trait level with task persistence. More specifically, the more distant participants felt from the ought self or the closer to the feared self, the less time they spend on an unsolvable anagram, reflecting a vigilant approach. Also, feeling distant from the ought self was associated with completing more blocks of anagrams.

In chapter 7 the results from the studies presented in the current thesis were integrated and discussed. The hypothesized model as presented in chapter I was discussed with respect to current findings and extented with newly fomulated hypotheses. Future directions, limitations and possible clinical implications are discussed. 
References 
Affleck, G., Tennen, H., Urrows, S., Higgins, P., Abeles, M., Hall, C., et al. (I998). Fibromyalgia and women's pursuit of personal goals: a daily process analysis. Health Psychology, $\mathrm{I}_{7}(\mathrm{I}), \mathrm{HO}^{-} 47$.

Affleck, G., Tennen, H., Zautra, A., Urrows, S., Abeles, M., \& Karoly, P. (200I). Women's pursuit of personal goals in daily life with fibromyalgia: a value-expectancy analysis. Journal of Consulting and Clinical Psychology, 69(4), 587-596.

Aiken, L. S., \& West, S. G. (I99I). Multiple regression: Testing and interpreting interactions. Newbury Park: Sage.

Aldrich, S., \& Eccleston, C. (2000). Making sense of everyday pain. Social Science and Medicine, $50($ II), I63I-I64I.

Austin, J. T., \& Vancouver, J. B. (1996). Goal Constructs in Psychology: Structure, Process, and Content. Psychological Bulletin, I2O(3), 338-375.

Beck, A. T., Steer, R. A., \& Brown, G. K. (I996). Manual for the Beck Depression Inventory, 2 nd ed. San Antonio. TX: The Psychological Corporation.

Beck, A. T., Steer, R. A., Brown, G. K., \& Van der Does, A. J. W. (2002). BDI-II-NL Handleiding (BDI-II-Dutch Manual). Lisse: The Netherlands: Psychological Corporation.

Bernardes, S. F., \& Lima, M. L. (20IO). Being less of a man or less of a woman: perceptions of chronic pain patients' gender identities. European Journal of Pain, I4(2), I94-199.

Birkholtz, M., Aylwin, L., \& Harman, R. M. (2004). Activity pacing in chronic pain management: One aim, but which method? Part two: National activity pacing survey. British Journal of Occupational Therapy, 67 (II), $48 \mathrm{I}^{-} 487$.

Boldero, J., \& Francis, J. (I999). Ideals, oughts, and self-regulation: are there qualitatively distinct selfguides? Asian journal of social psychology, 2, 343-355.

Boldero, J., \& Francis, J. (2000). The relation between self-discrepancies and emotion: the moderating roles of self-guide importance, location relevance, and social self-domain centrality. Journal of Personality and Social Psychology, 78(I), 38-52.

Boldero, J., \& Francis, J. (2002). Goals, standards, and self-regulation: Different types of reference values serving different self-regulatory functions. Personality and Social Psychology Review, 6, 232-24I.

Borkowski, J. G., Benton, A. L., \& Spreen, O. (I967). Word fluency and brain damage. Neuropsychologia, 5(2), I35-I40.

Brandtstädter, J., \& Renner, G. (I990). Tenacious Goal Pursuit and Flexible Goal Adjustment: Explication and age-related analysis of assimilative and accommodative strategies of coping. Psychology and Aging(5), 58-67.

Brandtstädter, J., \& Rothermund, K. (2002). The life-course dynamics of goal pursuit and goal adjustment: A two-process framework. Developmental Review, 22, II7-150.

Brouwer, S., Kuijer, W., Dijkstra, P. U., Goeken, L. N., Groothoff, J. W., \& Geertzen, J. H. (2004). Reliability and stability of the Roland Morris Disability Questionnaire: intra class correlation and limits of agreement. Disability and Rehabilitation, 26(3), I62-I65.

Brown, C. A. (2002). Occupational therapists' beliefs regarding treatment options for people with chronic pain. British Journal of Occupational Therapy, 65, 398-404.

Brown, K. W., \& Ryan, R. M. (2003). The benefits of being present: mindfulness and its role in psychological well-being. Journal of Personality and Social Psychology, 84(4), 822-848.

Bruch, M. A., Rivet, K. A., \& Laurenti, H. J. (2000). Type of self-discrepancy and relationships to components of the tripartite model of emotional distress. . Personality and Individual Differences, $29(\mathrm{I}), 37^{-} 44$.

Bybee, J., Luthar, S., Zigler, E., \& Merisca, R. (I997). The fantasy, ideal and ought selves: content, relationships to mental health, and functions. Social Cognition, I, $37^{-5} 53$.

Cane, D., Nielson, W. R., Ivey, B., Ivey, R., McCarthy, M., \& Mazmanian, D. (20o7). Development and preliminary evaluation of a measure of three pain-related patterns of activity. Paper presented at the 27th Annual Canadian Pain Society Meeting.

Carver, C. S. (200I). Affect and the functional bases of behavior: on the dimensional structure of affective experience. Personality and Social Psychology Review, 5, 345-356.

Carver, C. S. (2004). Self-regulation of action and affect. In R. F. Bameister \& K. D. Vohs (Eds.), Handbook of self-regulation: Research, theory, and applications. New York: Guilford Press.

Carver, C. S. (2006). Approach, avoidance, and the self-regulation of affect and action. Motivation and Emotion, 30, IO5-IIO.

Carver, C. S., \& Scheier, M. F. (I990). Origins and functions of olpositive and negative affect: a control process view. Psychological review, 97, 19-35.

Carver, C. S., \& Scheier, M. F. (I998). On the self-regulation of behavior. New York: Cambridge University Press. 
Carver, C. S., \& Scheier, M. F. (I999). Themes and issues in the self-regulation of behavior. In R. S. Wyer (Ed.), Advances in Social Cognition (Vol. I2). Mahwah, NJ: Erlbaum.

Carver, C. S., \& Scheier, M. F. (2000). On the structure of behavioral self-regulation. In M. Boekaerts, P. R. Pintrich \& M. Zeidner (Eds.), Handbook of Self-regulation. San Diego: Academic Press.

Carver, C. S., \& Scheier, M. F. (2008). Feedback processes in the simultaneous regulation of action and affect. In J. Y. Shah \& W. L. Gardner (Eds.), Handbook of Motivation Science. New York: Guilford.

Carver, S. C., Lawrence, J. W., \& Scheier, M. F. (I999). Self-discrepancies and affect: incorporating the role of feared selves. Personality and Social Psychology Bulletin, 25, $783^{-7} 792$.

Chulef, S. A., Read, J. S., \& Walsh, A. D. (200I). A hierarchical taxonomy of human goals. Motivation and Emotion, 25(3), I9I.

Crane, C., Barnhofer, T., Duggan, D. S., Hepburn, S., Fennell, M. J., \& Williams, J. M. (2008). Mindfulness-based cognitive therapy and self-discrepancy in recovered depressed patients with a history of depression and suicidality. Cognitive Therapy and Research, 32, 775-787.

Cross, S., \& Markus, H. (I99I). Possible selves across the life span. Human development, 34, 230-255.

Crowe, E., \& Higgins, E. T. (I997). Regulatory focus and strategic inclinations: Promotion and prevention in decision making. Organizational behavior and Human decision processes, $1997(69)$, II $7^{-}$I32.

Crowe, M., Whitehead, L., Gagan, M. J., Baxter, G. D., Pankhurst, A., \& Valledor, V. (20ro). Listening to the body and talking to myself - the impact of chronic lower back pain: a qualitative study. International Journal of Nursing Studies, $47(5), 586-592$.

Dahl, J. C., Wilson, K. G., Luciano, C., \& Hayes, S. C. (2005). Acceptance and commitment therapy for chronic pain. Reno, NV: Context Press.

de Ridder, D., \& de Wit, J. (2006). Self-regulation in health behavior: concepts, theories, and central issues. In D. de Ridder \& J. de Wit (Eds.), Self-regulation in Health Behavior. Chichester, UK: Wiley.

Deci, E. L., \& Ryan, R. M. (2002). Handbook of self-determination research. Rochester, NY: University of Rochester Press.

Eccleston, C., \& Crombez, G. (I999). Pain demands attention: a cognitive-affective model of the interruptive function of pain. Psychological Bulletin, I25(3), 356-366.

Eccleston, C., Williams, A. C., \& Rogers, W. S. (I997). Patients' and professionals' understandings of the causes of chronic pain: blame, responsibility and identity protection. Social Science and Medicine, 45(5), 699-709.

Elliot, A. J., \& Church, M. A. (2002). Client articulated avoidance goals in the therapy context. Journal of counseling psychology, 49, 243-254.

Elliot, A. J., \& Sheldon, K. M. (I998). Avoidance personal goals and the personality-illness relationship. Journal of Personality and Social Psychology, 75(5), I282-I299.

Elliot, A. J., Sheldon, K. M., \& Church, M. A. (I997). Avoidance personal goals and subjective wellbeing. Personality and Social Psychology Bulletin, 23, 915-927.

Emmons, R. A. (I992). Abstract versus concrete goals: personal striving level, physical illness, and psychological well-being. Journal of Personality and Social Psychology, 62(2), 292-300.

Engel, G. L. (I977). The need for a new medical model: a challenge for biomedical science. Science, 196, I29-136.

Ersek, M., Turner, J. A., \& Kemp, C. A. (2006). Use of the chronic pain coping inventory to assess older adults' pain coping strategies. The Journal of Pain, 7 (II), 833-842.

Faas, A., Chavannes, A. W., Koes, B. W., van den Hoogen, J. M. M., A., M. J. M., Smeele, L. J. M., et al. (I996). NHG-standaard M54 lage-rugpijn [Dutch]. Huisarts en Wetenschap, 39, I8-31.

Fairbrother, N., \& Moretti, M. (I998). Sociotropy, Autonomy, and Self-Discrepancy: Status in Depressed, Remitted Depressed, and Control Participants. Cognitive Therapy and Research, $22(3), 279^{-297}$.

Feltman, R., Robinson, M. D., \& Ode, S. (2009). Mindfulness as a moderator of neuroticismoutcome relations: a self-regulation perspective. Journal of Research in Personality, 43, 953-96r.

Ferrier, S. S., \& Brewin, C. R. C. R. (2005). Feared identity and obsessive-compulsive disorder. Behaviour Research and Therapy, 43 (IO), I363-1374.

Forster, J., Grant, H., Idson, L. C., \& Higgins, E. T. (200I). Success/failure feedback, expectancies, and approach/avoidance motivation: how regulatory focus moderates classic relations. Journal of Experimental Social Psychology, 37, 253-260.

Freitas, A. L., \& Higgins, E. T. (2002). Enjoying goal-directed action: the role of regulatory fit. Psychological Science, I3(I), I-6.

Freitas, A. L., Liberman, N., \& Higgins, E. T. (2002). Regulatory fit and resisting temptation during goal pursuit. Journal of Experimental Social Psychology, 38. 
Gil, K. M., Ross, S. L., \& Keefe, F. J. (I988). Behavioral treatment of chronic pain: four pain management protocols. In R. France \& R. Krishnan (Eds.), Chronic pain (pp. 376-4I3). Washington, D.C.: American Psychiatric Press.

Gill, J. R., \& Brown, C. A. (2009). A structured review of the evidence for pacing as a chronic pain intervention. European Journal of Pain, I3(2), 214-216.

Gollwitzer, P. M. (I999). Implementation intentions: strong effects of simple plans. American Psychologist, 54, 493-503.

Gonnerman, M. E., Parker, C. P., Lavine, H., \& Huff, J. (2000). The relationship between selfdiscrepancies and affective states: The moderating roles of self-monitoring and standpoints on the self. Personality and Social Psychology Bulletin, 26, 8I0-8I9.

Goossens, M. E., Kindermans, H. P., Morley, S. J., Roelofs, J., Verbunt, J., \& Vlaeyen, J. W. (20Io). Self-discrepancies in work-related upper extremity pain: relation to emotions and flexible-goal adjustment. European Journal of Pain, I4 (7), 764-770.

Gramzow, R. H., Sedikides, C., Panter, A. T., \& Insko, C. A. (2000). Aspects of self-regulation and self-structure as predictors of perceived emotional distress. . Personality and Social Psychology Bulletin, 26, I88-205.

Grant, H., \& Gelety, L. (2009). Goal content theories: why differences in what we strive for matter. In G. B. Moskowitz \& H. Grant (Eds.), The psychology of goals. New York: The Guilford Press.

Hamilton, N. A., Karoly, P., \& Kitzman, H. (2004). Self-regulation and chronic pain: the role of emotion. Cognitive Therapy and Research, 28, 559-576.

Hardin, E. E., \& Leong, F. T. L. (2005). Optimism and Pessimism as Mediators of the Relations between Self-Discrepancies and Distress among Asian and European Americans. Journal of counseling psychology, 52(2), 25-35.

Harris, C. A., \& D'Eon, J. L. (2008). Psychometric properties of the Beck Depression Inventory-second edition (BDI-II) in individuals with chronic pain. Pain, $137(3), 609-622$.

Harris, S., Morley, S., \& Barton, S. B. (2003). Role loss and emotional adjustment in chronic pain. Pain, I05( $\left.\mathrm{I}^{-2}\right), 363^{-} 370$.

Hasenbring, M. I., Hallner, D., \& Rusu, A. C. (2009a). Comment on: chronic pain: avoidance or endurance? by Petra Karsdorp and Johan Vlaeyen. European Journal of Pain, I3 (6), 662-663.

Hasenbring, M. I., Hallner, D., \& Rusu, A. C. (2009b). Fear-avoidance- and endurance-related responses to pain: development and validation of the Avoidance-Endurance Questionnaire (AEQ). European Journal of Pain, 13(6), 620-628.

Hasenbring, M. I., Plaas, H., Fischbein, B., \& Willburger, R. (2006). The relationship between activity and pain in patients 6 months after lumbar disc surgery: do pain-related coping modes act as moderator variables? European Journal of Pain, IO(8), $7 \mathrm{OI}^{-} 709$.

Hayton, J. C., Allen, D. G., \& Scarpello, V. (2004). Factor retention decisions in exploratory factor analysis: A tutorial on parallel analysis. Organizational Research Methods, $7(2)$, $\mathrm{I}^{-1} \mathrm{I}^{-20}$.

Heppen, J. B., \& Ogilvie, D. M. (2003). Predicting affect from global self-discrepancies: The dual role of the undesired self. Journal of Social and Clinical Psychology, 22, 347-368.

Heuvel van den, S. G., Beek van der, A. J., Blatter, B. M., \& Bongers, P. (2007). Workstyle and overcommitment in relation to neck and upper limb symptoms. International Journal of Behavioral Medicine, I4(I), I2-2O.

Higgins, E. (I987). Self-discrepancy: a theory relating self and affect. Psychological review, 94(3), 319340.

Higgins, E. (I999a). When do self-discrepancies have specific relations to emotions? The secondgeneration question of Tangney, Niedenthal, Covert, and Barlow (I998). Journal of Personality and Social Psychology, $77(6)$, 1313-1317.

Higgins, E. T. (I989). Continuities and discontinuities in self-regulatory and self-evaluative processes: a developmental theory relating self and affect. Journal of Personality, 57(2), 407-444.

Higgins, E. T. (1996). The "self digest": self-knowledge serving self-regulatory functions. Journal of Personality and Social Psychology, 7I(6), I062-1083.

Higgins, E. T. (I997). Beyond pleasure and pain. American Psychologist, 52(I2), I280-I300.

Higgins, E. T. (I999b). When do self-discrepancies have specific relations to emotions? The secondgeneration question of Tangney, Niedenthal, Covert, and Barlow (I998). Journal of Personality and Social Psychology, 77(6), 1313-1317.

Higgins, E. T., Bond, R. N., Klein, R., \& Strauman, T. (I986). Self-discrepancies and emotional vulnerability: how magnitude, accessibility, and type of discrepancy influence affect. Journal of Personality and Social Psychology, 5I(I), $5^{-}$I5.

Higgins, E. T., Friedman, R., Harlow, R. E., Idson, L. C., Ayduk, O. N., \& Taylor, A. (200I). Achievement orientations from subjective histories of success: promotion pride versus prevention pride. European Journal of Social Psychology, 3I. 
Higgins, E. T., Klein, R., \& Strauman, T. (I985). Self-concept discrepancy theory: A psychological model for distinguishing among different aspects of depression and anxiety. Social Cognition, 3 , $5^{\mathrm{I}^{-7}} 6$.

Higgins, E. T., Klein, R., \& Straumann, T. (I985). Self-discrepancy theory: a psychological model for distinghuising among different aspects of depression and anxiety. Social Cognition, $3\left(5 \mathrm{I}^{-} 76\right)$.

Higgins, E. T., Roney, C. J., Crowe, E., \& Hymes, C. (I994). Ideal versus ought predilections for approach and avoidance: distinct self-regulatory systems. Journal of Personality and Social Psychology, 66(2), 276-286.

Higgins, E. T., \& Spiegel, S. (2004). Promotion and prevention strategies for self-regulation: A motivated cognition perspective. In R. F. Baumeister \& K. D. Vohs (Eds.), Handbook of selfregulation: Research, theory and applications (pp. I7 $\mathrm{I}^{-1} \mathrm{I} 87$ ). New York: Guilford Press.

Higgins, E. T., Strauman, T. J., \& Klein, R. (I986). Standards and the process of self-evaluation: Multiple affects from multiple stages. In R. Sorrentino \& E. T. Higgins (Eds.), Handbook of motivation and cognition: Foundations of social behavior: Erlbaum.

Huijnen, I. P., Kindermans, H. P., Seelen, H. A., Peters, M., Smeets, R. J., Serroyen, J., et al. (2OII). Effects of self-discrepancies on activity-related behaviour: explaining disability and quality of life in patients with chronic pain. Pain.

Huijnen, I. P., Verbunt, J. A., Peters, M. L., Smeets, R. J., Kindermans, H. P., Roelofs, J., et al. (2OIO). Differences in activity-related behaviour among patients with chronic low back pain. European Journal of Pain.

Huijnen, I. P., Verbunt, J. A., Roelofs, J., Goossens, M. E., \& Peters, M. (2009). The disabling role of fluctuations in physical activity in patients with chronic low back pain. European Journal of Pain, I3(IO), го76-го79.

Huijnen, I. P. J., Verbunt, J. A., Peters, M. L., Delespaul, P., Kindermans, H. P. J., Roelofs, J., et al. (2010). Do depression and pain intensity interfere with physical activity in daily life in patients with Chronic Low Back Pain? Pain, I50(I), I6I-166.

Idson, L. C., \& Higgins, E. T. (2000). How current feedback and chronic effectiveness influence motivation: everything to gain versus everything to lose. European Journal of Social Psychology, 30, 583-592.

Jensen, M. P. (2009). Research on coping with chronic pain: The importance of active avoidance of inappropriate conclusions. Pain, I47 $\left(\mathrm{I}^{-} 3\right), 3^{-} 4$.

Jensen, M. P., Turner, J. A., Romano, J. M., \& Strom, S. E. (I995). The Chronic Pain Coping Inventory: development and preliminary validation. Pain, 60(2), 203-216.

Jimenez, S. S., Niles, B. L., \& Park, C. L. (2010). A mindfulness model of affect regulation and depressive symptoms: Positive emotions, mood regulation expectancies, and self-acceptance as regulatory mechanisms. Personality and Individual Differences, 49, 645-650.

Johansson, E. E., Hamberg, K., Westman, G., \& Lindgren, G. (I999). The meanings of pain: an exploration of women's descriptions of symptoms. Social Science and Medicine, 48(I2), I79 ${ }^{-}$ I8O2.

Kabat-Zinn, J., Lipworth, L., \& Burney, R. (1985). The clinical use of mindfulness meditation for the self-regulation of chronic pain. Journal of behavioral Medicine, 8(2), I63-190.

Karoly, P., \& Lecci, L. (I997). Motivational correlates of self-reported persistent pain in young adults. Clinical Journal of Pain, I3(2), IO4-109.

Karoly, P., Okun, M. A., Ruehlman, L. S., \& Pugliese, J. (2008). The impact of goal cognition and pain severity on disability and depression in adults with chronic pain: an examination of direct effects and mediated effects via pain-induced fear. Cognitive Therapy and Research, 32, 418-433.

Karoly, P., \& Ruehlman, L. S. (I996). Motivational implications of pain: chronicity, psychological distress, and work goal construal in a national sample of adults. Health Psychology, I5(5), $383-390$.

Karsdorp, P. A., Nijst, S. E., Goossens, M. E., \& Vlaeyen, J. W. (2010). The role of current mood and stop rules on physical task performance: an experimental investigation in patients with workrelated upper extremity pain. European Journal of Pain, I4(4), 434-440.

Karsdorp, P. A., \& Vlaeyen, J. W. (2009). Active avoidance but not activity pacing is associated with disability in fibromyalgia. Pain, $\mathrm{I}_{47}\left(\mathrm{I}^{-} 3\right), 29^{-} 35$.

Karsdorp, P. A., \& Vlaeyen, J. W. (2OII). Goals matter: Both achievement and pain-avoidance goals are associated with pain severity and disability in patients with low back and upper extremity pain. Pain.

Kindermans, H., Roelofs, J., Goossens, M., Huijnen, I., Verbunt, J., \& Vlaeyen, J. (2009). 772 Measuring avoidance, overdoing, and pacing in patienst with chronic pain: psychometric properties of the patterns of activity measure-pain. European Journal of Pain, I3, S222-S223.

Kindermans, H. P., Goossens, M. E., Roelofs, J., Huijnen, I. P., Verbunt, J. A., Morley, S., et al. (2010). A content analysis of ideal, ought, and feared selves in patients with chronic low back pain. European Journal of Pain, I4(6), 648-653. 
Lame, I. E., Peters, M. L., Vlaeyen, J. W., Kleef, M., \& Patijn, J. (2005). Quality of life in chronic pain is more associated with beliefs about pain, than with pain intensity. European Journal of Pain, 9(I), $15^{-24}$.

Leeuw, M., Goossens, M. E., Linton, S. J., Crombez, G., Boersma, K., \& Vlaeyen, J. W. (2007). The fear-avoidance model of musculoskeletal pain: current state of scientific evidence. Journal of behavioral Medicine, 30(I), 77-94.

Leikas, S., Lönnqvist, J., Verkasalo, M., \& Lindeman, M. (2009). Regulatory focus systems and personal values. European Journal of Social Psychology, 39, 415-429.

Lethem, J., Slade, P. D., Troup, J. D., \& Bentley, G. (I983). Outline of a Fear-Avoidance Model of exaggerated pain perception--I. Behaviour research and therapy, $2 \mathrm{I}(4), 4 \mathrm{OI}^{-} 408$.

Lundberg, M., Styf, J., \& Bullington, J. (2007). Experiences of moving with persistent pain--a qualitative study from a patient perspective. Physiotherapy Theory and Practice, 23(4), 199-209.

Manian, N., Papadakis, A. A., Strauman, T. J., \& Essex, M. J. (2006). The development of children's ideal and ought self-guides: parenting, temperament, and individual differences in guide strength. Journal of Personality, 74(6), I6I9-I645.

Mansell, W. (2005). Control theory and psychopathology: An integrative approach. Psychology and Psychotherapy: Theory, Research and Practice, 78, I4I-178.

Markus, H., \& Nurius, P. (I986). Possible selves. American Psychologist, 4I, 954-969.

Martin, B. I., Deyo, R. A., Mirza, S. K., Turner, J. A., Comstock, B. A., Hollingworth, W., et al. (2008). Expenditures and health status among adults with back and neck problems. Journal of the American Medical Association, 299(6), 656-664.

Martin, L., Ward, D., Achee, J., \& Wyer, R. (I993). Mood as input: people have to interpret the motivational implications of their moods. Journal of Personality and Social Psychology, 64, 31 $7^{-}$ 326.

McCracken, L., \& Vowles, K. E. (2007). Psychological Flexibility and Traditional Pain Management Strategies in Relation to Patient Functioning With chronic pain: an examination of a revised instrument. . The Journal of Pain, 8(9), 700-7007.

McCracken, L. M. (20I0). Toward understanding acceptance and psychological flexibility in chronic pain. Pain, $\mathrm{I}_{49}(3), 42 \mathrm{O}^{-} 42 \mathrm{I}$.

McCracken, L. M., \& Gutierrez-Martinez, O. (20II). Processes of change in psychological flexibility in an interdisciplinary group-based treatment for chronic pain based on Acceptance and Commitment Therapy. Behaviour Research and Therapy, 49(4), 267-274.

McCracken, L. M., \& Samuel, V. M. (2007). The role of avoidance, pacing, and other activity patterns in chronic pain. Pain, I3O(I-2), II $9^{-} \mathrm{I} 25$.

McCracken, L. M., \& Velleman, S. C. (2010). Psychological flexibility in adults with chronic pain: a study of acceptance, mindfulness, and values-based action in primary care. Pain, I48(I), I4I-I47.

McCracken, L. M., \& Vowles, K. E. (2006). Acceptance of chronic pain. Current Pain and Headache Reports, $10(2), 90^{-9} 94$.

McCracken, L. M., \& Yang, S. Y. (2006). The role of values in a contextual cognitive-behavioral approach to chronic pain. [Research Support, Non-U.S. Gov't

Validation Studies]. Pain, I23(I-2), I37-I45.

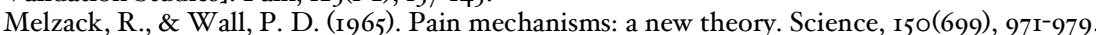

Merskey, H., \& Bogduk, N. (I994). Classification of chronic pain. In H. Merskey \& N. Bogduk (Eds.), Part III: Pain terms, a current list with definitions and notes on usage. IASP task force on taxonomy. (pp. 209-2I4). Seattle: IASP press.

Miles, A., Curran, H. V., Pearce, S., \& Allan, L. (2005). Managing constraint: the experience of people with chronic pain. Social Science and Medicine, 6I(2), 43 $\mathrm{I}^{-} 44 \mathrm{I}$.

Miller, A., \& Markman, K. (2007). Depression, regulatory focus, and motivation. Personality and Individual Differences, 43, 472-436.

Morley, S. (2008). Psychology of pain. British Journal of Anaesthesia, IOI(I), 25-3I.

Morley, S., Davies, C., \& Barton, S. (2005). Possible selves in chronic pain: self-pain enmeshment, adjustment and acceptance. Pain, II5(I-2), 84-94.

Morley, S., \& Eccleston, C. (2004). The object of fear in pain. In G. J. Asmundson, J. Vlaeyen \& G. Crombez (Eds.), Understanding and treating fear of pain. (pp. I63-188). Oxford: Oxford University Press.

Morone, N. E., Greco, C. M., \& Weiner, D. K. (2008). Mindfulness meditation for the treatment of chronic low back pain in older adults: a randomized controlled pilot study. [Randomized Controlled Trial

Research Support, N.I.H., Extramural]. Pain, 134(3), 310-319.

Mueller, D., \& Kim, K. (2004). The tenacious Goal Pursuit and Flexible Goal adjustment Scales: Examination of their Validity. Educational and Psychological Measurement, 46, I20- $\mathrm{I}^{2}$.

Nielson, W. R., \& Jensen, M. P. (2004). Relationship between changes in coping and treatment outcome in patients with Fibromyalgia Syndrome. Pain, I09(3), 233-24I. 
Nielson, W. R., Jensen, M. P., \& Hill, M. L. (200I). An activity pacing scale for the chronic pain coping inventory: development in a sample of patients with fibromyalgia syndrome. Pain, $89\left(2^{-}-3\right)$, III-II5.

O'Connor, B. P. (2000). SPSS and SAS programs for determining the number of components using parallel analysis and Velicer's MAP test. Behavior Research Methods, Instruments, \& Computers, 32(3), 396-402.

Ogilvie, D. M. (I987). The undesired self: A neglected variable in personality research. Journal of Personality and Social Psychology, 52, 379-385.

Ogilvie, D. M., \& Clark, M. D. (1992). The best and the worst of it: Age and sex differences in self discrepancy research. In R. P. Lipka \& T. M. Brinthaupt (Eds.), Self-perspectives across the life span (pp. I86-222). Albany, NY: SUNY Press.

Osborn, M., \& Smith, J. A. (I998). The personal experience of chronic benign lower back pain: an interpretative phenomenological analysis. British Journal of Health Psychology, 3, 65-83.

Ospina, M., \& Harstall, C. (2OO3). How prevalent is chronic pain? Pain: clinical updates, II(2), I-4.

Ostelo, R. W., van Tulder, M. W., Vlaeyen, J. W., Linton, S. J., Morley, S. J., \& Assendelft, W. J. (2005). Behavioural treatment for chronic low-back pain. Cochrane Database of Systematic Reviews(I), CDoo2OI4.

Oyserman, D., \& Markus, H. R. (I990). Possible selves and delinquency. Journal of Personality and Social Psychology, 59(I), II2-I25.

Ozgul, S., Heubeck, B., Ward, J., \& Wilkinson, R. (2003). Self-discrepancies: measurement and relation to various negative affective states. Australian Journal of Psychology, 55, 56-62.

Paulson, M., Danielson, E., \& Soderberg, S. (2002). Struggling for a tolerable existence: the meaning of men's lived experiences of living with pain of fibromyalgia type. Qualitative Health Research, I2(2), 238-249.

Philips, H. C. (I987). Avoidance behaviour and its role in sustaining chronic pain. Behaviour research and therapy, 25(4), 273-279.

Philips, H. C., \& Rachman, S. (I996). The role of activity pacing. In H. C. Philips \& S. Rachman (Eds.), The psychological management of chronic pain. A treatment manual. New York: Springer.

Phillips, A. G., \& Silvia, P. J. (2005). Self-awareness and the emotional consequences of selfdiscrepancies. Personality and Social Psychology Bulletin, 3I(5), 703-7I3.

Phillips , A. G., \& Silvia, P. J. (20IO). Individual differences in self-discrepancies and emotional experience: Do distinct discrepancies predict distinct emotions? Personality and Individual Differences, 49, I48-15I.

Phillips, A. G., Silvia, P. J., \& Paradise, M. J. (2007). The undesired self and emotional experience: a latent variable analysis. Journal of Social and Clinical Psychology, 26, I035-1047.

Pincus, T., \& Morley, S. (2OOI). Cognitive-processing bias in chronic pain: a review and integration. Psychological Bulletin, I27(5), 599-6I7.

Pollard, C. A. (I984). Preliminary validity study of Pain Disability Index. Perceptual and Motor Skills, 59,974 .

Powers, W. T. (I973). Behavior: the control of perception. Aldine: Chicago.

Pransky, G., Feurerstein, M., Himmelstein, J., Katz, J. N., \& Vickers-Lathi, M. (I997). Measuring functional outcomes in work-related upper extremity disorders. Development and validation of the Upper Extremity Function Scale. National Library of Medicine, 39, II95-I202.

Price, D. D., McGrath, P. A., Rafii, A., \& Buckingham, B. (I983). The validation of visual analogue scales as ratio scale measures for chronic and experimental pain. Pain, $\mathrm{I} 7(\mathrm{I}), 45^{-5} 6$.

Roelofs, J., Peters, M. L., McCracken, L., \& Vlaeyen, J. W. S. (2003). The pain vigilance and awareness questionnaire (PVAQ): Further psychometric evaluation in fibromyalgia and other chronic pain syndromes. Pain, IOI(3), $299^{-306 .}$

Roland, M., \& Morris, R. (I983). A study of the natural history of back pain. Part I: development of a reliable and sensitive measure of disability in low-back pain. Spine, 8(2), I4I-I44.

Roney, C. J., Higgins, E. T., \& Shah, J. (I995). Goals and framing: how outcome focus influences motivation and emotion. Personality and Social Psychology Bulletin, 2I(II).

Rothermund, K., \& Brandtstadter, J. (2003). Coping with deficits and losses in later life: from compensatory action to accommodation. Psychology and Aging, I8(4), 896-905.

Rowa, K., Antony, M. M., Swinson, R. P., Purdon, C., Antony, M. M., \& Summerfeldt, L. J. (2007). Exposure and Response Prevention Psychological treatment of obsessive-compulsive disorder: Fundamentals and beyond. (pp. 79-109). Washington, DC: American Psychological Association.

Ryan, R. M., Patrick, H., Deci, E. L., \& Williams, G. C. (2008). Facilitating health behaviour change and its maintenance: interventions based on Self-Determination theory. The European Health Psychologist, I0, 2-5.

Schmitz, U., Saile, H., \& Nilges, P. (I996). Coping with chronic pain: flexible goal adjustment as an interactive buffer against pain-related distress. Pain, $67(\mathrm{I}), 4^{\mathrm{I}^{-}} 5 \mathrm{I}$. 
Schokker, M. C., Links, T. P., Luttik, M. L., \& Hagedoorn, M. (2010). The association between regulatory focus and distress in patients with a chronic disease: the moderating role of partner support. British Journal of Health Psychology, ${ }_{5}(\mathrm{Pt} \mathrm{I}), 63^{-7} 7$.

Schrooten, M. G., \& Vlaeyen, J. W. (20IO). Becoming active again? Further thoughts on goal pursuit in chronic pain. Pain, I49(3), 422-423.

Scott, L., \& O'Hara, M. W. (I993). Self-discrepancies in clinically anxious and depressed university students. Journal of Abnormal Psychology, IO2(2), 282-287.

Shah, J., \& Higgins, E. T. (I997). Expectancy x value effects: regulatory focus as determinant of magnitude and direction. Journal of Personality and Social Psychology, 73(3), 447-458.

Shah, J., Higgins, E. T., \& Friedman, R. S. (I998). Performance incentives and means: how regulatory focus influences goal attainment. Journal of Personality and Social Psychology, 74(2), 285-293.

Sim, J., \& Madden, S. (2008). Illness experience in fibromyalgia syndrome: a metasynthesis of qualitative studies. Social Science and Medicine, $67(\mathrm{I}), 57^{-67}$.

Smith, J. A., \& Osborne, M. (2007). Pain as an assault on the self: An interpretative phenomenological analysis of the psychological impact of chronic benign low back pain Psychology and Health, 22(5), 517-534.

Spence, M., Moss-Morris, R., \& Chalder, T. (2005). The Behavioural Responses to Illness Questionnaire (BRIQ): a new predictive measure of medically unexplained symptoms following acute infection. Psychological Medicine, 35(4), 583-593.

Spielberger, C. D., Gorsuch, R. L., \& Lushene, R. E. (I970). State-trait anxiety inventory. Palo Alto: Consulting Psychological Press.

Spinhoven, P., Ormel, J., Sloekers, P. P., Kempen, G. I., Speckens, A. E., \& Van Hemert, A. M. (I997). A validation study of the Hospital Anxiety and Depression Scale (HADS) in different groups of Dutch subjects. Psychological Medicine, 27(2), 363-370.

Strauman, T., Vieth, A., Merrill, K., Koldem, G., Woods, T., Klein, H., et al. (2006). Self-System Therapy as an intervention for Self-Regulatory Dysfunction in Depression: A randomized Comparison with Cognitive Therapy. Journal of Consulting \& Clinical Psychology, 74(2), 367-376.

Strauman, T. J. (I989). Self-discrepancies in clinical depression and social phobia: cognitive structures that underlie emotional disorders? Journal of Abnormal Psychology, 98(I), I4-22.

Strauman, T. J. (1996). Stability within the self: a longitudinal study of the structural implications of self-discrepancy theory. Journal of Personality and Social Psychology, 7I(6), II42-II53.

Strauman, T. J. (2002). Self-regulation and depression. Self and Identity, I, I5 ${ }^{-}{ }^{-} 57$.

Strauman, T. J., \& Higgins, E. T. (I988). Self-discrepancies as predictors of vulnerability to distinct syndromes of chronic emotional distress. Journal of Personality, 56(4), 685-707.

Strauman, T. J., Kolden, G. G., Stromquist, V., Davis, N., Kwapil, L., Heerey, E., et al. (20or). The Effects of Treatments for Depression on Perceived Failure in Self-Regulation. Cognitive Therapy and Research, 25(6), $693^{-} 7 \mathbf{1 2}$.

Strauman, T. J., Vieth, A. Z., Merrill, K. A., Kolden, G. G., Woods, T. E., Klein, M. H., et al. (20o6). Self-system therapy as an intervention for self-regulatory dysfunction in depression: a randomized comparison with cognitive therapy. Journal of Consulting \& Clinical Psychology, $74(2), 367-376$.

Sullivan, M., Bishop, S., \& Pivik, J. (I995). The pain catastrophizing scale: development and validation. Psychological assessment, $7(4), 524^{-5} 532$.

Sutherland, R., \& Morley, S. (2008). Self-pain enmeshment: future possible selves, sociotropy, autonomy and adjustment to chronic pain. Pain, $137(2), 366-377$.

Tabachnick, B., \& Fidell, L. (200I). Using multivariate statistics. New York: Harper Collins.

Tait, R. C., Chibnall, J. T., \& Krause, S. (I990). The Pain Disability Index: Psychometric properties. Pain, $40(2), I_{7} I^{-I} 82$.

Tangney, J. P., Niedenthal, P. M., Covert, M. V., \& Barlow, D. H. (I998). Are shame and guilt related to distinct self-discrepancies? A test of Higgins's ( ${ }_{9987}$ ) hypotheses. Journal of Personality and Social Psychology, 75(I), 256-268.

Turk, D. C., \& Monarch, E. S. (2002). Biopsychosocial perspective on chronic pain. In D. C. Turk \& R. J. Gatchel (Eds.), Psychological approaches to pain management: a practioner's handbook. NY: The Guilford Press.

Van Damme, S., Crombez, G., \& Eccleston, C. (2008). Coping with pain: a motivational perspective. Pain, $\mathrm{I}_{39}(\mathrm{I}), \mathrm{I}^{-} 4$.

Van der Ploeg, H. M., Defares, P. B., \& Spielberger, C. D. (I980). Handleiding bij de Zelf Beoordelingsvragenlijst (ZBV). Lisse.

van der Zee, K., \& Sanderman, R. (I993). Het meten van de algemene gezondheidstoestand met de RAND-36: een handleiding [Dutch]. Groningen, The Netherlands: NCG.

van der Zee, K., Sanderman, R., Heyink, J., \& De Haes, H. (I996). Psychometric qualities of the RAND 36-item Health Survey I.o: a multidimensional measure of general health status. International Journal of Behavioral Medicine, 3, IO4-I22. 
Van Houdenhove, B., \& Neerinckx, E. (I999). Is "ergomania" a predisposing factor to chronic pain and fatigue? Psychosomatics, $40(6), 5^{22} 9^{-5} 30$.

van Koulil, S., van Lankveld, W., Kraaimaat, F. W., van Helmond, T., Vedder, A., van Hoorn, H., et al. (2008). Tailored cognitive-behavioral therapy for fibromyalgia: two case studies. Patient Education and Counseling, 7I(2), 308-3I4.

van Koulil, S., van Lankveld, W., Kraaimaat, F. W., van Helmond, T., Vedder, A., van Hoorn, H., et al. (2010). Tailored cognitive-behavioral therapy and exercise training for high-risk patients with fibromyalgia. Arthritis Care Research, 62(10), I377-1385.

Vangronsveld, K., Morley, S., Peters, M. L., Vlaeyen, J. W., \& Goossens, M. E. (2010). Psychological changes and the resolution of acute neck pain after a motor vehicle accident. European Journal of Pain.

Vieth, A., Strauman, T. J., Kolden, G., Woods, T., Michels, J., \& Klein, M. H. (2003). Self-system therapy: A theory-based psychotherapy for depression. Clinical Psychology: Science and Practise, IO, $245^{-2} 268$.

Vlaeyen, J. W., Crombez, G., \& Linton, S. J. (2009). The fear-avoidance model of pain: We are not there yet. Comment on Wideman et al. "A prospective sequential analysis of the fear-avoidance model of pain" [Pain, 2009] and Nicholas "First things first: reduction in catastrophizing before fear of movement" [Pain, 2009]. Pain, I46(I-2), 222; author reply 222-223.

Vlaeyen, J. W., Kole-Snijders, A. M., Boeren, R. G., \& van Eek, H. (I995). Fear of movement/(re)injury in chronic low back pain and its relation to behavioral performance. Pain, $62(3), 363^{-372 .}$

Vlaeyen, J. W., \& Linton, S. J. (2000). Fear-avoidance and its consequences in chronic musculoskeletal pain: a state of the art. Pain, 85(3), 317-332.

Vlaeyen, J. W., \& Morley, S. (2004). Active despite pain: the putative role of stop-rules and current mood. Pain, IIO(3), 5I2-5I6.

Vlaeyen, J. W., \& Morley, S. (2005). Cognitive-Behavioral Treatments for Chronic Pain: What Works for Whom? Clinical Journal of Pain, 2I(I), $\mathrm{I}^{-8}$.

Vlaeyen, J. W., \& Morley, S. (in press). Tailored treatment: It's not what you think it is. Arthritis Care Research.

Waddell, G. (2004). The back pain revolution. Edinburgh: Churchill Livingstone.

Walton, D. M., Macdermid, J. C., \& Nielson, W. (2010). Recovery from acute injury: clinical, methodological and philosophical considerations. Disability and Rehabilitation, 32 (IO), 864-874.

Waters, S. J., Keefe, F. J., \& Strauman, T. J. (2004). Self-discrepancy in chronic low back pain: relation to pain, depression, and psychological distress. Journal of Pain and Symptom Management, 27(3), 25 $\mathrm{I}^{-259}$.

Williams, S. (2000). Chronic illess as biographical disruption or biographical disruption as chronic illness? Sociology of Health and Illness, 22, 24I-257.

Williams, S., \& Wheatley, E. (2006). 'Third wave' pacing: reframing pacing in terms of contextual cognitive behaviour therapy. British Pain Society Newsletter, Spring, I9-20.

Zigmund, A. S., \& Snaith, R. P. (I983). The hospital anxiety and depression scale. Acta Psychiatrica Scandinavica, 67, 36r-370. 

Dankwoord 
Ik heb het geluk gehad om omringd en gesteund te worden door velen die, op wat voor manier dan ook, hebben bijgedragen aan het tot stand komen van dit proefschrift. Deze woorden van dank zijn dan ook voor jullie! Ik hoop echter dat onderstaande woorden slechts een bezegeling zijn van wat ik reeds eerder heb laten blijken, namelijk mijn oprechte waardering.

Johan, jij hebt je taak als promotor vervuld als een ware mentor. Ik wil je bedanken voor alle brainstorm momenten waarin je mijn gedachten uitdaagde en me stimuleerde het beste uit mezelf te halen om uit te groeien tot een zelfstandig onderzoeker. Je hebt een uniek en bewonderingswaardig talent voor onderzoek en ik ben blij dat ik hiervan heb mogen leren. Het was een eer om jou als promotor te hebben, dankjewel!

Marielle, als co-promotor en dagelijkse begeleider was jij degene die het dichtste betrokken was bij het project en dus bij mij. Je hebt me begeleid in mijn eerste stapjes als onderzoeker en ik ben je erg dankbaar voor de geruststellende en ondersteunende houding waarmee je dat gedaan hebt. Dankjewel ook voor de tijd die je steeds voor me vrij maakte en je nauwgezetheid die meer dan eens mijn ietwat chaotische aanpak compenseerde.

Jeffrey, ik ben blij dat jij als tweede co-promotor betrokken was bij mijn promotietraject. Het enthousiasme en gemak waarmee jij onderzoek doet werkten erg aanstekelijk en motiverend. Ik heb jou ervaren als een coach die me door moeilijke beslissingen heen hielp en steeds voor me klaar stond wanneer ik met (veel te ver doordachte) vragen zat. Dankjewel voor je inzet en betrokkenheid.

Jeanine, als projectleider van het disact project heb je vanaf het begin ook een rol gespeeld in mijn promotietraject. Ik ben blij dat ik ook van jou heb kunnen leren (en nog steeds!) en dan met name van je geweldige nononsense, enthousiaste en doelgerichte aanpak. Jij bent vanuit mijn optiek iemand die mogelijkheden creëert, zowel voor het project alsook voor de onderzoekers.

Linda en Ivan, als paranimfen zijn jullie degenen die letterlijk aan mijn zijde staan bij de verdediging van mijn proefschrift. Figuurlijk staan jullie daar al sinds het begin van mijn promotietraject. Ivan, we waren een goed multidisciplinair team en samen hebben we disact tot een goed einde gebracht. Het was en is nog steeds een verrijking om met jou samen te werken. Linda, over alles wat we in de afgelopen jaren besproken hebben, hadden we ook een boek kunnen schrijven! Dankjewel voor je luisterend oor, je relativeringsvermogen en je, toch wel amusante, verstrooidheid. Zonder jullie beiden was het allemaal minder leuk geweest. 
I would also like to thank the members of the examination board for the time and effort they have spend on evaluating this thesis.

Stephen, you have been involved in my Ph.D. project from the start and actually, even from before the start. It is namely thanks to you that the study of the self in chronic pain gained increased interest which made projects like mine possible. Besides that, I am grateful for your indisputable kindness and all the opportunities to discuss and share ideas (the self does matter! :) ).

Tim, thank you for serving the role of self-discrepancy/regulatory focus help desk! :) It is a fact that "you're the expert"! Thank you for always responding to my questions with much thought and genuine interest.

Er zijn een heleboel mensen die enorm hebben bijgedragen aan de verwezenlijking van dit proefschrift dankzij hun praktische, onmisbare ondersteuning. Sita, Astrid, Truus, Angela, Erik, Gerard, Jan, Rosanne, Charlie, Noël, Lindy en Emmy, naast het feit dat jullie op allerlei manieren bijdragen aan werkvreugde (ik denk bijvoorbeeld aan pingpong oftewel tafeltennis), zijn jullie ook degenen met dé oplossingen voor vanalles en nog wat. Dankjulliewel voor alles. Op deze plaats wil ik ook de studenten bedanken die bijgedragen hebben aan de studies en dan met name Hilde en Charlene.

Ook al geraakt een studie opgezet, er komen pas resultaten uit als er genoeg mensen bereid waren om eraan deel te nemen. Ik wil dan ook alle proefpersonen bedanken en vooral alle patiënten die bereid waren deel te nemen aan een studie waarin letterlijk en figuurlijk veel gevraagd werd. Op deze plaats wil ik ook alle verwijzers en secretariaten, die hebben meegewerkt aan de disact studie, bedanken voor hun onmisbare bijdrage.

Ik ben blij dat ik als promovenda deel mocht uitmaken van verschillende 'clubjes'. In de eerste plaats de pijnclub, aka behavioural medicine, dankjulliewel voor alle gedeelde kennis (en het feit dat ik kennis mocht nemen van jullie andere kantjes als we op uitstap of congres gingen). Hetzelfde geldt voor EPP en de EPP cursussen. In meerdere opzichten waren deze leerzaam. Daarnaast wil ik ook alle collega's bedanken van oud DMKEP en CPS in het algemeen. In al deze clubjes zitten enkele mensen verweven die ik extra wil bedanken. Namelijk: Marjolein (voor gedeeld lief en leed én muzikale autoritjes), Ken (voor uitzonderlijke en interessante discussies over stof en zo), Saskia (voor je positiviteit en aparte visie), Rilana (voor je humor en geruststellende herkenbaarheid), Lea (voor je luisterend oor en je party-personality), Lotte (voor je onovertroffen echtheid en oprechtheid) en Hugo (voor alle enligthening conversations). 
Een woord van dank is hier zeker ook op zijn plaats aan CAPHRI en de vakgroep Revalidatiegeneeskunde, met name Onno, Rob en Jeanine. Dankzij jullie kon ik het afronden van dit proefschrift in een nieuw perspectief plaatsen. Mijn (ondertussen niet meer zo) nieuwe collega's wil ik ook bedanken voor hun 'medeleven' (of was het medelijden?)

Kim, Eveline, Gonny en Joey, jullie ben ik het meest dankbaar voor alle gesprekken over en belevenissen van de mooie dingen des levens. Het feit dat we elkaar altijd te weinig zien is eigenlijk alleen maar een goed teken.

Tim, dankjewel voor je steun in de gehele promotie-periode en vooral voor mijn gerust hart op jouw dagen. Marijke en Jan, dankjulliewel voor jullie voort-durende betrokkenheid.

Andrée en Jan, dankjulliewel voor jullie 'open armen'.

Wouter, Carolien, Jarne (!), Maarten en Liesbeth, ik ben blij dat jullie er zijn en ik bij jullie waardevolle functies mag bekleden zoals 'liefste zusje' en 'tant'Han'. Daarnaast voel ik me ook gezegend met veel tantes, nonkels, nichtjes en neefjes (en er blijven er maar bijkomen!) aan wie ik ook veel momenten van gewenste afleiding dank.

Bomma, ik had het je graag nog kunnen zeggen, dat ik "afgestudeerd" ben. Ik weet dat je trots op me zou zijn en ik ben dat ook op jou.

Mama en papa, jullie hebben me opgevoed met onvoorwaardelijke liefde en steun en hebben me daarmee een geschenk voor het leven gegeven. Alleen daarvoor al ben ik jullie oneindig dankbaar. Maar ook voor alle waarden en normen (ook voor de omstreden bescheidenheid), voor zondagavonden, vakanties, voor de opvang van Jasper, voor ... alles eigenlijk. Ik prijs me erg gelukkig met jullie.

Gommaar, liefste, ik had me geen betere afleiding van mijn proefschrift kunnen voorstellen dan jou. Dankjewel voor alles.

Lieve Jasper, meer dan van jou kan ik van niemand leren. X 
Curriculum Vitae 


\section{About The AUThor}

Hanne Paula Joke Kindermans was born in Hasselt, Belgium, on the $22^{\text {nd }}$ of December 1983 as the youngest child in a family of five. She grew up in Boekhout, a small village near Sint-Truiden, Belgium. In 200I, she graduated from secondary school, Katholieke Centrumscholen SintTruiden, Belgium. She started her university studies in $200 \mathrm{I}$ at Maastricht University, The Netherlands, and obtained her master's degree in Mental Health Sciences in 2006. In February 2006 she was appointed as a Ph.D.student at the Department of Medical, Clinical, and Experimental Psychology (currently Department of Clinical Psychological Science), Maastricht University. Her Ph.D. project was entitled 'The role of selfdiscrepancies in chronic pain' and resulted in the present thesis. In June 2007 her son Jasper was born. Since January $201 \mathrm{I}$ she is appointed by the research school for Public Health and Primary Care (CAPHRI) as a researcher at the Department of Rehabilitation Medicine, Maastricht University, to continue her research on self-regulatory processes and personality factors in chronic pain.

\section{Publications}

Kindermans, H.P., Roelofs, J., Goossens, M.E., Huijnen, I.P., Verbunt, J.A., Vlaeyen, J.W. (20II) Activity patterns in chronic pain: underlying dimensions and associations with disability and depressed mood. Fournal of pain, I2, IO49I058.

Huijnen, I.P., Verbunt, J.A., Peters, M.L., Smeets, R.J., Kindermans, H.P., Roelofs, J., Goossens, M.E., Seelen, H.A. (2OII). Differences in activity-related behaviour among patients with chronic low back pain. European fournal of Pain, $15,748-55$.

Huijnen, I.P., Kindermans, H.P., Seelen, H.A., Peters, M.L., Smeets, R.J, Serroyen, J., Roelofs, J., Goossens, M.E., Verbunt, J. (20II). Effects of selfdiscrepancies on activity-related behaviour: explaining disability and quality of life in patients with chronic low back pain. Pain, 152, 2165-2172.

Kindermans, H.P., Huijnen, I.P., Goossens, M.E., Roelofs, J., Verbunt, J.A., Vlaeyen, J.W. (2011). "Being" in pain: the role of self-discrepancies in the emotional experience and activity patterns of patients with chronic low back pain. Pain, 152, 403-409.

Kindermans, H.P., Goossens, M.E., Roelofs, J., Huijnen, I.P., Verbunt, J.A., Morley, S., Vlaeyen, J.W. (2010). A content analysis of ideal, ought, and feared selves in patients with chronic low back pain. European fournal of Pain, I4, 648653 . 
Goossens, M.E., Kindermans, H.P., Morley, S., Roelofs, J., Verbunt, J.A., Vlaeyen, J.W. (2010). Self-discrepancies in work-related upper extremity pain: Relation to emotions and flexible-goal adjustment. European fournal of Pain, I4, 764-770.

Huijnen, I.P., Verbunt, J.A., Peters, M.L., Delespaul, P., Kindermans, H.P., Roelofs, J., Goossens, M., Seelen, H.A. (2010). Do depression and pain intensity interfere with physical activity in daily life in patients with chronic low back pain? Pain, I50, I6I-166. 